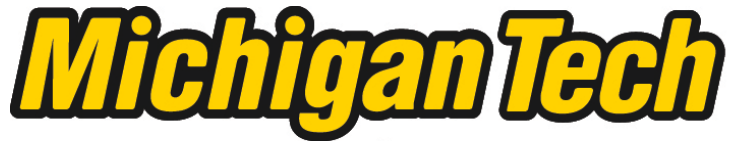 \\ Michigan Technological University Create the Future Digital Commons @ Michigan Tech
}

Dissertations, Master's Theses and Master's Reports - Open

Dissertations, Master's Theses and Master's

Reports

2014

\section{Reclaiming Indigenous Narratives through Critical Discourses and the Autonomy of the Trickster}

Robert D. Hunter

Michigan Technological University

Follow this and additional works at: https://digitalcommons.mtu.edu/etds

Part of the Rhetoric Commons

Copyright 2014 Robert D. Hunter

\section{Recommended Citation}

Hunter, Robert D., "Reclaiming Indigenous Narratives through Critical Discourses and the Autonomy of the Trickster", Dissertation, Michigan Technological University, 2014.

https://doi.org/10.37099/mtu.dc.etds/746

Follow this and additional works at: https://digitalcommons.mtu.edu/etds

Part of the Rhetoric Commons 
RECLAIMING INDIGENOUS NARRATIVES THROUGH CRITICAL DISCOURSES AND THE AUTONOMY OF THE TRICKSTER

By

Robert D. Hunter

\begin{abstract}
A DISSERTATION
Submitted in partial fulfillment of the requirements for the degree of DOCTOR OF PHILOSOPHY

In Rhetoric and Technical Communication
\end{abstract}

MICHIGAN TECHNOLOGICAL UNIVERSITY

2014

(C) 2014 Robert D. Hunter 
This dissertation has been approved in partial fulfillment of the requirements for the Degree of DOCTOR OF PHILOSOPHY in Rhetoric and Technical Communication.

Department of Humanities

Dissertation Advisor: $\quad$ Elizabeth A. Flynn

Committee Member: Dieter Wolfgang Adolphs

Committee Member: Kette Thomas

Committee Member: Latha Poonamallee

Department Chair: Ronald Strickland 


\section{TABLE OF CONTENTS}

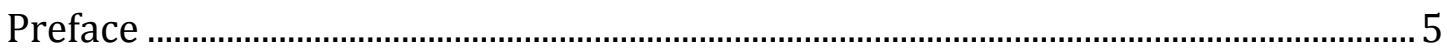

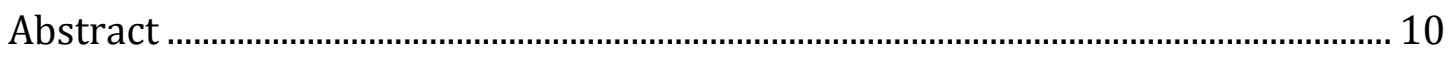

\section{Chapter I}

Promoting an Indigenous Cinema............................................................................... 12

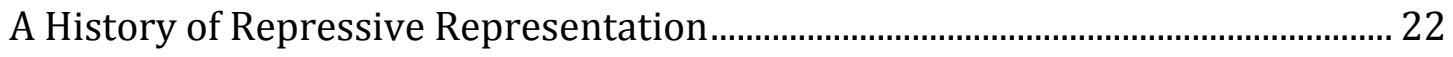

The Postcolonial Lens ....................................................................................................... 24

The Critical Cinematic Lens ................................................................................................ 27

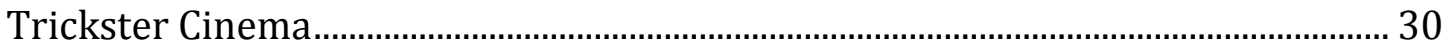

Chapter II

The Hollywood Indian: A Repressive Representational Schema ............................... 34

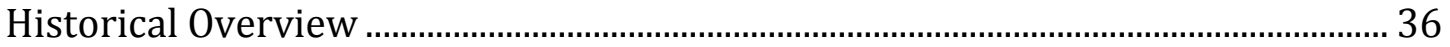

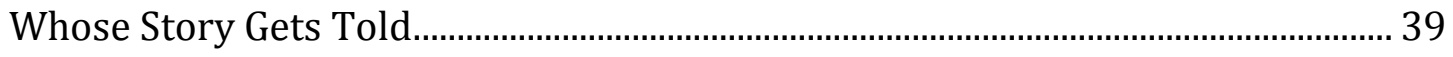

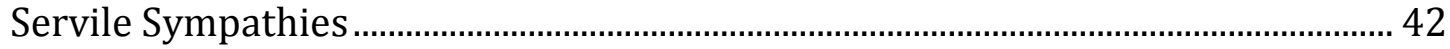

Better Indian than the Indians.......................................................................................... 44

Who Gets to Tell the Story............................................................................................... 47

\section{Chapter III}

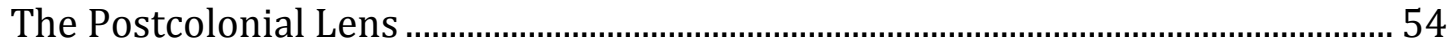

The Genesis of Stereotype ............................................................................................ 59

Other Marginalizing Stereotypes................................................................................ 65

Psychoanalytic Spectating ......................................................................................... 70

Paternalism and Postcoloniality …………………………………………………. 77

Affirming the Anticolonial .............................................................................................. 83 


\section{Chapter IV}

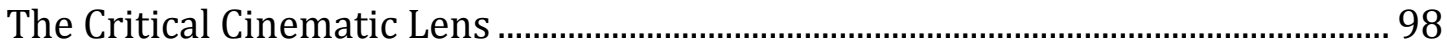

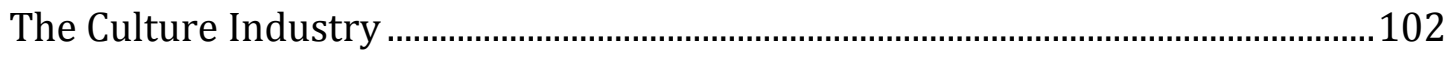

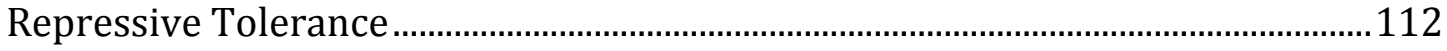

The Public Sphere: Reification and Rupture ................................................................125

\section{Chapter V}

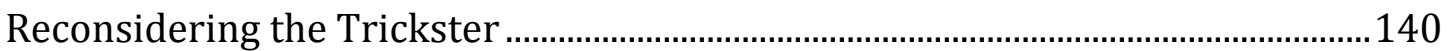

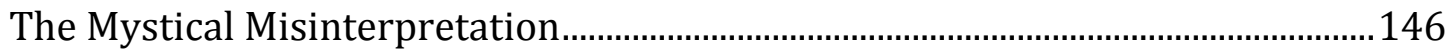

The Trickster as an Animal ......................................................................................... 149

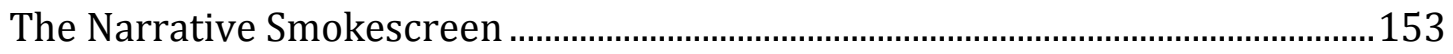

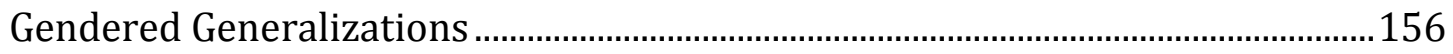

Organic Traces in Third Spaces..................................................................................

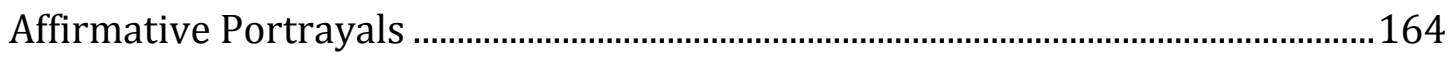




\section{PREFACE}

It is with careful consideration that I approach the subject of writing about Native Americans in film. Keenly aware of the author's unavoidable presence in any text, my attention is drawn to three important matters of authorship. First is the implicit understanding that no author can every really erase the trace of his or her own self-interestedness. This is the first order of deliberation, where the very decision itself—-to write about something of interest—already renders some type of judgment relevant to that topic. Second are the parameters of the narrative position. Authors are confined to the binary of either the first or third person, and must choose between "speaking for," or "speaking with," those of whom the subject most relates. Finally is the acknowledgement that anyone participating in this type of work cannot avoid the entanglement of certain boundaries. The simple act of writing about something removed from one's own experience prerequisites a self-reflexive understanding of the author's encroachment into what is otherwise sovereign territory.

While the research in this dissertation is not ethnographic in the strictest sense, it nonetheless hinges on some of the key cautions of ethnography. For example, I cannot erase the traces of my own self-interestedness, which is doubtlessly borne of twenty years of professional involvement in the field of tribal education. Serving as Dean of Instruction for the Alamo Navajo Community Schools in rural New Mexico has deepened my interest in the salient 
issues of Indigenous advocacy and autonomy. As Peter Barry asserts, a "notion of disinterested enquiry is untenable," and no matter one's efforts to press lightly, "all investigators have a thumb on one side or the other of the scales" (34-35). The thumb administers the proverbial weight, while its print is responsible for leaving the residual trace. To deny how my professional experiences have influenced my personal perspectives is to pretend that I can ever be unbiased.

The second caution concerns the linguistic binary of "speaking for," or "speaking with," those who collectively comprise the subject of this study. The issues are immediately apparent when confronted with the choice of which narrative position to use in locating my own interfering presence. The choices available between firstperson and third-person points of view are ultimately unsatisfactory. Consider the limitations inherent in the compulsory selection of either one of them. If I use the pluralizing voice of the subject pronoun "we," a transgressive sense of entitlement accompanies my actual stance as a nonmember of the subject group. Conversely, if I use the pronoun "they," it is justifiably vulnerable to allegations of essentialism and paternalism. It is this very complication that lies at the heart of the authorial position, in which the question of who may speak on behalf of others should never be without controversy.

Finally, another lesson learned from ethnography is that "it is always caught up in the invention, not the representation, of cultures" (Clifford 2). Where this is unmistakably evident in the world of film, especially such titles as discussed throughout this dissertation, it is also true of my own imagined understandings of 
what it means to advocate for a more accountable cinema. Supporting the notion of a more accountable cinema might involve interrogating most major motion pictures with criticality, while simultaneously promoting a relatively obscure collection of lower-budget independent films that appear to demonstrate greater cultural coherence to Indigenous epistemologies. The inherent danger, of course, is in the presumption of my own expertise. Though it may come with altruistic intentions, Michael Barber cautions "the result is that the expert, who began in subservience to the Other, assumes the role of representing and speaking for the Other, who ends up subordinate to that expert. The philosopher's near heteronomy before the Other leads to an eventual megalomaniac self-aggrandizement" (116). Perhaps the only way to counteract this arrangement is to be acutely aware of the fallacy of the expert and to know that his or her work is always held suspect at best. If this is so, why do this type of work at all? Ironically, the answer to this might also be explained in accordance with the insights of a couple of well- known ethnographers.

Practitioners such as Clifford Geertz and James Clifford maintain that "not only are translation/interlocution possible, but that there is a moral imperative that they should occur," and that "translation and interlocution are not just methods of research; they are the antidote for particular social sins" (Pearce and Chen 128). For example, one might critique Hollywood and its legacy of exploiting Native Americans. But one must also scrutinize his or her own involvement in the subject. The responsibility is to adopt a critical perspective, one in which the author is never exempt from the very criticisms that he or she leverages against others. In other 
words, it becomes necessary to identify not only the problem, but also the complications of one's own interference. It is in the presence of a healthy selfskepticism that I approach the following dissertation. If the study raises more questions than answers, perhaps it will also raise a deeper consciousness of the spectator's own ambiguous relationship to any external subject. 
Works Cited

Barber, Michael. Ethical Hermeneutics: Rationality in Enrique Dussel's Philosophy of Liberation. New York: Fordham UP, 1998. Print.

Barry, Peter. Beginning Theory: An Introduction to Literary and Cultural Theory. New York: Manchester UP, 2002. Print.

Clifford, James and George E. Marcus. Writing Culture: the Poetics and Politics of Ethnography. Berkeley, CA: U of California P, 1986. Print.

Pearce, W. Barnett and Victoria Chen. "Ethnography as Sermonic: The Rhetorics of Clifford Geertz and James Clifford." Rhetoric in the Human Sciences. Ed. W. Barnett Pearce and Victoria Chen. London: Sage Publications, 1989. 119-132. Print. 


\begin{abstract}
How do prevailing narratives about Native Americans, particularly in the medium of film, conspire to promote the perspective of the dominant culture? What makes the appropriation of Indigenous images so metaphorically popular? In the past hundred years, little has changed in the forms of representation favored by Hollywood. The introductory chapter elucidates the problem and outlines the scope of this study. As each subsequent chapter makes clear, the problem is as relevant today as it has been throughout the entire course of filmic history.

Chapter Two analyzes representational trends and defines each decade according to its favorite stereotype. The binary of the bloodthirsty savage is just as prevalent as it was during the 1920 s and 30s. The same holds true for the drunken scapegoat and the exotic maiden, which made their cinematic debuts in the 1940s and 50s. But Hollywood has added new types as well. The visionary peacemaker and environmental activist have also made an appearance within the last forty years. What matters most is not the realism of these images, but rather the purposes to which they can be put toward validating whatever concerns the majority filmmakers wish to promote. Whether naïvely or not, such representations continue to evacuate Indigenous agency to the advantage of the majority. A brief historical overview confirms this legacy.

Various disciplines have sought to interrogate this problem. Chapter three
\end{abstract}


investigates the field of postcolonial studies, which makes inquiry into the various ways these narratives are produced, marketed, and consumed. It also raises the key questions of for whom, and by whom, these narratives are constructed. Additional consideration is given to their value as commodities in the mass marketplace. Typically the products of a boutique-multiculturalism, their storylines are apt to promote the prevailing point of view.

Critical theory provides a foundational framework for chapter four. What is the blockbuster formula and how do the instruments of capital promote it? Concepts such as culture industry and repressive tolerance examine both the function and form of the master narrative, as well as its use to control the avenues of dissent. Moreover, the public sphere and its diminishment highlight the challenges inherent in the widespread promotion of an alternative set of narratives.

Nonetheless, challenges to prevailing narratives do exist, particularly in the form of Trickster narratives. Often subject to persistent misrecognition, the Trickster demonstrates a potent form of agency that undeniably dismantles the hegemony of Western cinema. The final chapter examines some of the Trickster's more subtle and obscure productions. Usually subjugated to the realm of the mystical, rather than the mythical, these misinterpreted forms have the power to speak in circles around a majority audience. Intended for an Other audience, they are coded in a language that delivers a type of direction through indirection, promoting a poignant agency all their own. 


\section{CHAPTER I}

\section{Promoting an Indigenous Cinema}

Films about Native Americans have a long history in Hollywood. That is not to say that they have evolved much since the earliest days of celluloid. On the contrary, film scholars typically point out the recyclability of Western themes and images and note a predictable range of stereotypes that have been used to promote the Western point of view. There is little shortage of scholarship on this subject. Perhaps it is because of the obviousness of this particular problem. But there are other problems as well, and ones that are best served by delving deeper beneath the surface. While it is certainly necessary to focus on questions of representation and stereotype, exploration of these matters tend to look mostly at what is wrong, rather than questioning why these images have been promoted and what the purposes are to which they have interminably been put. Deeper investigation begins with a look into the fields of scholarship that have questioned the motives behind these narratives and images. Postcolonial and critical theories are especially appropriate for this purpose.

Postcolonial scholars understand that power relations are resultant of the forces of colonialism. All manner of exploitation, whether material or cultural, informs their work. For the purposes of this dissertation, a selection of those working specifically within Indigenous contexts is included in the conversation. Some of the earliest work dates back nearly four decades, when Robert F. 
Berkhofer, Jr. began analyzing representational trends in comparison to U.S. Governmental policies, such as those of relocation or reform. His observations suggest that images of the Indian strongly correlate with whatever policy objectives were the concern of the day. For example, the politics behind forced removal saw the Indian as a savage whose coexistence was most peaceably tolerated only when confined to a reservation. Depictions of this era framed the Native American as the antithesis of civilization. Likewise, when assimilationist policies dominated the political landscape, the Indian was cast as down and out, the subject of paternalistic concern. Either way, it was the political majority who determined how the American Indian was to be represented.

Following Berkhofer, the works of Mary Louise Pratt and Roberto Fernández Retamar examined the ongoing subjugation of Indigenous images as part of a majority effort to defend its own privileges and practices. For example, Pratt contends that Indigenous lands provided the impetus for all manner of European conquest. By presenting the Indians as uncivilized and incapable of recognizing their lands' true potential, European colonizers found justification for territorial encroachment and exploitation. Retamar looked at how this analysis could be traced all the way back to Shakespeare, where in dramatic literary form the Indigenous characters could be posed to represent any of the so-called lesser nations in opposition to those more powerful ones. Caliban as a Caribbean cannibal, for example, was meant to signify the untamed wilderness, the colonies 
whose resources were yet to be extracted and refined. Retamar's reclamation of the cannibal, as a type of anti-servant, stands in defiance of Western hegemony. Beyond reclaiming the stereotypes, postcolonial scholars have broadened understanding in other ways. George Yúdice and Graham Huggan are two such contributors. Each looks at how culture is objectified in the name of profitability. Yúdice describes the uses to which cultural images are put as measures of their expediency. In other words, film, music, and other media are a commodified means of cultural acquisition. In the age of corporatized media, multicultural images are exploited to reinforce a majority point of view. Moreover, these media products are increasingly available for consumption alongside all other manner of popular entertainment. Huggan introduces the term postcoloniality, referring to the exchange value of culturally othered goods in a globalized marketplace. It is yet another measure of exploitation that takes into account the profit that can be earned in promoting a generally stereotypical array of productions.

Equally as promising as the contributions of postcolonial theory are those of critical theory. Because of its interrogational perspective, it questions everything from the production to the distribution and reception of cultural commodities. From the earliest criticisms of Theodor Adorno to the later contributions of Ariel Dorfman and Armand Mattelart, Fernando Solanas and Octavio Gettino, the industry of culture is chastised for its one-sidedness. Aptly named, the culture industry translates all manner of media into a striving for 
profit. Adorno saw beyond any benign or innocuous motive. Instead he recognized the industry's goal of pacifying the masses. As time has shown, this is most expediently accomplished with productions that appeal to majority sentimentalities. Unfortunately, this means that alternative productions are also most broadly accepted when they too conform to the status quo and anything that faithfully reproduces it. Stereotypes serve such a function. Remarkable in their ability to promote the majority point of view by subduing the efficacy of minority characters, Adorno recognized how the culture industry feeds on their existence. From early on, their expedience as a tool for this purpose was identified. Thus acknowledged, early critical theorists discerned their continuance but did not necessarily offer explanations as to how to overturn them. Various methods to address this would come later.

One approach, taken by Dorfman and Mattleart, is to confront these images directly. They do so by taking to task such corporate media moguls as Walt Disney. Not only do they dismantle the condescending stereotypical portrayals by which Disney represents its Indigenous cartoon characters, they also call attention to the motives behind these portrayals, mainly to advantage its imperialistic expansion into other markets. Further still, the ideas espoused by filmmakers Fernando Solanas and Octavio Gettino insist that it is not enough to simply subvert the stereotypes. Rather, it is incumbent upon critical thinkers to challenge establishment monopolies through the introduction of a revolutionary cinema. They are not naïve to this difficulty, as they understand that economic 
power resides with the major motion picture industry. They recognize that "the camera is the inexhaustible expropriator of image-weapons; the projector, a gun that can shoot 24 frames per second" (Solanas and Gettino 279). In other words, the same critical acumen that is used to dismantle the dominant ideology can also be used to construct a series of compelling alternatives.

In short, postcolonial and critical theories work in tandem. Each intersects with and informs the other in their analyses of the motives behind the exploitative uses of stereotype. While the aforementioned scholars offer a preliminary glimpse into the applications of postcolonial and critical perspectives, they have not dealt necessarily, or at least specifically, with the tribes of North America. This is a pertinent acknowledgement because it indicates that there is much yet to be learned. It also leaves room for recognition of the uniqueness of Native North Americans. Scholars in other disciplines have been seemingly influential in drawing specific conclusions about certain North American tribes. Their work is also necessary in considering the course one might take in affirming a uniquely sovereign cinema, one that is inclusive of a very specific type of character.

Claude Lévi-Strauss asks, "Why is it that throughout North America the Trickster role is almost everywhere assigned to either coyote or raven?" (440). It is a simple question, but one that is densely packed with various allegorical associations. To get at its answer requires the unpacking of just a few of them. Most immediately, it presents the Trickster as an animal personified. But look 
again at the manner in which Lévi-Strauss poses the question. Is it not also a person animalized? Hierarchical associations become apparent when the question is flipped. The role is seemingly diminished when assigned to lesser creatures. So are the various narratives in which their stories are included. Categorized as such, scholars might ask why is it that throughout all of mainstream cinema movies produced about Native Americans are catalogued to the back shelf, if allowed any shelf space at all?

A few conspicuous exceptions do exist. A little forward of the back shelf is the movie Windtalkers (2002). Ostensibly about the Navajo code talkers of World War II, it played to a larger audience precisely because it was not really about them. Instead, it chronicled the experiences of a white sergeant who commanded them. The film exemplifies that space where popular fiction distorts reality. In its presentation of the cast as unquestioningly patriotic it ignores certain contentious truths. Why, for example, would a tribe who had been forcibly removed from their homes and marched 350 miles to a place of imprisonment join forces with the very military that had orchestrated this event? As it turns out, they had not actually joined the branch of service that was specifically responsible for the infamous Long Walk (the Army). Electing instead to volunteer for the Marines, their code word for the regular Army became 'lei-cha-ih-yil-knee-ih' or 'dog faces'. But little is ever mentioned of this witty reversal, in which the majority is 'animalized' by the minority. It is certainly not mentioned in the film. Many such examples exist but are buried 
beneath layers of narrative omission and historical elision. Attempts to set the record straight are additionally buried under the weight of the majority master narrative.

The secondary status of Indigenous film and the characters therein is the product of a longstanding Hollywood fiction, which goes some distance toward explaining why films about Native Americans, such as Windtalkers, never deliver on their promises. Instead of affirming the Indigenous experience, they continue to be films about the Western hero. Non-Native actors in lead roles tend to promote the idea that Indians are a people of the past. Likewise, the practice of setting most of these narratives in the past only contributes to this illusion. Hollywood underscores the notion that Native Americans have become "trapped in the history of film" (Riley 58). This becomes an even bigger problem when one considers the present manner in which general audiences both locate and consume these films.

On-demand Internet-streaming services such as Netflix have changed consumers' viewing habits. Gone are the days when audiences' primary source of information about upcoming attractions is advertised through cinematic trailers preceding a feature presentation at the theater. Granted, this still occurs. But now more than ever, people are locating movies through subscriber services that offer personalized recommendations based on previous viewing habits. For example, Netflix uses a video recognition algorithm that matches key content from one film to similar features in another. Fans of Hollywood director John 
Woo, known for such blockbusters as Face/Off (1997) and Mission Impossible: II (2000), would be informed of his somewhat lesser known works, such as Windtalkers. Likewise, fans of action film star Nicolas Cage would also be directed to this film. Viewers who otherwise have little or no interest in movies about Native Americans might be drawn to this title simply because it belongs to the John Woo repertoire or includes a main character portrayed by Nicolas Cage.

The issue at stake is about which narratives become most accessible to a network of consumers, many of which are now available through Internetsubscription services. Obviously, those that feature big name actors in storybook roles are bound to outpace those that deliver points of view which are not congruent with the expectations of mainstream audiences. By virtue of the way it is programmed, the algorithm exponentially favors better-known films. This guarantees the promotion of the master narrative in which Indigenous peoples become little more than the supporting casts in what are ostensibly billed as their own stories. It teaches that the Navajo Code Talkers, for example, could not have succeeded without the intervention of White officers. It is a colonizing fiction that fails to raise any critical questions about the ethics of representation.

Belonging to a moment in time when these questions still remain partially unanswered, when sports teams continue to co-opt images of Native Americans but would dare not exploit any other ethnicity, it is incumbent on spectators to become better informed about the fictions surrounding these images. Two of the 
biggest reasons for their perpetuation include a Western sense of entitlement and the consequent practices of exploitation. In political parlance these socioeconomic forces are referred to as colonialism and capitalism. Contentious analyses have arisen in the areas of postcolonial and critical theories. Yet in their latent contributions to the world of film, they have been applied only narrowly to this medium. Fortunately, such instances have proven productive and are worthy of deeper consideration. For this reason, they form the basis of the present study.

Insomuch as postcolonial and critical perspectives can identify a rationale for examining filmic representations of Native Americans, they tend to go so far as to interrogate the master narrative and its associated motivations without necessarily offering much by way of a viable alternative. It is important to trace their contributions in order to gain a broader understanding of the hegemony of the master narrative. To this end, much of the present study is directed toward this purpose. But just as important, if not more so, is the emergence of a truly Indigenous alternative. Therefore, the present study concludes with a prescient view of what might best be called a Trickster cinema. Within the scope of this amorphous space can be observed the beginnings of a cinematic form that privileges the minority audience. The Trickster operates on multiple levels. On the one hand, it speaks to a general audience in terms and actions that denote a benign and often humorous story. Yet this is merely a smokescreen behind which an ulterior story exists. The other hand directs its attention toward a 
story hidden within the story, one that is meant for a specifically Indigenous audience who can read its allegorical intentions.

The main challenge in developing a Trickster cinema is that it must vie for notice among a plethora of popular narratives that reinforce the status quo. The channels of distribution are subsequently very narrow for this type of cinema. Its expansion presently appears to depend upon its ability to produce a set of narratives that generate at least a modicum of appeal among the demographic majority. Against stifling odds, some of them do. But it is important to situate such a cinema against which it stands in contradiction. Namely, the dual forces of colonialism and capitalism demand scrutiny. The present study aims to address these issues by examining the cinematic Indian through various lenses.

Beginning with the second chapter's analysis of representational trends, the historical lens is used to examine how Hollywood defines each decade according to its favorite stereotype. Whether naïvely or not, these representations continue to evacuate Indigenous agency to the advantage of the majority. Chapter three investigates the field of postcolonial studies, which makes inquiry into the various ways these narratives are produced, marketed, and consumed. It also raises the key questions of for whom, and by whom, these narratives are constructed. Critical theory provides a foundational framework for chapter four. Concepts such as culture industry and repressive tolerance examine both the function and form of the master narrative, as well as its use in controlling the avenues of dissent. Moreover, the public sphere and its diminishment highlight 
the challenges inherent in the widespread promotion of an alternative set of narratives. The study concludes with an affirmative look at the Trickster as an agent of a Third Cinema. Presently underdetermined within the widespread reach of mass media, it nonetheless signals a veritable challenge to the way in which Indigenous narratives are produced, distributed, and consumed.

\section{A History of Repressive Representation}

Even prior to the advent of film, Indigenous peoples and landscapes have been exploited to serve the personal and financial interests of the majority. Chapter Two reveals these exploitative trends, beginning with the justifications that are frequently given by the majority to validate its own privilege. Most commonly implied is the notion that privilege flows along a 'natural' continuum of evolution, endorsing the Darwinian ideal of survival of the fittest. According to this scheme, the Hollywood Indian serves as little more than fodder for the White man's imagination. Rarely is it the American Indian's story that gets told. Rather, it is the White man's point of view that skews the silver screen.

The first fifty years of filmmaking set the precedents under which movies continue to be made. Carried over from this legacy is the belief that accuracy is less important than the purposes to which Indigenous images can be put. How obscene is the notion of presenting Indians as invaders or unlawful occupiers of their own lands? Yet this is precisely what Hollywood has done. Less obvious and just as troubling is the industry's omission of any fact or circumstance that 
does not support the majority's point of view. Ignoring Kit Carson's condemnation of the Navajos to the Long Walk allows Hollywood to present him as sympathetic to the Indians' plight, a fiction that is ludicrously promoted in the 1925 film, The Vanishing American. Again, it is not the facts that matter, but rather their co-optation by the majority that enables them to promote the premises of propaganda.

Another form of image colonization involves placing Indigenous characters into the roles of sidekick or surrogate to the majority point of view. The sidekick, of course, supports the main character whose story is really the central focus of any typical Hollywood narrative. The surrogate, on the other hand, stands in for whatever concern may be occupying the mind of the filmmaker. In the 1970s, for example, Native Americans became a favorite countercultural icon and were often used to represent the political passions of the day, such as the protest against the war in Vietnam. During the 80 s and early 90 s, environmental concerns carried the day, to which the Indian became the characterological symbol of ecocriticism. In whatever manner it has been used, the image of the American Indian chronicles the servile sympathies of the directors and filmmakers who continue to co-opt it for purposes of their own.

Many times these films include a narrator who is most usually non-Native and always speaks for, rather than with, the Native characters. This belies an ever-present paternalism, in which the narrator claims some type of transgressive authority, usually to save the Indians from themselves or to rescue 
them from the clutches of some greater foe, such as industrialization. Whatever the case, this character generally proves to be a "better Indian than the Indians," able to lead them in ways that they could not lead themselves (Kilpatrick 105).

Finally, most narrators or popular protagonists engage in the curious custom of 'trying on' Indianness in order to live out all manner of exoticist fantasies. It is an immensely common invention in the collection of films about Native Americans. Perhaps it is related to both practical and economic concerns, as Hollywood is in the business of making money. This requires making a movie that sells, which for most viewers means a White hero for a White audience. Either way, the convention of a majority character playing Indian demonstrates the hegemonic influence and monetary might of a media that is entirely organized around the interests of the dominant culture.

\section{The Postcolonial Lens}

The third chapter considers how those with economic and political influence determine what dominates the media. It examines power relations and filmic reifications of inequalities, rather than liberating those who are gripped in its clutches. Exploitation plays out in film space, much the same as it does in land and material space. The minority screenplay is promoted when it supports the majority's opinion, or else it gets rewritten to support that opinion. Small wonder that most minority characters are subjected to a fairly rigid set of stereotypes. 
Whether bloodthirsty savage or noble Indian, Hollywood's Indigenous cast serves the common purpose of providing little more than a backdrop against which the main character's story can unfold. Indeed, Academy Award nominations for Indians fall only under the category of best supporting actor, and even then it is sometimes a white actor portraying an Indian who receives this recognition. There is very little space for a character to evolve when the roles are so narrow. Beyond savages and nobles, additional stereotypes might include the drunken Indian and the Indian princess, both of whom are doomed to a tragic ending.

The case of the princess inevitably involves a love affair. But as she belongs to a separate race, she is seldom allowed to evolve into anything beyond an exotic lover. To eliminate the threat of a more stable interracial union, Hollywood simply eliminates her character at some point within the screenplay. Most commonly, she is murdered by the protagonist's foes, which motivates him to escalate his revenge. Designed for the spectator who is vicariously meant to associate with the protagonist, this narrative device is troubling in that it exploits all of the Indigenous characters, the enemy tribe who is vilified, and the princess who is sexualized. Yet from a psychoanalytic perspective, such associations are precisely what the story is meant to produce.

Spectators associate with the protagonist as their screen surrogate. Whatever happens to this character in terms of conflict and development is meant to resonate with the majority male viewer, therefore reinforcing his own image of 
himself. This also explains why nearly every story about Indians, even the socalled sympathetic ones, always seems to be told by a White man. But not just any White man, one who is knowledgeable of the ways of the Indians. As Mary Louise Pratt points out, such colonizing images have "produced the rest of the world" for a White readership (5). Paternalism takes many forms.

Postcolonial theory unmasks the various paternalistic forms, beginning with the assertion that paternalism is nothing more than a charitable racism in which all paternalists speak for rather than with their so-called subjects. Paternalists are therefore colonizers, often claiming stewardship of one tribe over another, and readily placing that tribe in conflict with this other in an arrangement that ultimately serves the paternalists' own economic and political purposes. Further, the paternalists' insistence on promoting only positive images ignores the notion that these images can be just as pernicious as the overtly degrading ones. Neither allows for much character depth. Moreover, paternalists generally control the channels of production and distribution, allowing them to determine which narratives are promoted and how far they will reach. Anticolonial productions are faced with daunting odds when attempts are made to challenge the status quo.

Causing these productions additional difficulty is the credentialing system itself. So long as the metropolis remains the granting authority, minority narratives will always be subject to revisionist interpretation. Walt Disney represents a case in point. Not the innocent children's company it presumes to 
be, it is especially adept at indoctrinating youth with the idea that privilege is natural to some, while others exist solely to reinforce that privilege. The New World exists for John Smith's discovery, Pocahontas and all.

Nonetheless, anticolonial productions do get made. They are recognizable in their ability to confront hegemony in various ways. Common tactics include such practices as poaching from majority cultural forms and turning the majority's own cultural ignorance against them. This requires a great deal of skill in the art of analogy, as these narratives necessarily involve two levels of reading. While the surface level is meant to be understood by all, it is the deeper layer that encodes its messages for the minority audience. The greatest trick, however, often comes in locating these productions, as anticolonial films are typically limited in their distribution and only accessible via a very narrow set of channels.

\section{The Critical Cinematic Lens}

An obvious observation, all popular films are subject to the controlling interests of capital. Film critics discuss the movie industry, but critical theorists speak of the culture industry. While both regard human beings as customers, critical theorists see them also as commodities. In other words, they are seen as people whose interests have been commodified to fit within the capitalistic framework of society. As Theodor Adorno explains, "The entire practice of the culture industry transfers the profit motive naked onto cultural forms," which because 
they are lucrative, have been "earning a living for their creators as commodities in the marketplace ever since these forms first began" (129).

In response to the commodification of culture, critical theorists favor "Marxian arguments [that] stress capitalist control of culture, the commodification and reification of culture, its ideological functions and the ways in which it integrates individuals into capitalist society" (Kellner 132). The unfortunate reality is that those who resist the culture industry are well outnumbered by those who acquiesce to it. But even the resistance of the industry's opponents is factored into the equation. In very subtle ways, people are conditioned to tolerate the repression of meaningful alternatives.

The most effective method of getting people to accept things as they are is defined as repressive tolerance. In the world of cinema this is accomplished by promoting an illusory presentation of choice. While it may be true that people have a choice in deciding which narratives they wish to consume, they are conditioned to believe that a narrow set of alternatives is proof that all voices are equitably represented. The meager existence of so-called 'minority' narratives is (uncritically) given as proof that alternative points of view are present and accounted for. But as Stephen Brookfield notes, "The fact that dissenting voices are sometimes heard [falsely] reassures people that the system is working to give fair and equal representation to all points of view ... By allowing a certain amount of social criticism in the name of free speech, the 
dominant group convinces the rest of the people that they live in a democracy" $(60)$.

But the reality of democracy or tolerance is that it does not truly exist in any situation that fails to protect the rights of the minority. It must be more than a theoretical idea. As Herbert Marcuse explains, "I call this non-partisan tolerance 'abstract' or 'pure' inasmuch as it refrains from taking sides-but in doing so it actually protects the already established machinery of discrimination" (36). For minority concerns to truly be heard, they must be able to claim a viable space wherein their voices can be more widely broadcast. But here again, such spaces are already heavily saturated with the voices of the majority.

The public sphere is defined as a restricted and shrinking space, but also the site of a dialogue of resistance and liberation. It is the place where readymade opinions presented in "newspapers and magazines, radio and television [become] the bearer of public opinion" (Habermas 136-37). Insofar as corporate media shapes public opinion, this means that minority points of view are gravely underrepresented. The same is true of independent film, which does not have the resources of a Walt Disney or an MGM and subsequently must struggle to compete for space within the public sphere. Nonetheless, some titles do infiltrate this space. And as the final chapter elucidates, they are often those that incorporate the ruse of the Trickster. 


\section{$\underline{\text { Trickster Cinema }}$}

The importance of the Trickster in Indigenous cinema cannot be overstated. It is a character who is frequently misunderstood, the ambiguity of which only adds to its mystique. Majority audiences, in particular, are apt to misinterpret this figure. They eagerly ascribe a mystical interpretation, rather than a mythical one such as they generally reserve for their own heroes. Further, they misunderstand its various animal associations, allowing it to move unseen among the human landscapes that dominate their own imaginations.

Unfortunate as this may seem, such majority misinterpretations actually permit the Trickster a fertile space to operate within the narrative smokescreen. An organic intellectual of sorts, the Trickster is in tune with the language of its constituents, an activist who pulls the rug out from underneath its enemies. But for this to happen, a number of key elements must be in place. First, it must retain its duplicitous status, in which it signals one thing to the majority, while meaning something entirely different to the minority. Secondly, it must claim as much space as possible in order to get its message out there where its intended audience can more readily receive it. This may be the Trickster's biggest challenge.

So long as Hollywood dominates the movie market, alternative cinemas will have to work twice as hard, their productions twice as good, in order to become known. As the present study suggests, this will likely come at the hands of the inventive Trickster, whose stories are able to simultaneously deliver two 
separate messages to two separate audiences. Indigenous film is especially poised to accomplish this monumental task. And central to this process stands the Trickster. 
Works Cited

Adorno, Theodor W. "The Culture Industry Reconsidered." Critical Theory and Society. Ed. Stephen Eric Bronner and Douglas MacKay Kellner. New York: Routledge, 1989: 128-35. Print.

Brookfield, Stephen D. The Power of Critical Theory: Liberating Adult Learning and Teaching. San Francisco, CA: Jossey-Bass, 2005. Print.

Face/Off. Dir. John Woo. Perf. John Travolta and Nicolas Cage. 1997.

Dorfman, Ariel and Armand Mattelart. How to Read Donald Duck: Imperialist Ideology in the Disney Comic. New York: International General, 1971. Print. Habermas, Jürgen. “The Public Sphere: An Encyclopedia Article.” Critical Theory and Society. Ed. Stephen Eric Bronner and Douglas MacKay Kellner. New York: Routledge, 1989: 136-142. Print.

Kellner, Douglas. Critical Theory, Marxism, and Modernity. Baltimore, MD: The Johns Hopkins UP, 1989. Print.

Kilpatrick, Jacquelyn. Celluloid Indians: Native Americans and Film. Lincoln, NE: U of Nebraska P, 1999. Print.

Lévi-Strauss, Claude. "The Structural Study of Myth.” The Journal of American Folklore 68.270 (1955): 428-444. Print.

Marcuse, Herbert. "Repressive Tolerance.” The Essential Marcuse: Selected Writings of Philosopher and Social Critic Herbert Marcuse. Ed. Andrew Feenberg and William Leiss. Boston, MA: Beacon P, 2007: 32-59. Print. Mission Impossible: II. Dir. John Woo. Perf. Tom Cruise and Dougray Scott. 2000. 
Pratt, Mary Louise. Imperial Eyes: Travel Writing and Transculturation. New York: Routledge, 1992. Print.

Riley, Michael J. "Trapped in the History of Film: Racial Conflict and Allure in The Vanishing American." Hollywood's Indian: The Portrayal of the Native American in Film. Ed. Peter C. Rollins and John E. O'Connor. Lexington, KY: The UP of Kentucky, 1998. 58-72. Print.

Solanas, Fernando and Octavio Gettino. "Towards a Third Cinema." Film Theory: An Anthology. Ed. Robert Stam and Toby Miller. Malden: Blackwell Publishers, 2000. 265-286. Print.

The Vanishing American. Dir. George B. Seitz. Perf. Richard Dix and Lois Wilson. Paramount, 1925.

Windtalkers. Dir. John Woo. Perf. Nicolas Cage and Adam Beach. MGM, 2002. 


\section{CHAPTER II}

The Hollywood Indian: A Repressive Representational Schema

In 2002, the much-anticipated premiere of John Woo's blockbuster film, Windtalkers, opened to packed theaters all across the Southwestern United States. It was the first major motion picture about the Navajo Code Talkers. Initial expectations were high; subsequent reviews were low. With such an iconic director as Woo, much lauded for the larger-than-life action epics Face/Off (1997) and Mission: Impossible II (2000), how did this next film fall so far short?

It was not that it failed to deliver the usual goods. Indeed, Windtalkers earned the 2003 Taurus Award for best fire stunt in a motion picture with its over-thetop depiction of a flame-engulfed soldier dying a "balletic death in slo-mo, John Woo style" (King and Krzywinska 6). It delivered precisely what audiences had come to expect in the hands of such trademark directorial vision. But the usual goods in this instance did not resonate with moviegoers in quite the same way.

As a war film, its plot is familiar enough - a combat-scarred officer returns to the battlefield on a risky mission to disable the enemy's advantage. But it may be the plot's very predictability that makes the film duplicitous at best. No doubt, viewers take comfort in convention. Successful screenplay author Cynthia Whitcomb reinforces this notion when she advises aspiring writers not to "stretch the [expected] time frame beyond an audience's capacity" (60). While Windtalkers conforms quite comfortably to such specifications, it also fits 
astonishingly well within another set of parameters. And herein lies the problem.

As a movie ostensibly about the Code Talkers, it mostly deals with concerns that are curiously outside the scope of this expectation. Instead, it is a movie about the Western hero, his noble quest and honorable redemption. Like Dances With Wolves (1990) and many others before them, the story hailed much promise as a narrative in which Native Americans would finally get their due. Instead, it became the latest in a long line of films destined to tell only one side of the story.

The initial problem with these films is that they do not live up to the claim of promoting a truly Indigenous perspective. Consider the title Windtalkers, a direct and unmistakable reference to the venerated Code Talkers. Disappointingly, the movie relies upon the Navajos' historic contribution to World War II as merely a narrative backdrop. This presents the bigger problem. The trouble with these films goes beyond what they are not (i.e. films about Native Americans) and extends into what they truly are (films about the Western hero).

Within this theme can be found many supporting factors. For one, the protagonist is seldom a Native character. In the case of Windtalkers, he is Nicolas Cage, whose warrior ways proves that he is a "better Indian than the Indians'. So is Adam Beach for that matter. While himself an Indigenous actor, he is most decidedly not Navajo. Additionally, the very theme of the movie 
vampirically draws upon the real lived experiences of a group of valiant individuals, whose own interests are subverted by the great myths of the majority culture-a self-serving sense of patriotism, for example.

As Native people have long observed, the image of the Indian is granted little opportunity to evolve. It serves the all-purpose metaphor for an abundance of various uses, adoptions, and comparisons. From sports mascots to vehicle models (think Pontiac and Winnebago), the image is mostly of a foregone people in a foregone era. Hollywood knows this best. The filmmaking industry profits from such historical re-arranging and re-imagining. Despite the present realities of Native peoples today, Michael J. Riley suggests that the American Indian of imagination has become "trapped in the history of film" (58).

\section{Historical Overview}

In his book World War II and the American Indian, Kenneth William Townsend writes how wartime legislation both "widened the opportunity for Indian movement into mainstream society ... and promoted [a greater sense of] cultural pluralism" (73). Despite this development, however, the concerns of Native Americans continued to play second fiddle to the interests of mainstream culture. Nowhere is this in greater evidence than in popular film and literature, a dependable archive of the prevailing thought of any given period.

This long-established history can be traced back to the narratives predating film. European contact with Native Americans generated fantastic accounts of 
exotic lands and peoples. These were startling accounts, rife with the language of fear, indignation, and conquest. Such language as might be expected in any alien encounter. But these narratives also heralded an egoistic voice of entitlement, in which Native lands and peoples were coveted in the indulgent pursuit of personal ambitions.

Mary Louise Pratt describes this quite fittingly in her explanation of "the European improving eye" that perceives Indigenous "habitats as 'empty' landscapes, meaningful only in terms of a capitalist future and of their potential for producing a marketable surplus" (61). Should the consumption of land not be exploitive enough, there is also the consumption of exoticized people. Pratt discusses this, too. As a means of reinforcing its powerful image of itself, "the imperial metropolis tends to understand itself as determining the periphery," repositioning its dominion through an "obsessive need to present and re-present its peripheries and its others continually to itself" (6). Advancing its own interests, the majority culture promotes itself as the vanguard of the entire civilized world. It is a representational trend that continues to this day, albeit usually in somewhat subtler form.

As the art of travel writing paved the cinematic image, early film narratives continued the portrayal of righteousness and wickedness, barbarism and civilization. It was Manifest Destiny reborn, or what Robert F. Berkhofer, Jr. describes as the birth of "evolutionary anthropology," in which "civilization differentiated [from savagery] according to technological innovation and 
economic development" (52-53). The Indian did not occupy a commensurate space along the evolutionary continuum. Thus, according to Michael J. Riley, early films about Native Americans made "reference to the widespread public interest in Social Darwinism that had carried forth, in numerous permutations, from the late nineteenth century into the 1920s" (59).

One need only look at the very first film ever made about the Navajo, The Vanishing American (1925), to see the Darwinian ideal in motion. Not only does the title convey a foregone sense of inevitability, the opening scene reinforces it as well. It begins with the quotation "We have unmistakable proof that throughout all past time there has been a ceaseless devouring of the weak by the strong ... a survival of the fittest" (qtd. in Riley: 59). "The opening sequence [begins] with a series of fleeting images ... First we are shown arcane paleoIndians, rough-hewn caricatures intended to represent the first inhabitants of North America. Then other fictive aboriginal denizens of the past follow: the 'Basket Makers,' 'Slab-House People,' 'Cliff Dwellers,' and the 'Indians.' And then finally the 'whites'" (60). As Jacquelyn Kilpatrick notes, "Native Americans were set firmly in this line of cultural development—further along than cavemen but not as evolved as white men" (30).

There are other reasons for the pernicious persistence of this image, as well. The myth of the 'vanishing' Indian asserts a certain material profitability. As Ward Churchill admonishes, "Given that they no longer exist, that which was theirs - whether land and the resources on and beneath it, or their heritage - can 
now be said, without pangs of guilt, to belong to those who displaced and ultimately supplanted them" (702). Either way, the story clears the stage for the advancement of the white man's interests. No matter the qualifying reason, his is the story which seems always to be told.

\section{Whose Story Gets Told}

Even when the story ostensibly deals with Native Americans' interests, they are often confined to a narrow set of concerns that are designated by the majority culture. This is easiest to observe in the decades of filmmaking devoted to the idea of 'Cowboys and Indians'. The genre itself, known simply as 'the western,' belies the privileged perspective afforded the majority. As film critics Robert Stam and Louise Spence point out, "Hundreds of Hollywood westerns turned history on its head by making the Native Americans appear to be intruders on what was originally their land, and provided a paradigmatic perspective through which to view the whole of the non-white world" (239).

In the face of such obvious misrepresentation, one might question how this image has managed to persist for so long. Perhaps it is because later narratives have not completely abandoned the notion of an evolutionary continuum, or as Michel Serres' frames it, the mischievous assumption that "the reason of the strongest is always the best" (260). To emphasize this power differential, Serres employs the mathematical concepts of majorant and minorant, in which the higher value assigned the former always trumps the lesser value of the latter 
(more on this in Chapter IV). It is an inequality that plays out in more subtle ways, as well.

Consider the various uses to which 'the white man's Indian' has been put. Whether as sidekick or surrogate, Tonto to the Lone Ranger or heathen to the holy, Native Americans have been cast into "roles in which they no longer recognize themselves" (qtd. in Young: 45). Perhaps this is because the accuracy of the image is less important than the uses to which it is often put in affirming the majorant's role in the story. It is not without reason that this might rightly be considered a form of propaganda.

Roland Barthes provides one of the best-known examples of this, describing a magazine cover in which "a young Negro in a French uniform is saluting, with his eyes uplifted, probably fixed on a fold of the tricolour" (116). Interrogating the photograph, he explains:

Naïvely or not, I see very well what [the image] signifies: that France is a great Empire, that all her sons, without any colour discrimination, faithfully serve under her flag, and that there is no better answer to the detractors of an alleged colonialism than the zeal shown by this Negro in serving his so-called oppressors. (116)

An astonishingly similar image adorns the cover of Sally McClain's Navajo Weapon, a popular book about the Navajo Code Talkers. The photograph depicts retired Code Talker, James Nakai (though his name is not mentioned in the photographer's credits). He is wearing a commemorative uniform and holding a 
large U.S. flag, which effectively frames his head and shoulders in the patriotic colors of 'Old Glory'. Much like the image described by Barthes, this photo is meant to reinforce a particular ideological myth, namely that the military is a great melting pot of equal opportunity to people of all colors. Moreover, it suggests that the man holding the flag is a patriot of the highest degree, one who both accepts the U.S. military's actions and policies and is proud to have performed a service in the name of them.

But to anyone who has ever observed an event like the one from which this photograph was almost certainly taken, such as the veteran's parade at the Navajo Nation Fair, it is the conspicuous absence of the Navajo Nation's own flag that is most revealing of this myth. The Code Talkers have never been known to display the colors of the United States without the Great Seal of the Navajo Nation flying beside it. Such representations are problematic in that they promote the point of view of the majorant, while systematically editing and erasing those parts of the picture that might make a non-cohering or more ambiguous viewpoint possible.

While the first fifty years of filmmaking documented the subjugated role of the Native American, the fifty years since appear to have focused even more acutely on the myriad subtle ways in which the role of the minorant affirms the position of the majorant. As a narrative device, "this level of character is rarely the protagonist, and rarely ever makes any shift in consciousness ... Not much can be said in terms of evolution here" (Whitcomb 53). Examples provided thus far 
have focused primarily on the ways in which the Native image is often used to promote a pro-majority agenda. But such has not always been the case. Indeed, Native Americans have also been used to generate anti-establishment sympathies.

\section{Servile Sympathies}

Particularly beginning with the 1970 s and what Kilpatrick terms "the sympathetic 1980s and 1990s," the image of the Native American has been put to various countercultural uses (101). Ralph Nelson's Soldier Blue (1970) is a fitting example of this. With the atrocities of the Vietnam War making nightly news, Nelson found a convenient parallel in the 1864 massacre at Sand Creek, Colorado. As Kilpatrick explains, "His intention was to sensitize the American public to the 'plight' of the Vietnamese by relating similar atrocities committed by the U.S. government ninety years before," and to achieve this aim he chose "the all-purpose metaphor for the oppressed, the American Indian" (77).

As disillusionment grew within certain sectors of American society, the Native image came to represent a reckoning with perceived injustices. Whether real or imagined, this malleable image now served a twofold purpose. First, it became the favored figure of the universal victim. While most clearly observed in a film like Soldier Blue, it is noticeable in any narrative in which the image is employed as "a mere substitute for the oppressed Black or hippie White youth alienated from modern mainstream American society" (Berkhofer 103). Add to this list a 
number of environmental and new age spiritualist groups, and the second appropriation becomes obvious.

Against the avarice of unmitigated industrialization, the Native American landscape supposes an innocent, uncorrupted backdrop. This is a strict departure from the nineteenth century's view of the land as ripe for development, but one that reveals the more recent sympathies of environmentalists who "argue that colonialism and deforestation have frequently gone together" (Barry 251). A number of films highlight this theme. Chief among them is The Emerald Forest (1985). Set and filmed in the Brazilian jungle, a conflict between hydroelectric developers and the local Indigenous population emerges. When the project leader's son is abducted and adopted by the local tribe, viewers are given a front row seat to what Berkhofer defines as "alienation from industrial society, praise for Indian ways, and [the] quest for identity in the modern world" (107).

But The Emerald Forest is not a film about Indians per se. Rather, it is one of a collection of movies in which "filmmakers [wanting] to use their art to educate audiences about the earth's devastation turned to the Indian as metaphor once more" (Kilpatrick 104). This is evident in the white protagonist's incredible ability to become a "better Indian than the Indians" (105). In the sophisticated world of environmental warfare, the most effective warrior, it turns out, will always be the white man. John Boorman recognized this in 1985 . Kevin Costner would reiterate it five years later. 


\section{Better Indian than the Indians}

Dances With Wolves (1990) embodies yet another troubling trend in the long tradition of narrational narcissism. Produced, directed, and starred by Kevin Costner, the movie plays like a sentimentalist's dream, as the main character goes to live among the Indians and teaches them to outsmart their enemies. The movie demonstrates just how quickly a naïve form of sentimentalism can reveal a readymade paternalism. Dubbed "Costner's folly," its portrayal of the messianic white man hailed the nickname "Lawrence of South Dakota" (Baird 154; Churchill 239).

An interesting contrast is 1992's Thunderheart, in which Val Kilmer plays a mixed-blood FBI agent returning to the reservation to investigate a murder. Predictably, the conflict is as much about his internal ambiguities as it is about the uncertainties of the investigation. It is a troubling narrative, replete with many of the standard stereotypes. Kilmer first pretends to play Indian (the guise under which he is sent to investigate), later transforms (the quest through which his native roots resolve the mystery), and ultimately abandons what he learns (the life of the Indian is contemptible at best). As Ted Jojola confirms, "the film resurrects the plot of the urban Indian who returns to his reservation. There he unravels corruption ... and learns enough about his cultural values to escape from it for good" (26). Although a different take on the idea, Thunderheart nevertheless supports the notion of a 'better Indian than the Indians.' 
But in terms of cinematic impact, no film appears to master this notion better than Michael Mann's Last of the Mohicans (1992). The third big screen adaptation of James Fenimore Cooper's classic 1826 novel disregards the author's intention of "exploring larger moral issues," a theme that Jeffrey Walker insists, "Hollywood has not recognized in [any of] its adaptations of the novel" (180). Instead, the enigmatic myth of the western hero is artfully employed to bolster a more profitable return in ticket sales. To achieve this aim, Mann takes certain liberties with Cooper's characters. Chief among them is his portrayal of Hawkeye, the white scout who lives among 'the last of the Mohicans.'

As Walker points out, "Hawkeye, for all his centrality in the tale, never serves as the romantic lead or as the hero, of the story, the role that Hollywood has assigned him in all screen adaptations of Cooper's work" (181). But as Angela Aleiss observes, Michael Mann "changed the crusty middle-aged Hawkeye into the young and sexy Daniel Day-Lewis," thereby ensuring that "the real star [would be] the swashbuckling Hawkeye, who dominates many scenes and easily upstages his Indian mentor and advisor Chingachgook (an unusually subdued Russell Means)" (147-148). While never the novel's intention to portray Hawkeye as the dominant figure, "as is common with white heroes in films with Indians, however, he is better at everything than they are" (Kilpatrick 142).

Any move toward colonizing the Native image evacuates its potential for generating a truly productive and peaceful coexistence. So long as only one side profits in this lopsided arrangement, the other continues to serve only the 
interests of the profiteer. As usual, it is the subordinate placement of the minorant that affirms the superior position of the majorant. This is most easily seen in films like Dances With Wolves and Last of the Mohicans. Each relies upon the existence of its auxiliary others in order to emphasize the comparative greatness of its leading characters.

But the same can also be said of films that de-emphasize the virtue of the majorant. Soldier Blue "merely reverses the bad-Indian-good-white stereotypes" and portrays "the obvious goodness and humanity of the Cheyennes [as] simply a backdrop that sets off the despicable nature of the soldiers, who seem intent on killing and/or raping everything in sight" (Aleiss 127, [sic] Kilpatrick 77-78). "The Cheyennes [sic] in this film appear only twice" and are afforded no real opportunity for character development (77). Clearly, they are not the majorant. They do, however, represent a countercultural device used to protest the majorant. Their agency, it seems, is compromised by the service to which it is put, namely to satisfy the filmmaker's moralistic intent to deliver a film about the atrocities of a nation at war.

But while Soldier Blue is intended to deliver a moral message, there is another layer of moral comprehension at play. The simple reversal of stereotypes confronts the audience with a spectatorial dilemma. With whom are they supposed to relate? The viewer is morally better than the soldier-perpetrators, but cannot identify with the comparatively undeveloped Indian-victims. The audience is unable to relate with either side. Morally superior to the majorant, 
yet narratively distant from the minorant, where is Kevin Costner or Daniel DayLewis to offer a comfortable fix to this ambiguous situation? Better yet, where is the Native protagonist in any of these films?

\section{Who Gets to Tell the Story}

Whether as the basis of an imagined social hierarchy or the representative of an ulterior social motive, the Native image is molded to suit a set of foreign purposes. The autonomy of the image is evacuated in such hands. Consider what this means for those films in which a white narrator commandeers the story. He is placed in the role of expert, often 'speaking for,' rather than 'speaking with,' the Native subject. All others are relegated to the role of supporting cast. It is not just a question, therefore, of whose story gets told, but also of who gets to tell the story.

In response to these questions, one might investigate for whom such films are most often made. Many filmmakers endorse the idea that "because Indians are, in relation to the vast majority of the film's audience, the Other, a mediator of sorts is required to make the viewer more comfortable and more capable of developing an understanding" (Kilpatrick 83). To this end "an appropriation of Indian identity by the white hero [is] desirable" (83). This reasoning appears to confirm that a majority audience is better able to sympathize and relate with a narrator who is most like themselves. This may be indisputable, but is not without controversy. 
Consider Arthur Penn's Little Big Man (1970). Often cited by critics as one of the more sympathetic films, it nevertheless relies upon a white narrator (Dustin Hoffman), who exuberantly proclaims, “I wasn't just playin' Indian, I was livin' Indian!” Perhaps this exclamation encapsulates the very essence of what is most troubling about these films - they make no qualms about confiscating Native identity in order to fulfill the majority culture's exoticist fantasies. Michelle Raheja takes this analysis even further when she confirms that it is yet another form of conquest, one which "is conjoined to twin desires that seek to simultaneously celebrate Native American cultures by domesticating them for mass consumption, and in a more literal form of consumption, embody in European Americans the desire to be Native American" (37). The paradox of this situation is best summarized by Churchill's observation that films like "Soldier Blue and Little Big Man ... each purport to provide an 'accurate and sympathetic treatment of the American Indian' while utterly crushing native identity under the heel of Euroamerican interpretation" (700).

Moreover, directors have a long history of conflating Indigenous identity. As Berkhofer points out, "Whites and Asians frequently act the leading Indian parts, and those Native Americans hired for background action have to play any tribe because all Indians look alike to movie and television directors" (103). Dances With Wolves and Last of the Mohicans sustain this latter practice, as Graham Greene (an Oneida) was cast to play the part of Kicking Bird (a Lakota), and Russell Means and Eric Schweig (Lakota and Inuvialuit, respectively) were cast 
as Mohican characters. Even the more recent Windtalkers uses Adam Beach (a Canadian Saulteaux) to portray the film's namesake character, a Navajo Code Talker.

While narratives about Native Americans have been put to many uses, most tend toward a paternalistic engagement with the subject. This is clearly evident in the long tradition of films in which the white protagonist takes center stage. Considering the audience for whom these films are produced, "this is probably good economic, ticket-selling reasoning. But the fact remains that Indian experiences are being sifted, interpreted, and delivered through a decidedly nonIndian interpreter" (Kilpatrick 83).

Most troubling is how easily these narratives allow big screen actors to become "clothed in Indianness" (126). "Stars like Gary Cooper, John Wayne, and even Paul Newman playing savvy woodsmen or plainsmen who were raised by Indians ... become more and more Indian until, in the final absurdity, [they are] a better Indian than the Indians themselves" $(4,126)$. What is more, this trend is especially notable in films widely considered to be sympathetic to Native American concerns, such as Dances With Wolves. But as the evidence suggests, these films are not really about Indians' interests.

Indeed, most films about American Indians promote an agenda that is not their own. As Berkhofer observes, “The Indian of imagination and ideology continues to be derived ... from the polemical and creative needs of Whites" (71). Whether as surrogate for some other group (the Vietnamese in Soldier 
Blue), or some other sympathy (the defense of The Emerald Forest), "American Indians have been, for the full run of film history, a sort of weathervane of social and political currents" (Kilpatrick 178). Their story is hidden between the pages of history and lines of script. The real story, it turns out, is a long and violent struggle against the abiding forces of colonialism. 
Works Cited

Aleiss, Angela. Making the White Man's Indian: Native Americans and Hollywood Movies. Westport, CT: Praeger Publishers, 2005. Print.

Baird, Robert. "'Going Indian': Dances With Wolves." Hollywood's Indian: The Portrayal of the Native American in Film. Ed. Peter C. Rollins and John E. O’Connor. Lexington, KY: The UP of Kentucky, 1998. 153-169. Print. Barthes, Roland. Mythologies. New York: Hill and Wang, 1972. Print.

Barry, Peter. Beginning Theory: An Introduction to Literary and Cultural Theory. New York: Manchester UP, 2002. Print.

Berkhofer, Robert F., Jr. The White Man's Indian: Images of the American Indian from Columbus to the Present. New York: Vintage Books, 1978. Print.

Churchill, Ward. "Fantasies of the Master Race: Categories of Stereotyping of American Indians in Film." Film Theory: An Anthology. Ed. Robert Stam and Toby Miller. Malden, MA: Blackwell Publishers, 2000. 697-703. Print.

Churchill, Ward. "Lawrence of South Dakota.” Fantasies of the Master Race:

Literature, Cinema, and the Colonization of American Indians. San Francisco, CA: City Light Books, 1998. Print.

Dances with Wolves. Dir. Kevin Costner. Perf. Kevin Costner, Mary McDonnell, And Graham Greene. Tig Productions, 1990.

The Emerald Forest. Dir. John Boorman. Perf. Powers Boothe, Meg Foster, and Charley Boorman. Christel Films, 1985.

Jojola, Ted. “Absurd Reality II: Hollywood Goes to the Indian.” Hollywood's 
Indian: The Portrayal of the Native American in Film. Ed. Peter C. Rollins and John E. O'Connor. Lexington, KY: The UP of Kentucky, 1998. 12-26. Print. Kilpatrick, Jacquelyn. Celluloid Indians: Native Americans and Film. Lincoln, NE: U of Nebraska P, 1999. Print.

King, Geoff, and Tanya Krzywinska. Screenplay: Cinema/Videogames/Interfaces. London: Wallflower Press, 2002. Print.

Last of the Mohicans. Dir. Michael Mann. Perf. Daniel Day Lewis, Madeleine Stowe, and Russell Means. Morgan Creek Productions, 1993.

Little Big Man. Dir. Arthur Penn. Perf. Dustin Hoffman, Faye Dunaway, and Chief Dan George. Cinema Center Films, 1970.

McClain, Sally. Navajo Weapon. Tucson, AZ: Rio Nuevo Publishers, 1994. Print. Pratt, Mary Louise. Imperial Eyes: Travel Writing and Transculturation. New York: Routledge, 1992. Print.

Raheja, Michelle H. Reservation Reelism: Redfacing, Visual Sovereignty, and Representations of Native Americans in Film. Lincoln, NE: U of Nebraska P, 2011. Print.

Riley, Michael J. "Trapped in the History of Film: Racial Conflict and Allure in The Vanishing American." Hollywood's Indian: The Portrayal of the Native American in Film. Ed. Peter C. Rollins and John E. O'Connor. Lexington, KY: The UP of Kentucky, 1998. 58-72. Print.

Serres, Michel. "The Algebra of Literature: The Wolf's Game." Textual Strategies: Perspectives in Post-Structuralist Criticism. Ed. Josué V. Harari. Ithaca, NY: 
Cornell UP, 1979. 260-276. Print.

Soldier Blue. Dir. Ralph Nelson. Perf. Candice Bergen and Peter Strauss. AVCO Embassy Pictures, 1970.

Stam, Robert and Louise Spence. “Colonialism, Racism, and Representation: An Introduction." Film Theory and Criticism: Introductory Readings. Ed. Leo Braudy and Marshall Cohen. New York: Oxford UP, USA, 1998. 235-250. Print.

Thunderheart. Dir. Michael Apted. Perf. Val Kilmer, Sam Shepard, and Graham Greene. TriStar Pictures, 1992.

Townsend, Kenneth William. World War II and the American Indian. Albuquerque: U of New Mexico P, 2000. Print.

The Vanishing American. Dir. George B. Seitz. Perf. Richard Dix and Lois Wilson. Paramount, 1925.

Walker, Jeffrey. “Deconstructing an American Myth: The Last of the Mohicans (1992)." Hollywood's Indian: The Portrayal of the Native American in Film. Ed.

Peter C. Rollins and John E. O’Connor. Lexington, KY: The UP of Kentucky, 1998. 170-186. Print.

Whitcomb, Cynthia. Writing Your Screenplay: How to Write Great Screenplays for Movies and Television. Waukesha, WI: Kalmbach Publishing Co., 2002. Print. Windtalkers. Dir. John Woo. Perf. Nicolas Cage and Adam Beach. MGM, 2002. Young, Robert J. C. White Mythologies. New York: Routledge, 2004. Print. 


\section{CHAPTER III}

\section{The Postcolonial Lens}

Any film might be considered an artifact of its time, a barometer against which the concerns of its day are recorded and preserved in subsequent measure. As such, one might expect productions about Native Americans to have shown a gradual progression toward a more favorable image of America's Indigenous inhabitants. Instead, the trend seems to have shifted from repressing their story to appropriating it for other causes and interests. In neither case do their very own claims carry the day. This arrangement reveals the colonial underpinnings of most major cultural forms, including the vast motion picture empire, an industry of images. That these images can be hijacked to serve another purpose is precisely the point of a postcolonial understanding of narrative and the uses to which it is often put.

A major concern of Postcolonial Studies is the analysis of power. Broadly conceived, it is the question of how the so-called "white, superior, plutocratic, civilized world founded its power on the repression of populations who had suddenly become 'invisible'" (Young 32). As to how this circumstance avails itself to the 'civilized' world, one need only recognize "a commonplace gesture of History: there have to be two races - the masters and the slaves" (32). It is this dyadic interpretation that provides a glimpse into the majorant's exploitive egoism. Influenced by Hegel's seminal work on 'Lordship and Bondage', many 
scholars have observed how "the relation of master and slave" is a dependent "form that lacks reciprocal recognition" (Gogol 19). This is especially true in film, a medium designed entirely for the spectator. It is a form that privileges a voyeuristic glimpse into a narratively confined world in which the filmic subjects cannot 'talk back'.

Moreover, this glimpse often becomes the basis for a superficial imagining of the spectator's own mastery over the story and its elements. Consider how even a film that is based upon the real life experiences of the Navajo Code Talkers, such as John Woo's Windtalkers (2002), can fall subject to ulterior motivations. Recruited during World War II to devise a top secret code based upon their own language, the Code Talkers were enlisted to confuse the Japanese Military which was renowned for its ability to decode US radio transmissions. Without their aid, it would have been exceedingly difficult to coordinate troop movements and air strikes, let alone target enemy embankments without inadvertently alerting them to the fact that their positions had been compromised. Antonia Felix's book Windtalkers: The Making of the Film About the Navajo Code Talkers of World War II includes an introduction by U.S. Senator Jeff Bingaman (D-NM) who writes, “The Navajo code talkers are part of our nation's living heritage, the fabric that makes this country great" (18). He goes on to explain how a bill he sponsored to honor them "met with some legislative obstacles," but "slowly gained bi-partisan support" to demonstrate how "we as Americans, individually 
and as a whole, will rise above adversity and divisiveness to unify and fight for the greater good" (21).

Not to discredit the attention, it is the motives that must be called into question. Consider Bingaman's accolades and the service to which they are put. By subsuming the Code Talkers' story under a broader banner, they can be presented as the supporting cast in a greater American triumph. Their real story, in which they provided the Military its first ever unbreakable code yet were denied their promised promotions, is rewritten as a triumph over political bipartisanship. But what of the bipartisanship that is wedged between the majorant and the minorant, that which entitles the former to dispossess the latter? How is the privileged spokesman "author'-ized not only to read what he sees, but to write over it in roman letters?" (Pratt 224).

Such notions complicate a film like Windtalkers. They beg the questions, whose story is it and who is the story really for? If one is to believe Senator Bingaman's claim, it belongs to all Americans. Yet for Indigenous moviegoers who might have hoped that Hollywood had finally produced a film that afforded them some measure of autonomy, this was simply not the case. As Laura Mulvey points out, "The cinema has distinguished itself in the production of ego ideals," in which movie "stars provide a focus or centre both to screen space and screen story" (178). Hence, the protagonist always occupies the film's center space. "By structuring the film around a main controlling figure with whom the spectator can identify," such as Nicolas Cage in the present example, it is his persona of the 
rogue sergeant who becomes the viewer's de facto "screen surrogate" (180). The movie does not center on its Navajo characters, nor does it permit enough narrative space for an audience to truly identify with them.

Film space, in other words, can be colonized much like land and material space. Big budget Hollywood movies seek a maximum return on investment, thereby promoting an imbalanced perspective that privileges the majority culture's point of view. The industry is in the business of making money, and that which is most profitable invariably carries the day. What applies to physical types of property appears also to count toward various spectated properties. Each relies upon the correlated fantasies of ownership and supremacy, a set of ideas the majorant advances to reinforce his own image.

These, and other concerns are taken up by the discerning lens of postcolonial theory. From the simple theft of a story to the subtle repositioning of its teller, the "idea of privilege is at the heart of the colonial relationship—and that privilege is undoubtedly economic" (Memmi xii). Those with the capital to control the story, financially and politically, arrange it to their own benefit. Those upon whom such narrative advantage is claimed are cast not only as socially and economically underprivileged, but as characterologically impoverished as well. This is most evident in the persistence of such devices as stereotype.

Ward Churchill reminds the reader of the function of stereotype. As a colonizing force it has shaped "the public perception of the historical existence of 
Native Americans [as] beings who spent their time serving as little other than figurative pop-up targets for non-Indian guns" (698). It persists, therefore, not by account of its historical accuracy, but because it serves the interests of the colonizer. He wishes to convince himself that his oppressive actions have always been warranted. Consider Robert Stam's and Louise Spence's application of this concept as it relates across the broader spectrum of race:

Racism comes "in the wake" of concrete oppressions. Amerindians were called "beasts" and "cannibals" because white Europeans were slaughtering them and expropriating their land; blacks were slandered as "lazy" because they were being exploited as slaves; Mexicans were caricatured as "greasers" and "bandidos" because the United States had seized half their territory; and the colonised were ridiculed as lacking in culture and history because colonialism, in the name of profit, was destroying the basis of that culture and the memory of that history. (237)

While an analysis of stereotype is pertinent to any discussion of representational strategy, it is but one of several telling avenues one might pursue via the postcolonial perspective. Others include interrogating such practices as paternalism, or examining the interpretations of alterity as correlated with the psychoanalytic tradition, each of which appears to fit the West's obsession with defining it's self in relation to a subordinate Other. Further still, one might look at the subtle ways in which production and marketing strategies ultimately shape the story that is both sold and told. Each 
of these instances might explain how a film about the Navajo Code Talkers can be made to fit some other expedient outcome, such as a public figure's political reputation.

\section{The Genesis of Stereotype}

Director John Woo's assertion that his film's namesakes were "happy to know that we wanted to make all the Marines heroes" reveals considerably more about his own assumptions than it does of those for whom the story is ostensibly told (Felix 12). As a film based on actual events, Japanese military and Navajo code talker advisors were on set, as well as a knowledgeable military historian (126). Yet despite these resources, the script maintains a decidedly myopic point of view. This is particularly troublesome given the presumption of authority afforded to such experts. As Trinh Minh-ha reminds us, "Anthropologists always set out to depict that which the natives live or carry on in their lives 'without their knowing it' and to see through the latter's eyes with, in addition, God's grasp of the totality" (73).

How an anthropologist, filmmaker, or senator is 'author-ized' to tell a story that is undeniably someone else's, and to subsequently profit from that story, is one of the cleverest maneuvers of colonialism. Similar to the acquisition of land and raw materials, the trade in images is also profitable. Moreover, it is accessible to a wider range of people, including those without the resources to exploit others financially. Just as the "European improving eye" sees Indigenous 
landscapes as "meaningful only in terms of ... a marketable surplus" rather than as "intensely humanized [spaces] saturated with local history and meaning [understood within] indigenous knowledge formations," the same can be said of Indigenous bodies, which the Euro-American eye also commodifies in pursuit of its own purposes (Pratt 61). The most expedient form of image colonization is stereotype. From bloodthirsty savage to noble Indian and all points in between, the Native image has been exploited to serve a multitude of colonizing purposes. The most recognizable stereotype is that of the bloodthirsty savage. Cynthia Whitcomb identifies this representation as a "sub-zero" character type, which also includes "sociopaths, psychopaths, sadists, Gestapo, and serial murderer types" (53). She goes on to explain, "this level of character is rarely the protagonist, and rarely ever makes any shift of consciousness" (53). Throughout film history, the bloodthirsty savage has stood not only as antagonist to the Western hero, but as antithesis to Western ideals as well. Two notable examples include Dances with Wolves (1990) and Last of the Mohicans (1993). Like scores of films before it, the first depicts the brutal death of a frontiersman at the edge of a scalping blade. As Jacquelyn Kilpatrick comments, "the Pawnees are not allowed to surface as anything but vicious killers" (124). Not to be outdone, it is the Huron in Last of the Mohicans who epitomize the height of gratuitous violence. This is evident when the character Magua cuts the heart from an enemy officer after vowing, "before you die know that I will put under the knife your children, so I will wipe your seed from the earth forever." 
In such contexts, the bloodthirsty image serves a double purpose. First, it presents a formidable foe, one who in terms of narrative is "a worthy opponent-strong enough to be a real challenge to [the] protagonist" (Whitcomb 17). But there is a secondary, ideological function as well. By opposing it against a more complimentary image, such as peaceful interlocutor (Kevin Costner) or adventurous wayfarer (Daniel Day Lewis), the perception of lawlessness and primitivism persists. Moreover, it is personified in the form of a cruel and inimical figure. How ironic that Magua is cast as a threat to the white man's propagation when all along it is the white man who threatens to annihilate the Huron.

But it is not always the bloodthirsty savage that inhabits the Euro-American imagination. Sometimes, the noble Indian makes an appearance. These binary representations need not be considered in strict opposition to one another. They are part of the same intersecting background, one whose purpose is to provide sharper focus to the Euro-American foreground. As Robert F. Berkhofer, Jr. suggests, "The Indian of imagination and ideology continues to be derived from the polemical and creative needs of Whites," a characterized literary device that "could be viewed as either bad or good depending on the observer's feelings about his own society and the use to which he wanted to put the image" $(71,27$ 28).

Two uses come immediately to mind. First is the ulterior motive. What does the white man gain from promoting this image? An ally who conveniently 
reinforces his actions, even when such actions render the Indian a willing accomplice to his own destruction? Such a theme undeniably supports the Last of the Mohicans. An imagined partnership in which the other party's motives are interpreted to be in support of his own? Consider a film like Windtalkers, which opens with such unmistakably patriotic images that "the entire theme and heart of the movie are shown symbolically before the first word is even spoken" (Whitcomb 128). Or a vehicle through which he is able to recite his own story and advance his own interests? By associating himself with an honorable cause, such as campaigning to award legislative recognition to the Code Talkers, he gains political capital from the arrangement. Whatever purpose the image pretends, an ulterior explanation is almost always applicable.

And serving the ulterior motive is the second application of the noble Indian, the idea that he is among the last of his kind. It is also curious to note Hollywood's tendency to always depict such characters as masculine personalities. This is sarcastically noted by Berkhofer, who suggests, "Given the conventions of rugged individualism, physical conflict, and the absence of civilized institutions, in the Western the hero regardless of nominal occupation is always athletic and masculine, even Calamity Jane!" (98). A salient construct of 'the last of his kind' is the narrative purpose he is scripted to serve. This is most notable in the diegetically shifting space he occupies, where he is restricted in both time and space. He could either "exist before the coming of White society or [he] could help the White settler and then die forecasting the wonders and 
virtues of the civilization that was to supersede the simplicity and naturalness of [his] aboriginal life" (91). Not only is this true of Chingachgook, the namesake last Mohican, who stands atop a mountain and surveys what is left of his world. It is also true of other prescient characters, including those scripted to appear in an otherwise more sympathetic narrative.

Among the earliest examples is Delmer Daves' Broken Arrow (1950). As Frank Manchel notes, the film was recognized for "its groundbreaking efforts to promote tolerance and racial equality" (92). Yet the movie's very theme can be summed up in the dialogue delivered by Jeff Chandler, who was nominated for best supporting actor for his portrayal of Cochise. In acquiescence to the white man, he rebukes the defiant Geronimo, "Why should not the Apache be able to learn new ways? It is not easy to change, but sometimes it is required. The Americans are growing stronger while we are growing weaker. If a big wind comes, a tree must bend or be lifted out by its roots." Perhaps this was in line with the sympathies of the 1950s. Twenty years later, however, it would be put quite another way.

By 1970, the noble Indian would make his appearance in a film entitled Little Big Man. Though narrated by Dustin Hoffman, it is the character Old Lodge Skins, portrayed by Tsleil-Waututh actor Chief Dan George, who adds depth and humanity to the story. As is custom with many tribes who collectively refer to themselves in their own tongue as 'the people' or 'original people', Old Lodge Skins speaks to Little Big Man (Dustin Hoffman) of the problem of the white 
man, "Whatever else you can say about them, it must be admitted: you cannot get rid of them. There is an endless supply of white man, but there always has been a limited number of Human Beings." A more critical and cleverly worded perspective, it nonetheless forecasts the coming of the end of America's Native Beings.

Is it not also telling that a non-Native actor (Jeff Chandler) would receive academy award recognition for his portrayal of an actual Indigenous leader, while it would take another twenty years for an actual Native American to be nominated for such an award? Chief Dan George was recognized for his performance of the fictitious character Old Lodge Skins in 1970's Little Big Man. And it would take another twenty years for the next Indigenous actor to receive a nomination (Graham Greene in Dances with Wolves). "It is worth noting," writes Manchel, that as far back as Broken Arrow's release, "almost a quarter of all Hollywood movies made up to that time had been Westerns" (92). This is to say that a great many films have been produced about Native Americans. Few, however, have sought to vindicate their image. And of those receiving Academy Award nominations, it is conspicuous that the only role reserved for an Indigenous screen artist is that of best supporting actor.

This is unlikely to change so long as the majority culture takes comfort in the predictability and superficiality of the Native image. As Kilpatrick explains, “The Native Other as sidekick has always been comforting to that part of the audience that desired a painless solution to racial harmony" (12). Best supporting actor, 
therefore, goes hand in hand with the idea of sidekick. It is also worth mentioning that only the most deferential character earns such accolades. The savage Magua, no matter how well depicted by legendary Cherokee actor Wes Studi, will not merit consideration as a 'supporting' actor.

Images of the noble Indian and bloodthirsty savage serve a similar purpose. Neither attempts to deny the white man's presumed dominion over other lands and peoples. The "celluloid Indian" is confined to the roles of savage obstacle or noble convert (xvii). Put quite simply, “'Good' Indians would conform to white society, 'bad' Indians would not" (Aleiss 90). Either way, the majorant's perspective prevails, whether through assimilation or annihilation (the former achieving much the same goal as the latter). The bloodthirsty savage and noble Indian represent two of the most expedient stereotypes of colonialism, yet these are not the only images proposed by a colonialist agenda.

\section{Other Marginalizing Stereotypes}

In the perpetuation of additional images such as the exotic princess or drunken Indian, few media possess the captivating power of film. Audiences gravitate "to the movies for escape and to experience places and situations that [are] beyond their economic, social, or cultural" affiliations (Kilpatrick 18). This fascination with the vicarious experience, the making of something strange into something familiar, is nothing new. It is borne from a longstanding tradition of imagining oneself at the pinnacle of discovery. In the days before film, this was done 
through travel writing. But as Pratt points out, the notion of discovery is often farcical because it lays claim to those very "same spaces [that] are lived as intensely humanized" by those who already inhabit them (61). This raises a number of key questions and concerns regarding the metropolis' propensity to perceive the entire world, its people and places, with "God's grasp of the totality" (Trinh 73). Pratt interrogates:

How has travel and exploration writing produced 'the rest of the world' for European readerships at particular points in Europe's expansionist trajectory? How has it produced Europe's differentiated conceptions of itself in relation to something it became possible to call 'the rest of the world'? How do such signifying practices encode and legitimate the aspirations of economic expansion and empire? (5)

Stereotype, of course, helps to encode colonialist thought and action. Concerning the cinema, "The particular Indian on the screen, whether noble or savage, might have been a screenwriter's fleeting invention, but the viewer is repeatedly exposed to the same general ideas about Indianness represented in the characters" (Kilpatrick 18). Such reinforcement elevates the majorant's motives, agenda, and self-conception. But for efficiency's sake, the noble and savage stereotypes need not be the only projections to accomplish this goal. While the aforementioned examples constitute the most familiar stereotypes of Native Americans, occasionally there are others. "If there is a third major White image of the Indian, then the degraded, often drunken, Indian constitutes 
the essence of that understanding ... neither noble or wildly savage but always scorned, the degraded Indian exhibits the vices of both societies in the opinion of White observers" (Berkhofer 30). It is an image employed for obvious reasonsto mark the existence of a peripheral or marginal other. Max Horkheimer and Theodor Adorno illustrate how majority culture universally degrades most "anyone who goes hungry and suffers from cold" (121). This analysis is often extended to cultural minority groups. By categorically portraying any of these characters as despicable, the majorant distinguishes itself as the moral superior. In the cinematic world, the degraded character serves to reinforce the virtuous one. As Horkheimer and Adorno confirm, "In films such a person is, at best, an eccentric, an object of maliciously indulgent humor; but mostly he is a villain and is identified as such on his very first appearance" (121).

The 1989 film Powwow Highway includes just such an example. In his first motion picture appearance, Wes Studi enters a café to announce that he's "heading into Billings for a little pussy." "It's Friday night, two weeks from Christmas," he explains, and "the bars will be crawlin' with fa-la-la and horny little elves." When the waitress, a blonde-haired white woman, regards him with a look of disgust, he replies, "Hey Betty, how 'bout you and me going into Billings tonight?" This is a particularly insidious stereotype as it conjures the anachronous image of the lustful savage. As Kilpatrick observes, it is reminiscent of earlier films in which "we repeatedly see the lustful savage attacking the white woman, requiring that he be killed immediately" (xvii). Yet 
the inverse situation, a white man pursuing a Native woman, arrives at a conspicuously different conclusion.

Hollywood's interracial depictions seem always to promote an egregious double standard. Whereas "a white woman could never give herself willingly to an Indian man ... an Indian woman-usually a 'princess' — could give herself to a white man" (64). “The whole affair," from a bourgeois standpoint, "actually carries a romantic aura about it," as the "Indian Princess' is enormously attractive," making the liaison "tragically [tempting] and provocative" (xvii, 6364). For the protagonist, it is a seductive indulgence. He is permitted to take her as his lover, but is forbidden to take the relationship any further. As Hollywood demonstrates time and again, "to allow an illicit relationship without due punishment of the culprits is strictly tabooed," and "the lovely 'Indian Princess' . . . must die before any real damage is done to the purity of the gene pool" (Horkheimer and Adorno 113; Kilpatrick xvii).

Broken Arrow delivers one of the most indelible examples of this. Protagonist Tom Jeffords, played by James Stewart, "falls immediately in love with Sonseeahray, played by a darkened and contact-lensed Debra Paget" (59). No sooner does he marry into the tribe, however, "when a group of Indian-hating miners ambush" them (Aleiss 92). A wounded Jeffords tells Sonseeahray to run. She refuses and pulls a knife from his belt. Charging toward the attackers, she is shot and killed. Jeffords vows vengeance, but is rebuked by Cochise who tells him, "It will not be done ... Are you a child that you thought peace would come 
easy, you who taught me so well?" In a troubling sort of paradox, "the permanent peace between Apaches and whites, then, becomes possible only through the sacrifice of Jeffords' Indian wife" (92). Riding off into the sunset, the movie concludes in true sentimental and stereotypical form, as Jeffords' voiceover relates, "As time passed, I came to know that the death of Sonseeahray put a seal upon the peace." Although tragically romantic, the prospect of miscegenation "was a scary proposition to audiences in the 1950s," an idea that would continue to "hold true in films made through the ... 1990s" and beyond (Kilpatrick 59, 62).

Nineteen ninety-four's Legends of the Fall affirms this belief. Perhaps no more restless or reckless a character was ever penned than the Odyssean figure Tristan Ludlow (Brad Pitt). Heralding the metaphorical journey of discovery, he embarks on an epic quest to assuage his adventuresome wanderlust. His travels permit him a rarefied glimpse into various exotic places and peoples. But it is an affair with an Indigenous woman closer to his Montana home that forestalls his restless journey.

Portrayed by Lakota model and actress Karina Lombard, the alluring woman becomes his wife. An example of the exotic landscape personified, her pregnancy might be perceived as a mark of the protagonist's territorial claims. As Mulvey reminds moviegoers, "In a world ordered by sexual imbalance ... the determining male gaze projects its fantasy on to the female figure, which is styled [and] coded for strong visual and erotic impact" (179). Her image, in 
other words, only counts insofar as what it provokes in the protagonist, whose gaze is vicariously relayed to the spectator. As Budd Boetticher defines the heroine's presence, "She is the one, or rather the love or fear she inspires in the hero, or else the concern he feels for her, who makes him act the way he does" (qtd. in Mulvey: 179). This is certainly true for Tristan, whose rage knows no bounds when his wife is slain by Irish bootleggers. As Kilpatrick contends, "It was a touching love story, but it could not continue" (59).

Just as Boetticher implies of the heroine's narrative function, the same can be said of all formative stereotypes. From the bloodthirsty savage who must be eradicated to the Indian princess who inspires adventure, moviegoers are treated to a steady diet of consumable images. As Horkheimer and Adorno summarize, "The bread on which the culture industry feeds humanity remains the stone of stereotype" (119). A presence to be acted upon and never to act on its own, the Indigenous image is meant to tell the majority culture more about itself rather than to truly identify with its Others. To do otherwise might call into question the entitlements of colonialism.

\section{Psychoanalytic Spectating}

The construction of fictional characters and their subsequent placement within an imagined storyline represents a condensed set of roles that are often so fixed and narrow that they appear only as caricatures, whose deconstruction can be achieved simply enough through the basic application of some of the principles 
of psychoanalysis. This has been done extensively with respect to film. But what has also been examined is the role of the spectator with respect to how these films are consumed. Protagonists are generally meant to represent spectators' ego ideals and to function as their screen surrogates. Insofar as this occurs for a majority audience, minority characters appear to exist only to reinforce the egocentered position of the privileged spectator.

The majority audience does not find its 'screen surrogate' in the Native figure. Indeed, it seldom ever has to look for it there. The Hollywood plot revolves almost invariably around the central character of the Western hero. Alternative viewings are possible but require a disciplined and often frustrated encounter with the screen story. A classic example is the 1988 film Die Hard. Thomas McLaughlin writes how the film's plot includes a sequence in which "terrorists seize a corporate headquarters building" in brazen "challenge to official power" (18). He cites media scholar John Fiske who observed a group of men watching this film in a homeless shelter and explains how these viewers were able to "resist the ideological message by identifying with the terrorists [and] ignoring the reassertion of power-simply turning off the tape when the tide turned in favor of official order" (18). An undeniable expression of the spectators' agency, it nonetheless demonstrates a less-than-gratifying viewing experience.

Further, the above example reveals the lengths to which an Other audience must go to resist the majority-privileged interpretation. The decisive break, or interruption, often must begin within the imaginings of the minority spectator, 
as only rarely is there narrative relief for this audience. Stam and Spence discuss an emboldened exception from the mid-1960s. One Potato, Two Potato (1964) is "a film about interracial marriage," in which "the black husband ... attends a western in a drive-in movie theatre," where "he screams his support for the Indians, whom he sees as his analogues in suffering" (249). The husband's own “experience of oppression inflects a character's reading of the film-within-thefilm" and offers a "reading [that] goes against the grain of the colonialist discourse" (249). But more often than not the minority spectator must regard his or her self through what Fanon describes as a "third-person consciousness" (110). Aided by cinematic images, or what Mark B. N. Hansen calls 'bodies in code', "The clear implication here is that black men and women [spectate] their bodies not directly, or firsthand, but as objectifications ... through images created by others" (149).

One of the most curious narrative inventions is the sympathetic mediator who serves as a point of reference for the spectator. But for whom is this character constructed? With hardly an exception, the mediator is almost always a majority figure. Legends of the Fall is notable for its use of Gordon Tootoosis, who plays the minor character role of One Stab. A member of the Cree and Stoney Nations, it is his voice that diegetically tells the story of Tristan Ludlow. Aside from this narration, however, he speaks not a word of English. As Tristan's older brother explains to a family visitor, "He wouldn't lower himself to speak English.” The fact that he uses it in off-screen narration might seem to support bell hooks' 
notion of "this is the oppressor's language / yet I need it to talk to you," except that he expresses no opinion outside of that which concerns Tristan (1995). Additionally, he occupies so little screen space that it would be a considerable stretch to affirm that he is anything but a supporting character.

The insertion of a sympathetic narrator, then, is clearly an invention of the majority culture's fancy. As Michelle Raheja explains, "the aesthetic diplomacy" that such a character is meant to engender "complicates a colonial binary where the Indigenous subject is merely talking back to the metropolis, often through a non-Native interpreter" (19). Kilpatrick puts it bluntly when she reasons "that because Indians are, in relation to the vast majority of the film's audience, the Other, a mediator of sorts is required to make the viewer more comfortable and more capable of developing an understanding" (83). Hence, the inverse strategy applies. Rather than telling the story from an acculturated Indian's point of view, the majority audience favors "an appropriation of Indian identity by the white hero" (83). Such is an example of the ever-present sense of entitlement that seems to always walk so comfortably hand-in-hand with colonialism.

It is a narrative configuration that is meant to privilege the majority spectator. It eases the position from which he or she is able to surveil the foreign world. Stam and Spence describe a near corporeal sense of gratification when they assert:

The magic carpet provided by these apparatuses flies us around the globe and makes us, by virtue of our subject position, its audiovisual masters. It 
produces us as subjects, transforming us into armchair conquistadores, affirming our sense of power while making the inhabitants of the Third World objects of spectacle for the First World's voyeuristic gaze. (238) It is a one-sided affair in which the majority culture perceives itself as the beacon illuminating "the periphery (in the emanating glow of the civilizing mission)" (Pratt 6).

Adding to this dispensation, the majority audience routinely misreads Indigenous epistemes in an effort to reaffirm its own jurisdictional claims. Traditional cultural narratives are re-envisioned in such a way that "Europeans are often interpreted to be gods or Christ-like, thereby viewed to be lightbearers to pagans living in the darkness" (Raheja 185). The narrator, with whom the spectator is meant to identify, is therefore the enlightened figure, the one whose identity is in contrast with all the other peripheral characters. In the case that such other characters are members of a minority cultural group, the majority spectator assembles their differences as evidence that he or she is not one of them. The Western audience fixates upon such differences in forging its own identity.

As Berkhofer elaborates, the assemblage of such difference fits within "a centuries-old White effort to understand themselves through understanding Native Americans," and "since Whites primarily understood the Indian as an antithesis to themselves, then civilization and Indianness as they defined them would forever be opposites" (xvi, 29). This is important, of course, considering 
the context to which it has repeatedly been put-the confiscation of one group's land and resources by another and the latter group's claim of governing authority over the former. To better understand how this occurs on such a broad scale, it is instructive to examine how it manifests at the individual, psychoanalytic level.

Recalling Mulvey's explanation of how the ego ideal is associated with the protagonist, it is easy to perceive the remaining characters' purpose as that of being acted upon. The spectator, through vicarious association with the protagonist, is free to act upon these characters in much the same way as his or her screen surrogate does. Devoid of any real agency, they are little more than accessories to the narrative plot, invisible as human beings.

One such example includes a scene from Windtalkers, in which 'master' Sergeant Joe Enders blames Private Ben Yahzee for being the object of a racially motivated assault. The scene bears further analysis, as both its narrative and technical constructions reveal a troubling set of presumptions about racial autonomy. It begins with a reverse angle long shot of a lone figure. The man is bent over knee deep in water with his back to the camera. As the angle shifts to confirm his identity, the camera pans beyond Ben's face to reveal an eerily vacant riverbank. Once this has been established, the camera returns to its original 'off guard' angle. Although Ben finally gets his moment alone on the screen, the spectator's gaze is fixed upon a distant and vulnerable image. It is a sequence that consciously orients the spectator toward the recognition that Ben 
is endangered by something as of yet unseen. As he approaches the riverbank to reach for his shirt, another marine emerges to threaten him. In the fight that ensues, Joe arrives to rescue Ben. Afterward, he admonishes him with the threat, "Next time you decide to take a bath, private, you let me know or I'll kick your ass." Clearly, and in a very overt manner, Ben is punished for acting on his own. This is framed not only by the narrative, but by the camera as well.

What this scene really promotes is the idea that there are two races, that Ben is a slave among masters. But it goes even deeper than this. As scholar Eugene Gogol notes, the "master-slave [dynamic] involves a production relationship" in which "the master holds the bondsman in subordination" through his obeisance and labor $(16,20)$. Indeed, there would have been no story to tell had there never been a bondsman to support it. The United States Marine Corps, in other words, would have been unable to speak of victory in the South Pacific without the involvement of the Navajo Code Talkers. Even a fictional hero such as Joe Enders derives his narrative authority through the scripted actions of a subservient like Ben. As Gogol restates, "The master can only relate to the thing through the bondsman who labors upon it. Thus, just where the master has effectively achieved lordship, he really finds that it is not an independent, but rather a dependent [position] that he has achieved" (20). Indeed, what more expedient way to bolster his political celebrity than for Senator Bingaman to position himself as the champion of a popular proposal, albeit one that exists only on account of the courageous acts of others? 
It is indeed a relationship built upon exploitation, the very nucleus of colonial interaction. It demonstrates how advantage is claimed at both the individual and societal levels. The release of the film Windtalkers ushered an opportune moment for several personalities to deny that intentions were anything but admirable. The media greeted the film with a general attitude of goodwill, lauding it with such statements as "the Navajo code talkers have waited a long time to have their story told" (Ebert 33). The acclaim it heralded made possible the presumptions of many ambitious individuals, media and political figures alike. That its aim was ultimately unsuccessful is a testament to the recyclability of its theme. But this is of little concern to the colonialist whose own image is heroically reinforced through such comfortable assurances. Colonialism requires the Indigenous narrative to fall in place lockstep with the master narrative. The ideological dream of America cannot be accomplished otherwise.

\section{Paternalism and Postcoloniality}

It is instructive to note how the media sets the Indigenous story not in opposition to the popular cultural one, but rather in support of it. As observed in the functions of stereotype, this is present at the individual character level as well. But it is not to say that the master narrative is always so blatant in its conquest of the minorant. For certain, the image of the savage serves a contrasting purpose to the supposedly civilized Western hero, but so too does the eager sidekick. What better way to reveal the hero's benevolence than to 
depict the dutiful care and responsibility with which he charitably looks after his 'lesser brother'?

Among the representational strategies most favored by cultural imperialism is the benign-appearing deception defined as paternalism. The concept is akin to making informed decisions for a presumably uninformed group of underprivileged individuals under the guise of advocating for them. As Berkhofer puts it, “The last persons presumed to know their own larger interests were the Indians, and policy makers therefore assumed a stewardship over native interests in the American scheme of things" (153). Yet, "a paternalist is one who wants to stretch racism and inequality farther," writes Memmi, further explaining that the idea is borne of disjunctive situations in which "the colonized [is expected to] be grateful to [the colonialist] for softening what is coming to him" (76). "It is [an] astonishing mental attitude ... a charitable racism, if you like - which is not thereby less skillful nor less profitable. For the most generous paternalism revolts as soon as the colonized demands his union rights, for example" (76). One way to spot a paternalist, therefore, is to identify the person who speaks for, rather than with, the charitably oppressed and dispossessed.

Western interpretations of tribes, for example, are often grounded in such false allegiances. The colonizer aligns himself with one clan in the interests of overpowering another. By inserting himself into the relationship, he assumes a form of stewardship over the preferred group. Furthermore, the conflict is projected away from his self as catalyst and directed toward the exploited clans 
whose rivalries are overplayed for the benefit of the colonizer. As Ngũgĩ wa Thiong'o observes, "Whatever happens in Kenya, Uganda, Malawi is because of Tribe $A$ versus Tribe $B$. Whatever erupts in Zaire, Nigeria, Liberia, Zambia is because of the traditional enmity between Tribe $D$ and Tribe $C^{\prime \prime}(1)$. Or in the context of Hollywood, it is typically the noble Sioux or Cheyenne versus the bloodthirsty Pawnee or Comanche. Seemingly absolved from all responsibility, the Western hero is seen as simply aiding a deserving group in its time of need.

A closer examination, however, reveals how the colonizer profits from such an arrangement. One of the clearest examples of this can be seen in the Oscar winning documentary Broken Rainbow (1985). The film exposes the truth behind the eviction of 10,000 Navajos from what the U.S. Government deemed to be Hopi tribal land. Of little concern to the architects of this relocation plan was the fact that these two nations had coexisted peacefully for several hundreds of years, relying on one another as primary allies and trading partners. Nevertheless, the passage of Public Law 93-531 paved the way for "the forced relocation of the Navajos so that their land in the four corners region of the Southwest could be strip-mined" by the Peabody Coal Company (Kilpatrick 102). Through the creation of artificially contested space, the Government could claim stewardship over the land and ultimately determine its division and use.

It is a centuries old tale that harkens back through various permutations. In 1856, for example, "the Mormons who had fled religious persecution in Illinois, Missouri and England to establish their Zion in Utah were being harassed by the 
United States" (Locke 298). Feigning a paternalistic interest in the Navajo, they began a campaign of arming and "encouraging the southwestern tribes to drive the 'Gentiles' out” (298). Stirring up the Navajo had little to do with advocating on their behalf and much to do with trying to keep the U.S. Government from encroaching upon the Mormons' own religious affairs. In the broader scheme of things, this practice has always served the majorant's own economic and political interests.

Consider the context of World War II, nearly a full century later. The European and Pacific theatres of battle had already been raging for a few years prior to the recruitment of the Navajo Code Talkers. Until that moment, the Navajos' only relationship with the U.S. Military had been a largely adversarial one. To think that they were now being asked to assist in the U.S. war effort came as a great surprise to the Navajo people. Particularly perplexing was the notice that they were to use their Indigenous language in this effort, the very same words that they had been forbidden to speak at government-funded boarding schools. In a personal interview with retired Code Talker, Samuel Tso, he recalls telling a recruiter, "Hey, the federal government told me not to use that anymore. Besides that, the United States Government and the Navajo tribe have an agreement. We're not supposed to bear arms anymore" (Tso). Nevertheless, the United States had an ulterior motive at the time and insisted that both parties had a common enemy in the Japanese. 
Interestingly, the story of the Code Talkers was held in secret until more than twenty years after the conclusion of the war. While justifiably hidden so that they might be called upon to lend clandestine assistance in future conflicts, it is notable how public opinion favored the storyteller almost as much as the characters who were involved in the actual story. From Presidents Nixon and Reagan, who publicized and signed Presidential Declarations, to Senator Bingaman, who lobbied for Congressional recognition, the personalities who remained foremost in the public spotlight were the sponsors of said acknowledgements. While certainly admirable accomplishments, it is the position of the benefactor that stands to gain the most. By aligning himself with a popular cause, such as campaigning on behalf of the minorant, he reinforces his own role as benevolent leader. The image he promotes on behalf of others helps to cultivate his own.

As Stam and Spence point out, “The insistence on 'positive images', finally, obscures the fact that 'nice' images might at times be as pernicious as overtly degrading ones, providing a bourgeois façade for paternalism, a more pervasive racism" (236). They masquerade as altruistic examples, when in reality they often serve a more subtle purpose. Both forms hollow out the complexity of the image so that each might be filled according to the colonizer's own interpretation. The underlying purpose, then, is to discern how the Indigenous image promotes capital, whether economic or political. 
Paternalism provides a profitable conquest. Just as pseudo-sympathetic instigators incited the Hopi against the Navajo in order to gain mineral rights to newly 'disputed' land, others found a ready market in self-imagined sympathizers who were eager to collect the cultural products of such encounters. It can be said to begin with the "boutique multiculturalist" who accords a "celebratory but largely cosmetic [and] superficial respect to cultures other than his own" (Huggan 124). But it is also present with the academician who searches for authenticity in various marketable forms. What constitutes an authentic source versus one that is heavily mediated is the subject of much debate. But as Ngũgĩ notes, there are certain indicators that are given higher value in the postcolonial marketplace. He explains how "literature is often evaluated in terms of the 'tribal' origins of the authors or the 'tribal' origins or composition of the characters in the given novel or play" (1). Perhaps the tribesperson is speaking for his or her self, but it is the cultural capitalist who gets to determine whether the Indigenous voice will be heard at all.

This is precisely the premise of postcoloniality. As Graham Huggan explains: Value is constructed through global market operations involving the exchange of cultural commodities and, particularly, culturally 'othered' goods ... In the overwhelmingly commercial context of commodity culture ... postcoloniality [determines] the value equivalence of putatively marginal products in the global marketplace. (6) 
What better way to explain the critical acclaim given a film like Dances with Wolves, which sells the idea of authenticity through intercultural immersion? Academicians like Robert Baird underestimated the reception of a film "released too long since any other great, epic Western to be anything but a boondoggle, until 'Costner's folly' was seen by millions and had won seven Academy Awards” (154). What made this film marketable, in other words, was not its novelty (indeed the storyline offered little by way of this), but rather its comfortable fit within the ethic of the presumably authentic. As Kilpatrick notes, its "use of the Lakota language is one of its most positive aspects" and its subtitles "were more successful than most, artfully constructed and therefore relatively unobtrusive" (129).

In other words, a tired narrative dressed in authentic-looking and -sounding garb is apt to be more successful than one that delineates a truly Indigenous point of view, particularly if that point of view challenges the accepted order.

\section{Affirming the Anticolonial}

The laws of postcoloniality 'defend' the margins. They guarantee their availability to the metropolis, while at the same time buffering it against any substantial outside threat. Largely impermeable, this buffer restricts what flows into the mainstream while ensuring a steady flow of commercial capital outward. Aijaz Ahmad alludes to an imbalanced trade relationship in which "metropolitan countries accumulate cultural artefacts from the whole world" 
(Ahmad 15). This importation is then further unbalanced in what gets manufactured for export. In a strange twist, even the credibility of anticolonial productions is subject to the metropolis' official endorsement. As Roberto Fernández Retamar explains, “We have been so thoroughly steeped in colonialism that we read with real respect only those anticolonialist authors disseminated from the metropolis" (Retamar 18).

So long as the metropolis bestows credibility, works of a truly anticolonial nature are subject to censorship, revision, or any such less official form of suppression. They remain marginalized in this buffer zone, where their novelty may be the only quality recognized by the boutique multiculturalist. Yet this buffer zone might also be understood in the postcolonial parlance as a "contact zone," which Pratt describes as those "spaces where disparate cultures meet, clash, and grapple with each other, often in highly asymmetrical relations of domination and subordination" (4). Vying for position, anticolonial matter must search for fault lines or other areas of potential rupture in order to traverse the boundaries put in place by a market-rigged postcoloniality. The evidence suggests there may be more than one way to approach this challenge.

The first and most obvious approach is to directly confront and interrogate colonial objectives. This is precisely the approach used by Ariel Dorfman and Armand Mattelart in their analysis of imperialism, as applied to such apparently benign forms as children's cartoons. The authors state, "Disney colonizes the everyday world ... with the analgesic of a child's imagination" (141). As the 
Disney vault shows, early cartoon narratives generally promoted an ethnocentric majority view of cross-cultural contact, often justifying the Western exploitation of Indigenous lands and peoples. Dorfman and Mattelart unmasked the early collection of Disney characters, revealing them to be lecherous, profitseeking imperialists bent on exploiting the land and its people. The theme is exemplified in a 1954 comic entitled The Land of Tralla La, in which Uncle Scrooge McDuck attempts to 'exchange' the hustle and bustle of a consumer driven lifestyle with the relative peace and tranquility 'afforded' by a trip to the paradisiacal land of Tralla La (Barks). (Note how even the simple usage of the most casual vocabulary reveals a language commodified by metaphors of consumption).

As McDuck enters this rehabilitative landscape he accidentally drops a bottle cap. The cap is discovered by a local inhabitant and, because it is the only one, quickly becomes a prized commodity that upsets the delicate balance of this peaceful land. The story is naïve and transgressive on many counts. It presumes that the Indigenous community is without resilience and paints an insipid picture of the land and its people. And while it may do an admirable job in identifying the impact of capitalist colonial intrusion, it depicts a sympathetic portrait of an innocent character who unwittingly contributes to this development, which after all is merely the 'product' of the people's own natural instincts. 
Contrast this example with Dorfman and Mattelart's How to Read Donald Duck, squarely aimed at Disney's conspicuous tradition of cultural imperialism. Their native Latin America had long stood witness to a steady stream of colonialist propaganda in such animated films as Saludos Amigos (1943), in which Goofy tries on the romanticized lifestyle of the Argentine gaucho and the actual cartoonists are filmed enjoying an asado of choice roasted meats and world class wine before returning to the United States with suitcases stuffed full of intricate saddles and other fine souvenirs, and The Three Caballeros (1944), in which Donald goes berserk chasing after the local women on the beach at Acapulco, unabashedly calling, "Come here my little enchiladas.” It is no surprise, then, that How to Read Donald Duck's introduction states, "Mr. Disney, we are returning your Duck. Feathers plucked and well-roasted. Look inside, you can see the handwriting on the wall, our hands still writing on the wall: Donald, Go Home!” (Dorfman and Mattelart 10).

That the publication fomented such political dissent in its home country of Chile, where the military dictatorship of Augusto Pinochet had just been newly installed courtesy of U.S. corporate and governmental interests, accounted for its nationwide ban. Anyone found to be in possession of it was subject to arrest. But it is not just a Chilean dictator who disapproved of the material. According to the Microcosm Publishing homepage, "this seminal deconstruction ... is still banned here in America [as] Disney will sue into oblivion anyone who publishes it" (http://microcosmpublishing.com). Publishing companies forewarned, 
Disney continues to be hard at work manufacturing pseudo-sympathetic cultural narratives, often similar in theme to its tremendously popular animated version of Pocahontas (1995).

The problem with Disney is that its stock in trade is predicated on the notion that the company is in the business of providing nothing but wholesome family entertainment. In the case of Pocahontas, the story eschews historical accuracy in favor of an amateurishly concocted love story that is really meant to romanticize the white man's conquest of an enchanted New World as personified in the "exotic, sensual, copyrighted Pocahontas," who "according to Supervising Animator Glen Keane" is quite intentionally depicted as a "'tribal Eve'” (Strong 196-97). Rather than an actual "ten- to twelve-year-old girl," the animator "made a few adjustments" to create a more "voluptuous young woman" (Kilpatrick 151-53). “Besides her beautiful 'more Asian' eyes, he gave her a body with a waspish waist, sexy hips and legs, and breasts that are truly impressive" (153). While the actual John Smith "was a thirty-something mercenary who more resembled a tree stump than a blonde superhero," Disney opted for "a distinctly Nordic John Smith" (Kilpatrick 151; Strong 198). That Pocahontas "falls desperately in love with the first white man she sees" says more about the West's grandiose sense of itself, which is all the more troubling considering that Pocahontas "appears on the surface to be such an innocuous little children's movie" $(150,152)$. 
Aimed at such a young target audience, the colonial narrative reveals one of its most insidious objectives - to indoctrinate the most impressionable with its own brand of deception. But just as children are the object of many of Disney's productions, the majority culture's own impressionability is often the target of a well-scripted anticolonial cinema. The trick is to turn the majorant's own sense of arrogance, greed, and entitlement against him. If unwittingly kept off guard, the result can be highly effective. This type of narrative often takes the form of parody. The target audience is eagerly 'set up' through a deliberate framing of its own cultural beliefs and stereotypes about various different minority groups.

One such example occurs in the satirical film Harold of Orange (1983). An Ojibwé Trickster, Harold, invites a group of foundation directors to the reservation in an effort to entice them to fund a series of lucrative schemes. He devises an assortment of outrageous displays, the most effective of which turn upon the white characters' preconceived notions of what it means to live like an Indian. When Harold offers them the once-in-a-lifetime chance to participate in an authentic naming ceremony, they eagerly accept. After all, it is not every white man who is afforded the rare privilege of receiving a bona fide Indian 'warrior' name. But the joke is on them as Harold produces a cigar box and randomly draws a series of Monopoly game cards, dubbing each recipient with a name such as "Baltic" or "Connecticut" according to the luck of the draw. What makes this scene particularly effective is that it requires a spectatorial understanding of the kinds of stereotypes that inform this set up. 
Scenes that parody cultural stereotypes allow the audience to deconstruct those very stereotypes. That they are meant to advantage an Other audience is precisely the point. As Kilpatrick explains, Harold of Orange "privileges the Native audience in a way that Hollywood films have privileged the mainstream audiences from the beginning of film history" (192). But without the Hollywood budget, the laws of postcoloniality are proven- "Because it was made for an Other audience, Harold of Orange is available only through obscure sources and an occasional university video library" (193).

A somewhat more widely distributed film is House Made of Dawn (1973). Adapted from N. Scott Momaday's Pulitzer Prize winning novel of the same title, it displays a more subtle approach to the questions of cultural identity. Set during the 'relocation' era, Lakota activist Russell Means explains, "the Eisenhower administration had come up with yet another plan to depopulate Indian reservations. The idea was to integrate Indians into urban ghettoes so that in a few generations we would intermarry and disappear into the underclass" (68). As such, the film encourages a different reading of a dominant culture bent on assimilating, or rather erasing, any mark of the Other.

The narrative is rich in symbolism. Playing the lead role of Abel, Pueblo actor Larry Littlebird finds himself in an allegorical battle with the core institutions of white society. His troubles begin when he encounters a sinister albino Indian known locally as 'the white man'. A combination of technical and narrative screenplay conventions are employed to show that this is no ordinary character, 
but rather a witch who has amassed his wealth and power through the art of deception. This is a common construction in Native American lore, one that is likely to escape equivalent meaning among a majority audience. Other indicators, however, are not so subtle. For example, Abel's nemesis makes his first appearance as a rider atop a black horse. One might wonder if this is meant to parallel the apocalyptic horseman from the Book of Revelation. If so, Momaday is intentionally blurring the compositional boundaries between Indigenous and Biblical interpretations of the albino's presence. In the film, a distinctly snake-like rattle accompanies the scene in which Abel confronts this sinister figure before pulling his knife to slay him. This is an event that occurs early in the story. It sets the stage in which Abel must now face an even more formidable institutional foe.

As a result of his murder of the 'white man', Abel is sent to prison. Ostensibly a place of reform, it is here where he meets Tosomah, a master deconstructionist well versed in the subtle arts of subversion. The protagonist first encounters him while attending a quasi-religious rehabilitation meeting. Tosomah initiates the session by referring to the Bible and the power of the Word, which quickly transforms into a subversive lesson about "the turning of words against themselves" (Kilpatrick 182). To the warden and corrections officers, he appears as nothing more than a new age Christian minister; to the Others, a powerful imitator whose shamanic acumen is sharpened against the very tools of the majorant's trade. 
Such syncretic examples abound in this film, demonstrating "how subordinated or marginal groups select and invent from materials transmitted to them by a dominant or metropolitan culture" (Pratt 6). It is a salient feature of many anticolonial works, the most effective of which offer direction through indirection, or an ability to speak directly to an Other audience by running indirect circles around a privileged and unsuspecting majority audience. Because the latter is accustomed to the seat of privilege, it is not so quick to recognize when its presumed entitlements are being unseated. Nevertheless, for a film such as House Made of Dawn to achieve mainstream success is rare. Despite the Pulitzer Prize winning novel as its basis, "it is simply not available from sources that apparently have no trouble obtaining films of twice its age and half its merit" (Kilpatrick 182). As the laws of postcoloniality ensure, "it seems to have simply 'vanished' from all but a few university video libraries” (182).

The purpose of a truly revolutionary, or Trickster cinema, therefore is to deconstruct the hegemony of popular culture. As the Trickster Harold of Orange contends, "We are tricksters in the new school of social acupuncture." The challenge, of course, is to pinpoint the most promising pressure points. Smallrather than large-scale warfare is more the reality in this type of cinema. An independent release might challenge the Hollywood blockbuster in the world of the Academy and its illustrious Awards, but in the end it is all about the means of production. Add to this the growing trend in the consumption of culturally othered goods and it is not so difficult to understand how even "postcolonialism 
and its rhetoric of resistance have themselves become consumer products," commodified by a largely capitalistic "cosmopolitan alterity industry" (Huggan 6, 12). Hollywood filmmakers and political figures alike seem to understand the expedience of this.

As the following chapter illustrates, affirming the Indigenous perspective begins with an adept deconstruction of the majorant's dominion and influence over the controlling interests of capital. Identifying the myriad ways in which these interests are reified is a major task of revolutionary criticism. As Paulo Freire attests, the critical thinker is "one whose role is essentially to 'problematize,' to use the critical faculty" in decolonizing various hegemonies (33). It is therefore the task of an anticolonial thinker to liberate the margins, for the Trickster to assume the role of critical theorist. 
Works Cited

Ahmad, Aijaz. In Theory: Classes, Nations, Literatures. New York: Verso, 1992. Print.

Aleiss, Angela. Making the White Man's Indian: Native Americans and Hollywood Movies. Westport, CT: Praeger Publishers, 2005. Print.

Baird, Robert. "'Going Indian': Dances With Wolves." Hollywood's Indian: The Portrayal of the Native American in Film. Ed. Peter C. Rollins and John E. O'Connor. Lexington, KY: The UP of Kentucky, 1998. 153-169. Print.

Barks, Carl. The Land of Tralla La. New York: Dell Publishing, 1954. Print.

Berkhofer, Robert F., Jr. The White Man's Indian: Images of the American Indian from Columbus to the Present. New York: Vintage Books, 1978. Print.

Broken Arrow. Dir. Delmer Daves. Perf. James Stewart, Jeff Chandler, and Debra Paget. Twentieth Century Fox, 1950.

Broken Rainbow. Dir. Victoria Mudd. Perf. Martin Sheen, Buffy Sainte-Marie, and Burgess Meredith. Earthworks Films, 1985.

Churchill, Ward. "Fantasies of the Master Race: Categories of Stereotyping of American Indians in Film." Film Theory: An Anthology. Ed. Robert Stam and Toby Miller. Malden, MA: Blackwell Publishers, 2000. 697-703. Print.

Dances with Wolves. Dir. Kevin Costner. Perf. Kevin Costner, Mary McDonnell, and Graham Greene. Tig Productions, 1990.

Dorfman, Ariel and Armand Mattelart. How to Read Donald Duck: Imperialist Ideology in the Disney Comic. New York: International General, 1971. Print. 
Ebert, Roger. “Windtalkers.” Chicago Sun-Times. 14 June 2002: 33. Print.

Fanon, Franz. Black Skin, White Mask. New York: Grove, 1967. Print.

Felix, Antonia, ed. Windtalkers: The Making of the Film About the Navajo Code

Talkers of World War II. New York: Newmarket Press, 2002. Print.

Freire, Paulo. Pedagogy of Freedom: Ethics, Democracy, and Civic Courage.

Lanham, MD: Rowman \& Littlefield Publishers, Inc., 2001. Print.

Gogol, Eugene. The Concept of Other in Latin American Liberation: Fusing

Emancipatory Philosophic Thought and Social Revolt. Lanham, MD: Lexington

Books, 2002. Print.

Harold of Orange. Dir. Richard Weise. Perf. Charlie Hill, Barbara Davidson, and

Cathleen Fuller. Film in the Cities, 1983.

Horkheimer, Max and Theodor W. Adorno. Dialectic of Enlightenment:

Philosophical Fragments. Stanford, CA: Stanford UP, 2002. Print.

House Made of Dawn. Dir. Richardson Morse. Perf. Larry Littlebird, Judith Doty, and Jay Varela. Firebird Productions, 1973.

Huggan, Graham. The Post-Colonial Exotic: Marketing the Margins. New York:

Routledge, 2001.

Kilpatrick, Jacquelyn. Celluloid Indians: Native Americans and Film. Lincoln, NE:

U of Nebraska P, 1999. Print.

Last of the Mohicans. Dir. Michael Mann. Perf. Daniel Day Lewis, Madeleine

Stowe, and Russell Means. Morgan Creek Productions, 1993.

Legends of the Fall. Dir. Edward Zwick. Perf. Brad Pitt, Anthony Hopkins, and 
Aidan Quinn. TriStar Pictures, 1994.

Little Big Man. Dir. Arthur Penn. Perf. Dustin Hoffman, Faye Dunaway, and Chief Dan George. Cinema Center Films, 1970.

Locke, Raymond Friday. The Book of the Navajo. Los Angeles: Mankind Publishing Company, 1976. Print.

Manchel, Frank. “Cultural Confusion.” Hollywood's Indian: The Portrayal of the Native American in Film. Ed. Peter C. Rollins and John E. O’Connor. Lexington, KY: The UP of Kentucky, 1998: 91-106. Print.

McLaughlin, Thomas. Street Smarts and Critical Theory: Listening to the Vernacular. Madison, WI: The U of Wisconsin P, 1996. Print.

Means, Russell. Where White Men Fear to Tread: The Autobiography of Russell Means. New York: St. Martin's Griffin, 1995. Print.

Memmi, Albert. The Colonizer and the Colonized. Boston: Beacon Press, 1965. Print.

Microcosm Publishing. Home Page. 14 April 2012 <http://microcosmpublishing.com/catalog/zines/361/>. Web. Mulvey, Laura. "Visual Pleasure and Narrative Cinema." The Narrative Reader. Ed. Martin McQuillan. New York: Routledge, 2000. 177-181. Print. Ngũgĩ wa Thiong'o. Decolonising the Mind: The Politics of Language in African Literature. Portsmouth, NH: Heinemann, 1986. Print. Pocahontas. Dir. Mike Gabriel and Eric Goldberg. Perf. Irene Bedard, Mel Gibson, And Judy Kuhn. Walt Disney Pictures, 1995. 
Powwow Highway. Dir. Jonathon Wacks. Perf. A Martinez and Gary Farmer. HandMade Films, 1989.

Pratt, Mary Louise. Imperial Eyes: Travel Writing and Transculturation. New York: Routledge, 1992. Print.

Raheja, Michelle H. Reservation Reelism: Redfacing, Visual Sovereignty, and Representations of Native Americans in Film. Lincoln, NE: U of Nebraska P, 2011. Print.

Retamar, Roberto Fernández. Caliban and Other Essays. Minneapolis: U of Minnesota P, 1989. Print.

Saludos Amigos. Dir. Wilfred Jackson, Jack Kinney, Hamilton Luske, and Bill Roberts. Perf. Fred Shields and José Oliveira. Walt Disney Productions, 1943. Stam, Robert and Louise Spence. "Colonialism, Racism, and Representation: An Introduction." Film Theory and Criticism: Introductory Readings. Ed. Leo Braudy and Marshall Cohen. New York: Oxford UP, USA, 1998. 235-250. Print. Strong, Pauline Turner. "Playing Indian in the Nineties: Pocahontas and The Indian in the Cupboard." Hollywood's Indian: The Portrayal of the Native American in Film. Ed. Peter C. Rollins and John E. O'Connor. Lexington, KY: The UP of Kentucky, 1998. 187-205. Print.

The Three Caballeros. Dir. Norman Ferguson, Clyde Geronimi, Jack Kinney, Bill Roberts, and Harold Young. Perf. Aurora Miranda, Carmen Molina, and Dora Luz. Walt Disney Productions, 1944.

Trinh, Minh-ha T. Woman/Native/Other: Writing Postcoloniality and Feminism. 
Bloomington: Indiana UP, 1989. Print.

Tso, Samuel. Personal interview. 27 June 2004.

Whitcomb, Cynthia. Writing Your Screenplay: How to Write Great Screenplays for Movies and Television. Waukesha, WI: Kalmbach Publishing Co., 2002. Print. Windtalkers. Dir. John Woo. Perf. Nicolas Cage and Adam Beach. MGM, 2002. Young, Robert J. C. White Mythologies. New York: Routledge, 2004. Print. 


\section{CHAPTER IV}

\section{The Critical Cinematic Lens}

The preceding chapter's analysis of postcolonial power relations is perhaps best understood when one considers the controlling interests of capital. Often masquerading as something mundane or innocuous, yet always separating the privileged from the exploited, the master narrative is undoubtedly economic in origin and motivation. A critique of the instruments of capital is at the very heart of a commensurate theory of criticism. Grounded in Marxist thought and interpretation, critical theory paves the way to a deeper understanding of the extent to which our perceived freedoms are really the product of an expeditiously administered society.

The theory traces its roots to Frankfurt, Germany in the year 1923. In response to the growing threat of Nazism, critical theory's “distinctive intellectual project [became] to interpret, critique, and reframe the relevance of Marxist thought for contemporary industrial society" (Brookfield 22). Proponents argue that "a grossly iniquitous society" exists, in which people must "learn to recognize how uncritically accepted and unjust dominant ideologies are embedded in everyday situations and practices" (viii, 13). Major concepts affiliated with this theory include such discerning analyses as the culture industry, repressive tolerance, and the public sphere, all of which are reliant upon various methods of critical inquiry and interrogation. 
Karl Marx's broad appeal had much to do with his understanding of the class structure and its subsequent measures of exploitation. Critical theory draws from a diverse collective of disciplines, from economists and philosophers to psychologists and social critics. Major contributors include philosopher critics such as Max Horkheimer, Theodor Adorno, Herbert Marcuse, and Jürgen Habermas. A pioneer in the field of social psychology, Eric Fromm also traces his roots to the Frankfurt School. Subsequent generations of theorists and academicians have borrowed heavily from this tradition. Michel Serres' work with language and semiotics, Paolo Freire's principles of pedagogical praxis, Laura Mulvey's psychoanalytic analyses of film, and academicians such as Douglas Kellner, Allison Acker, and Michelle Raheja all give voice to the enduring relevance of critical theory. As Stephen Brookfield notes, "Thinkers identified within this tradition believed Marx's ideas could indeed breathe vigorously on the shores of the twentieth century, and they tried to restate and reinterpret the meaning of those ideas for a world Marx could not foresee" (21-22). He could not have foreseen the world of moving pictures, for example, or their influence as modern-day depictions of the popular master narrative. He would very likely have understood, however, their function as trade commodities in a global marketplace.

The questions of which narratives sell and why are largely dependent on the forces of capitalism. Movies are made to make money. Whatever is most agreeable to the majority audience is bound to make a larger profit. The 
problem, of course, is that such productions are often rife with stereotypes and self-ingratiating images of the majorant. This supports a repressive status quo and paints a picture that things appear exactly as they should be. Critical theory takes issue with such tacit assumptions. It recognizes how the system is rigged, beholden to the narrow interests of the elite and economically advantaged. This is the basis upon which critical theory offers its most penetrating analyses, the manner in which it problematizes the uncritical cultural perspective.

The present chapter begins with the assertion that little has changed. While historically films have been made to reify existing differentials of power, the manner in which present day material is produced continues to demonstrate that such differences are still considered a largely natural occurrence. There simply exist those who have and those who have not, and the master narrative innocently describes, rather than prescribes, the world as it is. Despite all scholarly work to the contrary, Hollywood recycles those themes that resonate with a relatively uninformed ticket-buying public. Consequently, critical theorists are engaged in a longstanding struggle against such reifications of power. The important work begun in the 1920 s is just as relevant today as it was in those beginning days of critical theory's emergence.

To say that critical theory is anti-capitalist is to affirm its emancipatory potential. Critical scholars keenly suspect the profit motive as the basis for what informs popular cinema. To this end, they leverage hermeneutical questions and strategies against the master narrative, calling attention to the underpinnings of 
exploitation that are present in any film that narrates a superficial point of view. A critically educated and informed public serves as countermeasure to the commercial interests of capitalism. As the present chapter makes clear, critical theorists have developed a number of tools and strategies for challenging a monopolistic media, for contesting capitalistic control over the means of both the production and distribution of an exploitative set of narratives.

Scholars working within this tradition are adept at looking at such narratives and interrogating them with criticality. In addition to deconstructing their content, they rely upon a number of key ideas that are specific to the discipline. Major framework components include the idea of a broad and encompassing culture industry, an acknowledgement that society is administered in such a way that a false promotion of alternatives conditions people to naïvely tolerate various forms of unseen repression, and a declining yet fertile forum for the free discussion and exchange of ideas called the public sphere. Considered collectively, such ideas as the culture industry, repressive tolerance, and the public sphere identify a subtle network of cultural control and complicity. Applying each of these concepts to a singular task, such as interrogating a specific cinematic production, shows just how much the tools of critical theory have come to be relied upon. 


\section{The Culture Industry}

Hollywood serves as both Wall Street and Main Street to the culture industry. It provides the finance capital and controls what is mass-marketed for popular consumption. Consider again the film Windtalkers. As discussed in the previous chapter, it is based on the real life experiences of the Navajo Code Talkers. As such, it had great potential for giving well-earned recognition to the Indigenous warriors whose linguistic contributions devised the unbreakable code that helped to turn the tide of World War II. As portrayed by Hollywood, however, one is left with the impression that the Navajos were little more than a minor supporting cast in the register of historical deeds.

In a review of the movie Windtalkers, film critic Roger Ebert questions how a story that "comes advertised as the saga of the Navajo Indians in World War II [can only be told] through the eyes of their white commanding officer," and wonders "why Hollywood finds it impossible to trust minority groups with their own stories?" (33). It is a telling question, suggestive of a longstanding tradition of appropriating other people's stories for the sake of profit and prestige. The script is transgressive on many levels. Consider the subtext of the film, in which the story's namesakes are depicted as naïve and impressionable, subject to the protection of a stern yet benevolent authoritarian figure. How does paternalism in due course and form reveal its colonialist agenda? What does it say about the majority culture's presumptive claim to ownership of other lands and guardianship over other people? How does the Hollywood theme, as 
exemplified in a movie like Windtalkers, reflect the complacency of larger society?

As the previous chapter suggests, paternalism is a "charitable racism," so long as the benefactor's presumptive dominion is not at risk (Memmi 76). In other words, whose interests are really being served in a Hollywood production about an Italian-American combat sergeant who escorts a Navajo subordinate on the battlefields of World War II? Imagine how the relationship between the Western hero and his Indigenous sidekick personifies a broader exploitative schema. The sidekick's skills are to the U.S. Marine Corps sergeant what any other Indigenous landscape or resource is to the U.S. Government. Both are expedient means to an end that primarily serves the majorant. Would there have been a film about the Code Talkers had not their story served the profitable interests of those who control the means of production? Hollywood understands this. There is great monetary reward in institutionalizing the master narrative.

When Windtalkers was released in June of 2002, moviegoers anticipated a film about the Navajo Marines of World War II. What they got instead was a story about the heroics of a white sergeant, while the Navajo characters provided little more than the subplot. To better understand how something like this happens, it is useful to refer to the criticism of mass culture as outlined in Max Horkheimer's and Theodor Adorno's Dialectic of Enlightenment, in which specific attention is given to media and the technical means and operations associated with it. If its aim is to envision "human beings only as its customers," it will 
undoubtedly seek to earn the greatest return on its investment (118). Culture is profitable and therefore subject to the forces of industry. As such, the culture industry is in the business of reinforcing whatever serves the interests "of those whose economic position in society is strongest" (95). Why is this?

Perhaps the profit-motive truly is to blame. From an economic standpoint, why produce a commercial film if not to make a great deal of money? Dances with Wolves made "more than $\$ 500$ m worldwide," according to a London based newspaper, The Independent, in which Kevin "Costner, as director, producer and star, took about 10 percent of that sum" while neglecting to donate "so much as a dollar to an Indian cause" (20 May 1995). That the movie fared so well at the box office demonstrates just how profitable it can be to appropriate an Indigenous theme for investment in the Hollywood repertoire. The industry simply has to shift the narrational point-of-view, include a big name (cultural majority) movie star, and commission a best-selling director to spearhead the enterprise. This so happens to be precisely what occurred with the movie Windtalkers.

Action film director John Woo delivered a violent drama, replete with epic hand-to-hand combat scenes and tough guy dialogue performed in characteristic manner by Nicolas Cage. That the story tells little about the Indigenous experience of World War II probably matters little to the majority audience. What it does tell, however, is meant to confirm a self-ingratiating portrait of mainstream America. More than this, it promotes the popular image of the 
mythical Western hero. Just as Nicolas Cage is the benevolent military strategist, other high profile, 'real-life' personalities often figure as political strategists. Consider the previous chapter's mention of Senator Jeff Bingaman, whose sponsorship of a relatively noncontroversial bill to honor the Code Talkers, nevertheless gained him the added reputation of a benefactor to the Navajo people. Personalities, both fictional and real life, often rely upon the sacrifice of others to bolster their own celebrity.

There is great profitability in promoting the status quo. People become objectified and culture gets exploited. It is for the purpose of perpetuating majority privilege that the culture industry continues to recycle and promote the profitable themes of postcoloniality. This not only advances the controlling interests of capital but ensures its dominance as well. As Adorno warns, "the cultural commodities of the industry are governed by the principle of their realization as value, and not by their specific content and harmonious formation. The entire practice of the culture industry transfers the profit motive naked onto cultural forms" (129).

None of this is really all that surprising to students of critical theory, who usually suspect the profit motive as the basis of all cultural commodification, whether economic or political. The culture industry is predicated on this motive, where nearly everything can be interpreted as commodity, including films and viewers alike. One is the market product, the other its customer. Consider the purpose of advertising dollars. Are they not some form of investment toward a 
greater return? In other words, are consumers not being 'bought' by an industry that invests its very resources in the duplication of various specious forms? Just as the culture industry presently "transfers the profit motive naked onto cultural forms," it has done so profitably "ever since these cultural forms first began to earn a living for their creators as commodities in the marketplace" (129).

Tangibly understood, a film is no doubt a commodity. As a whole, however, critical theorists understand that it is more than just the product that must be scrutinized. The industry itself is suspect to further interrogation as it serves a colonizing function in the name of this profitability. From a critical theoretical standpoint, "the analysis of the culture industry employs Marxian arguments by stressing capitalist control of culture, the commodification and reification of culture, its ideological functions and the ways in which it integrates individuals into capitalist society" (Kellner 132). Such analyses leave no doubt as to who is in charge. For example, those who observe a film like Windtalkers might note how often the white protagonist must "save" his Indigenous sidekick from grave harm and naïve error. Whether freeing him from the clutches of a Japanese soldier or reprimanding him for wandering off alone, viewers are reminded that it is the cultural majority who maintains the reigns.

The majority audience finds comfort in stories that are framed as such. Any production or performance of the formulaic is typically well received. Hollywood exemplifies this. A catalog of new and upcoming releases generally offers very little that is new in terms of actual content. This is by design. 
Successful screenwriter Cynthia Whitcomb summarizes the blockbuster formula as follows, "Act One, get your character up a tree. Act Two, throw rocks at him. And in Act Three, get him down" (26). When each subsequent release adheres to the same cookie cutter structure, the audience is conditioned to view and judge films in a particular way and according to a narrowly prescribed standard. No wonder there is such little variation in the films that are released for popular consumption.

The Hollywood industry may release a film like Windtalkers, ostensibly promoting a key event in Native American history. But given that such a story does not easily conform to the prescribed three-act structure, moviegoers are instead treated to a tall-tale about a Western protagonist's epic quest for redemption. It is the same tired theme as Dances with Wolves' story of John Dunbar (portrayed by Kevin Costner), whose first major on-screen action is to charge suicidally into enemy fire with outstretched arms. Indeed, most Hollywood films about Indians capitalize on just such a device-the insertion of a white savior who leads one minority group to victory over another minority group.

Even more insidious is what later generations of critical theorists postulated concerning the culture industry's capitalistic dominance over the individual, including the formation of his or her very own identity, as skillfully determined by a market-driven society. Stephen Brookfield points out, "In a commodified world people develop their identity and calculate their sense of self-worth in 
purely economic terms ... Moreover, people have become so seduced by the commodities produced by capitalism that their lives are geared to the pursuit of these" (70). They are regarded as consumers of culture among those who have made it their business to produce and sell cultural ideology and its synchronous images.

As Eric Fromm suggests in The Sane Society, the so-called experts and authority figures, "tell you what the 'normal' person is, and, correspondingly, what is wrong with you; they devise the methods to help you adjust, be happy, be normal" (168). In other words, one is expected to conform to the societal mold and all its trappings or else be perceived as irrational or possibly even abnormal. Such indoctrination aims at making all human beings into carbon copies of a pre-existing type. The nature of narrative often reinforces, rather than reinterprets, these types.

It is an idea that goes hand-in-hand with the critique of commodity culture. As stated earlier, "the process through which human beings are turned into things ... is an important component of the critique of capitalism" (Kellner 10). The movie industry is especially accomplished at objectifying people and relationships in an exploitative manner. Rife with stereotype and image ideals, it aims to sell identity. As George Yúdice explains in The Expediency of Culture, "film and music are crucial to cultural identity and should not be subject to the same terms of trade as, say, cars and running shoes" (18). Yet, movie studios "have countered that film and TV programs are commodities ... [and] that the 
rights of authorship should increasingly belong to producers and distributors, [by whom] intellectual property is possessed, such that [the actual] 'creators' are now little more than 'content providers'” (18).

Society is taught to literally buy these commodities, forged in stereotype, as well as to buy into the idea of stereotype itself. In any valuation that puts principal before people, the consumer public is skillfully manipulated, seen as both the source and target of financial exploitation. People are little more than numbers to be calculated, percentage rates and estimates, tokens and figures. Critical theory aims to import understanding into the various ways in which people are perceived as pawns in an ever-expanding marketplace. As Douglas Kellner describes in Critical Theory, Marxism and Modernity, "the concept of 'reification' - the process through which human beings are turned into things, and thing-like, objectified relationships and ideas come to dominate human life is an important component of the critique of capitalism" (10). From early on, commodity culture is imposed and ingrained.

These lessons of dominance are learned at an early age. Walt Disney, a multibillion dollar empire, is more influential in teaching children about consumer demand than perhaps any other company. As the previous chapter explained, it is an empire built largely upon the precedent of cultural exploitation. In a world in which even Disney attempts to narrate a vision of benevolent conquest, no cultural minority group - nor developing nation for that matter-is free from the stereotypes which the majorant uses to advance its own economic interests. 
It is a practice whose introduction can be traced as far back as the seemingly benign world of cartoons and comic books.

Critical scholars confront such benign-appearing imperialist intrusions. As Alison Acker notes, "In Walt Disney comic books there is featured an exotic land called Hondorica. It is a comic paradise, where shambling peasants welcome Donald [Duck] and gladly hand over all the treasures they have never learned to appreciate" (16). In this "caricature of Honduras as Hondorica ... comedy and commercialism" have conspired in such a way that "a dangerous kind of cultural denigration tends to hold sway" (17). That this is present in a popular literary form designed for children only seems to underscore the majority culture's obsession with making its story known widely and ensuring it gets told early. Any move toward abstracted acceptance and away from critical thinking is key to the aims of mass cultural reproduction. Small wonder critics have pounced on productions that cater to the impressionable imaginings of schoolchildren. Michelle Raheja compares "the practice of purposefully teaching children partial truths and historical inaccuracies to 'intellectual child abuse'” (223). The continuous presentation of stereotypical material dulls the critical faculty.

In a personal interview with Roger Willie, the Navajo actor portraying Charlie Whitehorse in the film Windtalkers, he describes the inflexibility of trying to correct cultural stereotypes once they appear in the final script. Particularly problematic was the scene in which he was directed to portray a ceremonial ritual of protection. Neither medicine man nor caricature, he refused to apply 
war paint on both grounds. The script called for a culturally inaccurate rendering of ashes to be smeared across the face of actor Adam Beach. Recognizing how an audience of his peers would receive this scene, Willie refused. It was explained to him that the script had gone through several levels of review prior to final approval and that thus validated could no longer be changed. Yet the impasse was so great that the production team was left with no choice but to acquiesce and bring a Navajo medicine man onto set. Under the medicine man's direction, the scene was modified to depict a more accurate ceremony, in which Willie used cedar smoke to envelop his comrade in a screen to filter against the spirits of the recently departed.

But for every conscientious objector, there are scores of others who are eager to promote the stereotype of the stoic warrior, a caricature that is profitable at both the individual and 'societal' levels. A case in point is Iron Eyes Cody, a "white, Louisiana-born son of Italian immigrants who broke into the movie business by masquerading as an Indian" (Raheja 104). "Best known for his role . .. in the 1971 Keep America Beautiful public service announcement, Cody became, for many people throughout the world, the quintessential symbol of the American Indian ... [weeping] bitter tears about the destruction of the environment; he appears as a stoic and silent wise elder" (104). The danger, of course, is that unlike Roger Willie, actors such as Cody are often more than willing to play up the images associated with mainstream stereotypes of Indigenous America. 
All of this gives insight into which narratives sell and why. Dances with Wolves falls in line with mainstream expectations that all Indians wear "leathers and feathers" and belong to the nostalgic days of yore, while a more realistic film like House Made of Dawn situates Native Americans in the present and squarely in contradiction with western notions of racial stability and contentment (104). Small wonder that congruent narratives yield the largest profit. It is the reinforcing image that sells. The social hierarchy unthreatened is what pacifies the majority audience. Upon all these things, the culture industry thrives. So long as capital is involved, all manner of sophisticated hegemony will prevail.

\section{$\underline{\text { Repressive Tolerance }}$}

Perhaps the most effective demonstration of uncritical reflection can be found in Herbert Marcuse's concept of repressive tolerance. It is instructive to examine this term one piece at a time. To begin with, Marcuse has written of repression "as a means for perpetuating the struggle for existence and suppressing the alternatives [in favor of] serving the cause of oppression" (33-34). Taken on its own the meaning of repression is that it is anything that restricts universal freedom. This is often misinterpreted by the majority, however, as this group is wont to justify its abuses of the minority by claiming that its actions are little more than an exercise of its right to personal freedoms. The inherent fallacy is that these freedoms are not granted equivalently to everyone. 
Tolerance is an even trickier word. On its surface, the word suggests an acceptance of multiple points of view. Yet the reality is that all viewpoints are not held as equal. While few would argue against the idea that freedom is a universal right, unrestricted freedom would be tantamount to abuse and disaster. Marcuse explains how "violence and suppression are promulgated, practiced, and defended by democratic and authoritarian governments alike," with the former extending "tolerance to policies, conditions, and modes of behavior which should not be tolerated because they are impeding, if not destroying, the chances of creating an existence without fear and misery" (34). Paulo Freire elucidates this clearly when he writes about an unfettered capacity to take license with other people's liberty. Plainly stated, "Freedom [can be] perverted into license," and should never be thought of as an "absence of limits" $(96,99)$. To see it as such is to tolerate all manner of advantage and exploitation in the name of liberty. In other words, no person should be entitled to exercise a freedom that selfishly impinges upon another's autonomy.

Yet western society extols the capitalistic virtues of entrepreneurship and industriousness. These subtle notions are reinforced in all manner of narrative, even those as seemingly benign as comic books. It is against such insipid depictions, like that of Disney's Hondorica, that students of critical theory are taught to question the underlying basis of said productions. Moreover, it is an important task of critical learning to bring consciousness to all forms of propaganda. Inspired by such critical pedagogists as Paulo Freire, "the discourse 
on education and democracy is re-centered around issues of power, dominance, subordination, and stratification" (Grande 34). A main task is to recognize any production that uncritically supports a dominating and false ideology and to consider how it might encourage students to tolerate repression in various structures and forms.

A case in point concerns political cartoons, such as those promoted by Teacher's Discovery, the publisher of a series of high school textbooks and posters. One of its more popular examples includes a comparison of political ideologies, including socialism and capitalism. The socialism cartoon explains, "You have two cows. The government takes them and puts them in a barn with everyone else's cows, then gives you as much milk as it thinks you need" (1999). This is contrasted with the capitalism cartoon, which simply states, "You have two cows. You sell one and buy a bull" (1999). The former example arranges to make it appear that socialism interferes unfairly with citizens' private property, while the latter one implies that capitalism rewards private citizens' industriousness. Clearly, these are ideological constructions. Whether they would be recognized as such by most U.S. high school students is debatable. What is actually needed in deconstructing them is a critical awareness of their underlying assumptions. Both begin with the statement "you have two cows." Set up in such a way, any evaluative comparison of their political ideologies, undertaken uncritically, would lead to the conclusion that capitalism is the most efficacious form of political economy. 
This conclusion, however, depends upon an unexamined or relatively invisible reading of the opening statement. The presumption of owning two cows sets the comparison up in such a way that capitalism shows itself to be the most categorically attractive organizational model. But what if the starting point positions the reader in a place where she or he cannot claim ownership of two cows? Approached from this position, indeed the one that is occupied by the majority of the world's population, capitalism can no longer be perceived as the only desirable model of political economy. The critical reader, then, is determinedly able to see through the codifying content.

It is only through such critically conscious forms of analysis that students are able to recognize the extent to which society is administered. Framed by those who champion the rules, it only pretends to be inclusive. Tolerance, insofar as its meaning is synonymous with acceptance, is an inert concept. It is ultimately a state of inaction. Its insistence on "the equal presentation of opposites easily loses its liberating force, [as the outcome is] far more likely to strengthen the established thesis and to repel the alternatives" (Marcuse 42).

It is an irony that is observable in the productions of mass media, where the illusion of choice and equivalency "blunts people's desire to pursue revolution," as they are led not to recognize that their menu of "choices are actually very limited" (Brookfield 60, 90). Major media corporations often point toward the evidence that so many options exist in order to support their claim that coverage is ultimately unbiased. Yet it is an untenable thesis. 
The recognition that our choices are really very limited is the key to understanding repressive tolerance. When people are conditioned to believe that a narrow set of alternatives is representative of a full continuum of choice, they unwittingly support a system that does little more than promote the status quo. In other words, this is the means by which they are taught to tolerate repression. The audience is lured into accepting the existing stereotypes as common truths.

One needs to look no further than the narrative convention of the medicine man to note how fickle the undiscerning audience can be. As described earlier, the war-painting-with-ashes ritual originally called for in the script of Windtalkers is transgressive on many levels. Not only is it culturally inaccurate, it presupposes that all Indians possess the innate knowledge to perform rituals of healing and protection. This is akin to thinking that all white people know how to organize a sales event or invest in the stock market. Stereotypical as these presumptions most certainly are, they nonetheless govern popular attitudes about culture and race.

Narratives that challenge these presumptions, no matter how accurate their alternative understanding, are discredited due to their contradictory nature. A case in point is filmmaker Chris Eyre's "representation of the medicine man in the film" Imprint (2007), which "overturns conventional Hollywood images of Native American medicine people and shamans. Rather than trafficking in alterity, extreme costumes, and incommensurability, Imprint's medicine man 
sports a cowboy hat, fleece vest, and dress pants" (Raheja 164). This is much more in line with contemporary reality. It does not, however, serve the stereotype very well.

Using the logic of the corporate media, the mere existence of a medicine man such as the one portrayed in a film like Imprint offers proof that Hollywood is capable of non-partisanship. But as Marcuse explains, "I call this non-partisan tolerance 'abstract' or 'pure' inasmuch as it refrains from taking sides-but in doing so it actually protects the already established machinery of discrimination" (36). In other words, the recognition of an alternative representation or point of view does not go far enough in promoting representational equity. The evidentiary truth of the matter is that "the tolerance which enlarged the range and content of freedom has always been partisan-intolerant toward the protagonists of the repressive status quo" (36). The medicine man in a cowboy hat (rather than 'leathers and feathers') does not conform to the majorant's expectations of what a medicine man is supposed to look like. Though closer to reality, he wears the markers of the present rather than the markings of the past. From a narrative point of view, this inconsistency troubles the privileged audience, the one for whom just about every major motion picture appears to have been made. It is this majority collection of narratives that enables viewers to dismiss any example that is incongruent. The construction of a Western-clad medicine man, therefore, may be regarded as either a fringe notion or incontrovertible evidence that all manner of stories are 
available. Either way, the majority maintains its position as the privileged standard among countless other stories. This maintains the status quo, ensuring its continuity for those who profit from it.

Yet it is interesting to note how freely a typical audience allows itself to be subjugated by the imaginative "production of ego ideals [in which] the glamorous impersonates the ordinary" (Mulvey 178). Is this not what occurs every time viewers sort, select, and separate fictional characters into various predefined categories in order to identify with those who are supposed to symbolize their "screen surrogate"? (180). For an audience belonging to the cultural majority, this is an easy transition to make. Most narratives fit comfortably with this demographic, as they include a 'like' protagonist with whom to identify, a token minority to promote the goals of the majorant, and a familiar plot in which all is recognized according to stereotype. It is this reaffirming type of narrative, where the predictable prevails amidst all manner of supposed choices, that best demonstrates how people learn to accept and tolerate repression.

Moreover, the concept of repressive tolerance can be used to explain how various productions not only recycle the same tired themes, but also how these themes are varied just enough to give the illusion of difference. Considering other films released during Windtalkers' debut, it seems only fitting that it opened alongside such action-packed blockbusters as Spider-Man and The Bourne Identity. Each of these plots centers on a death-defying main character, a 
heroic protagonist who just so happens to be a member of the majority cultural group. Interestingly, it is not only the fictional superheroes who are white, but also the actors who are meant to represent a nonfictional cast of characters, few of whom would actually have been white. Nonetheless, these popular titles are what greeted moviegoers in June 2002.

That patrons could choose between three variations on the same theme is precisely the ruse of a "monopolistic media" promoting a "'marketplace of ideas' [that] is organized and delimited by those who [retain] the instruments of economic and political power" (Marcuse 42, 51). Such skillful manipulation, the illusory presentation of choice, leads people to believe that a fair and balanced system is in place. That such choices are predetermined is supposed to go unnoticed and often does. This is what makes it possible for people to participate, often unwittingly, in repressive tolerance. The release of a film like Windtalkers, alongside other contemporary action titles, gives viewers a false sense of variety and avoids the "recognition of the frightening extent to which history was made and recorded by and for the victors, that is, the extent to which history was the development of oppression" (53). In other words, such movies as Spider Man and the Bourne Identity are actually thematically concurrent with Windtalkers, regardless of how different their titles may have appeared on the marquee alongside one another.

The fact that multiple such films exist gives rise to the notion that the consumer can exercise some degree of choice in selecting which one to watch. 
That the choice itself is confined to a relatively closed set of plotlines demonstrates that the readymade alternatives are not representative of a very wide array of viewpoints.

Such illusions are necessary to this aim, as its initiates often point to the existence of so-called 'minority' narratives as proof that alternative points of view are present and accounted for. But as Marcuse points out, the place "where false tolerance and free enterprise" intersect, "in reality, favors and fortifies the conservation of the status quo of inequality and discrimination" $(45,58)$. "The small and powerless minorities which struggle against the false consciousness and its beneficiaries must be helped: their continued existence is more important than the preservation of abused rights and liberties which grant constitutional powers to those who oppress these minorities" (51).

In the rare case that a critical film is successful, the attention given it by the industry is justifiably suspect. As Stephen Brookfield notes, "The fact that dissenting voices are sometimes heard reassures people that the system is working to give fair and equal representation to all points of view ... By allowing a certain amount of social criticism in the name of free speech, the dominant group convinces the rest of the people that they live in a democracy" (60). Such thinking is precisely the point of Marcuse's idea of repressive tolerance. How some might accept that a small platform for opposition means that the controlling party has an interest in the minorant's point of view is proof positive 
that "the conditions of tolerance are 'loaded"' (Marcuse 35). In the end, they serve only to tame the voices of dissent.

While it is evident that repression is expressed in obvious ways, the more subtle forms often slip by unnoticed. Not only that, they frequently include the illusion of honoring, or at least presenting, an alternative point of view. Marcuse reveals how "the decision between opposed opinions has been made before the presentation or discussion got under way-made, not by a conspiracy or a sponsor or a publisher, not by any dictatorship, but rather by the 'normal course of events,' which is the course of administered events, and by the mentality shaped in this course" (43). This is akin to the famous expression that "the Devil's greatest trick was convincing the world he didn't exist" (Baudelaire). In other words, to accept what is given as the 'normal course of events', uninfluenced by ulterior motives, is the very definition of hegemony. It is what anaesthetizes people to participate unwittingly in their own repression. A major task of critical theory is to show how the devil really does exist, safely disguised in all the little details.

A good place to find the devil is in the pages of a screenplay in which audiences are in utter disagreement over what is projected onto the big screen. Dances with Wolves is one of the most divisive of all major motion pictures about Native Americans. With respect to the notion of audience, its reception was very mixed. Among the majority culture it was largely considered a roaring success. Indigenous viewers, however, were less than enthusiastic about its theme, which 
relies on "the concept of good and bad Indians" as mediated by a white interloper (Buscombe 141). "Good Indians are those that whites can identify with. Bad Indians are those who threaten this process" (141). As the storyline goes, protagonist John Dunbar (portrayed by Kevin Costner) is 'adopted' by a band of generous Sioux. They in turn are attacked by a malicious group of Pawnee. To exact revenge, Costner leads the tribe to victory over its enemy. It is an age-old story in which the Western hero elevates his own status through teaching the Indians how to defend themselves against a greater threat. Majority culture often finds this type of story especially appealing. Not only does it glorify the white man, it does so in a way that justifies his actions. It is all in the way in which these actions are narrativized. Michel Serres deconstructs this problem in his landmark essay "The Algebra of Literature: The Wolf's Game." He describes how the wolf not only devours the lamb, but justifies the act as if it is the lamb's fault. As the story goes, the wolf accuses the lamb of contaminating the river from which he draws his drink and of saying slanderous things about him the previous year. For each rebuttal the lamb deliverspointing out that he was downstream of the wolf and that he had not yet been born at the time of accusal - the wolf continues to insist upon the lamb's guilt. Finally, he suggests that the lamb's protectors, the shepherd and his dogs, pose a mortal threat to him and that for this reason he must be avenged. From a narrative point of view, Dances with Wolves and The Wolf's Game may appear to be quite different from one another. But Serres uses his example to illustrate the 
ordering relation that is at work among the various characters of any given story.

To mark the relation, Serres borrows from the discipline of algebra. In the ordered sequence of greater than/lesser than, "he who occupies the lower position, let us call him the minorant, has no control over the majorant, who, on the contrary, has complete control over the former" (265). The wolf, in other words, controls the lamb. Yet he does so in a most unnatural way. Consider his justification that he has no other choice but to eat the lamb because of the threat posed by the lamb's protectors. "In short, the wolf 'majorizes' or maximizes the lamb, who 'minorizes' or minimizes himself" (266). According to Serres, "if you want to win, pretend the role of the minorant" (266-67). Great power comes from playing victim, the role in need of redress. Just like the majority of films about Native Americans, Dances with Wolves relies upon this very strategy in justifying the protagonist's actions, whether on behalf of or against the tribal groups with whom he dominates the screen space.

Consider the storyline of the film. John Dunbar is sent to a frontier outpost to assert the military's presence in the region. He encounters a band of desperate Sioux, whose supply of wild buffalo is dwindling and who must repeatedly defend themselves against the warring Pawnee. It is evident that Dunbar fulfills the role of majorant in this relation, while the Sioux represent the minorant. But even as early the film's release in 1990, this was not a politically correct arrangement. To mitigate this problem, the writer invents an even greater 
threat-one that challenges both the Sioux and their adopted commandant-the Pawnee. Much as the wolf accuses the shepherd's dogs for compelling him to act in a certain manner, the Western hero points to the existence of a graver threat than himself in order to justify his takeover and command of the tribe. He is, after all, only saving them from certain death at the hands of a more ferocious adversary. By 'majorizing' the Pawnee and subserving himself to the Sioux, Major Dunbar attempts to ingratiate himself into the most sympathetic role of all. It is this role that the majority audience relates with, the role of the so-called master, martyr, or hero.

This arrangement is promoted with hardly a second thought. From Donald Duck to Kevin Costner, it is clear whose interests are served in the ordered relation that defines each of the various characters. In such cases where second thought does exist, the productions are comparatively lower budget and decidedly limited in their release and distribution. This is justified by a culture industry that calculates the profit potential of each film according to its parity with the majorant's goals. As Buscombe puts it, "Speaking less moralistically and more practically, how far is it realistic to demand of a multi-million dollar epic, made with the intention of securing a profit, that it renounce the device, proven effective during a century of filmmaking, of offering a point of identification that the majority of the potential audience will find appealing?" (142-43). If ticket sales are the driving force, "Indians, as we have seen, make up only 1.5 per cent of the potential audience" (143). 
Nevertheless, minority productions do get made. But the fact that alternative narratives exist is often taken as proof by the majority culture that everyone's point of view is duly represented. Ironically, this dulls the critical faculty that many of these films were meant to promote, the very reason that some of them were made in the first place. Tepid support for minority productions offers convenient absolution to the majority audience. Rather than recognized for their critical content, these films are tokenistically regarded as evidence that adequate consideration is given to minority perspectives. This is the trick of repressive tolerance-to make believe that it is enough that everyone's voice is occasionally heard. But as Marcuse argues, "The small and powerless minorities which struggle against the false consciousness and its beneficiaries must be helped: their continued existence is more important than the preservation of abused rights and liberties which grant constitutional powers to those who oppress these minorities" (51). It is a question of authority and space, whose voice is heard and the arena in which it resonates.

The Public Sphere: Reification and Rupture

It can be appropriately said that Hollywood quiets the voices of dissent. This is accomplished in both subtle and obvious ways. Critical theorists have long noticed that it is a privileged minority, rather than the mass majority, who holds the greatest access and influence over society. This is the group that, in reality, 
both controls and determines the greater portion of the space known as the public sphere.

Scholars working within the critical tradition recognize two contradictory ideas regarding this concept. First, it is the space where public opinion is formed through common dialogue between private individuals, a space that is ever more restricted through the growth of profit-driven media conglomerates that choke out the free expression of competing ideologies. Secondly, it is an affirmative space that generates much potential as a site of both resistance and liberation.

Jürgen Habermas describes the public sphere as the "realm of social life in which public opinion can be formed [and] access guaranteed to all citizens" (136). But as the cinema makes clear, the prototypical spaces have already been largely predetermined. For this reason, he acknowledges both the utopian nature of the public sphere and its diminishing presence in today's technicized society. Where master narratives reign supreme, the average citizen is subjected to little that is new in terms of form and content.

Consider the theater as an obvious analogy. Patrons enter "a hermetically sealed world" in which "the extreme contrast between the darkness in the auditorium (which also isolates the spectators from one another) and the brilliance of the shifting patterns of light and shade on the screen helps to promote [a sense of] separation" (Mulvey 178). Because it is a movie theater, conversations among audience members would be considered distracting. Controls of both form and etiquette are in place to mitigate such interference. 
But the same can also be said of looser, seemingly less-controlled environments. After viewing a film like Windtalkers, for example, patrons may have questioned the movie's legitimacy. But unless their opinions could be shared via public assembly, including some form of media coverage or publication, their voices are destined to be unheard.

It is against this situation that scholars advocate on behalf of Habermas' "view of the public sphere as the definitive institution of democracy" (Borradori 57). But how to 'talk back' in a system in which "the speed involved in mass communication works in the interest of those who select and distribute the information rather than those who receive it"? (57). With such a steady bombardment of readymade ideas and images, it becomes difficult to engage in a truly democratic dialogue. The avenues of dissent are largely closed, and the places where one might join with others in common cause are woefully constrained. Habermas foresaw this. In a reflective analysis, he attributes the weakening of the public sphere to the instruments of media, which often work to deny a forum of "public discussion among private individuals" (142).

The blueprint of the Hollywood blockbuster contributes to this. It has changed little over the course of time. Particularly with respect to films about Native Americans, the viewer is pretty well assured that the story will be told through the majorant's eyes with an emphasis on the subject matter that most appeals to a majority point of view. In other words, it will be a conventional story stuffed within the confines of a conventional space. Such is the case with 
Windtalkers, which conforms neatly to the myth of the Western hero. The movie was billed to be the first of its kind to celebrate the heroism of a highly regarded group of Navajo Marines but did little to deliver on that promise. It is, instead, a story of redemption in which the majority figure confronts his own, insufferable mortality and 'rights past wrongs' through sacrifice to the subordinates he is sworn to protect. Much like Dances with Wolves, the notion of a majority 'savior' appeals to the multitude of moviegoers.

It seems that such narrational devices are standard and prerequisite in order for any Indigenous screenplay to be given serious consideration by Hollywood. In other words, films like Windtalkers and Dances with Wolves were bound to find an eager producer and sympathetic audience, while a more contemporarythemed movie like Powwow Highway (1989), which "Americanizes Native Americans and Native Americanizes the movies" (Anderson 150), was bound to "fail at the box office" (Rollins and O'Connor 8). Yet both types of films are instructive of the manner in which this genre must grapple for space within the public sphere. So long as the culture industry has its Hollywood, certain monopolistic themes will continue to hold sway. A blockbuster such as Dances with Wolves generated so much revenue that "Kevin Costner decided to invest some of the vast profits that the film had made in the construction of an entertainment complex in the Black Hills of South Dakota, [an] area considered by many Sioux as a sacred place" (Buscombe 145). The decision found him "accused of betraying the very people he had made his money from," but it was 
never a moralistic deliberation, rather a financial one (146). That the construction of such an entertainment facility only serves to cater to the majorant's fantasy is precisely the point. There is great profitability in stereotype.

The difficulty comes in trying to promote an alternative cinema that is woefully underfunded. No matter the broader, more inclusive nature of independent film, it cannot compete with the hefty resources amassed by such media empires as Metro-Goldwyn-Mayer (MGM) or Walt Disney Pictures. A case in point, film critic Roger Ebert complains, "There is a way to make a good movie like Windtalkers, and that's to go the indie route. A low-budget picture would focus on the Navajo characters, their personalities and issues. The moment you decide to make Windtalkers a big-budget action movie with a major star, you give up any possibility that it can succeed on a human scale" (33). Of course, the fact that Windtalkers was produced by MGM meant that it debuted to a wider audience. As this chapter has aimed to make clear, one need only study the socalled sympathetic era of Native American films, that narrow band of titles produced in the 1990s and shortly thereafter, in order to note the cultural contradictions uncovered by critical theory and its critique of consumer capitalism. Critical theory recognizes how narrow the scope truly is and questions why it is not broadened. In other words, why are there not more films inclusive of Indigenous points of view? 
That such voices are given so little space to speak in the first place is another concern of critical theory. In the day and age of the Blockbuster, it is difficult for independent filmmakers to compete with Hollywood's large-scale production and distribution networks. This appears to be the reason why a film like House Made of Dawn (1973) remains relatively obscure while the motion picture Windtalkers (2002) is so widely known. Both involve tribes that are native to the state of New Mexico, but this is where their similarities end. Considering that the first title is based on Pulitzer Prize winning author N. Scott Momaday's famous novel and that its content, the relocation and urbanization of Indians post World War II, is a matter of great concern and impact to so many Native peoples, one would assume that this allegorical work might resonate broadly with audiences everywhere. Instead, the latter film scripted by a lesser-known writer and dealing with a proportionately smaller group of Indigenous stakeholders is the one that is most widely known. Of course it goes without saying that one of these films was written and told from an Indigenous point of view, while the other was dominated by the voice of the Western hero.

More than that, House Made of Dawn's production company, Firebird Productions, has little of the influence and reach of Metro-Goldwyn-Mayer (MGM), the production company that financed the making of Windtalkers. The dissemination is undoubtedly economic, but as Horkheimer and Adorno also point out, the mechanisms of dispense and dispersal are suspiciously complicit. They cite the analogy of "the step from telephone to radio," in which 
The former liberally permitted the participant to play the role of subject, [while] the latter democratically makes everyone equally into listeners, in order to expose them in authoritarian fashion to the same programs put out by different stations. No mechanism of reply has been developed. (9596)

In other words, if capital controls which stories get produced, it also consolidates the channels through which they are received. Without a ready mechanism of reply, passive recipients are "condemned to unfreedom" (96).

The trick is to produce a film that both infiltrates the mainstream and 'talks back' in such a way that an audience of its peers can interpret its subtleties. This is the goal of a 'Trickster Cinema', as discussed in the following chapter. While seldom as commercially successful as big budget major motion pictures, such productions sometimes do receive widespread critical acclaim. Yet the public sphere is geared mainly toward the promotion of commercial productions. Revenue is spent on billboards and cinematic trailers. Such was certainly the case with Windtalkers and Dances with Wolves. Theater patrons would have learned of their expected arrival through the display of coming attractions that precede each cinematic showing. Absent from these titles would have been films like House Made of Dawn and Powwow Highway. Yet the latter movie succeeded in ways that were largely unexpected.

The interesting thing about Powwow Highway is that it claimed considerable attention in the public sphere, albeit through a much different and far less 
certain trajectory. As Rollins and O’Connor explain, “it gained popularity as a favorite video rental, building an underground audience among Native Americans" (8). What it lacks in terms of financial boon it has made up for in the continuity of conversation. It is this conversation that best exemplifies Jürgen Habermas' definition of the public sphere as "a network for communicating information and points of view" (360). The problem, of course, is that much of what enters this network already conforms to a skillfully manipulated point of view. Hollywood and the television networks are sure to see to this. Unless one consciously contends otherwise, what is often granted as the public sphere is in reality the expression of a more tightly confined space.

In “The Public Sphere: An Encyclopedia Article," Habermas elucidates the dynamic potential of any space that "calls for a rationalization of power through the medium of public discussion among private individuals" (142). The trouble is that most media, and motion pictures especially, relay a static, majority interpretation with little mechanism of reply, save for what might appear in the occasional critic's column. Habermas recognizes the inherent danger of mass communication and its corporatized and commodified public sphere. At the same time, he affirms these contested spaces as the most revolutionary sites for envisioning social change. Giovanna Borradori summarizes his seemingly paradoxical position, acknowledging that although "the speed involved in mass communication works in the interest of those who select and distribute the 
information rather than those who receive it ... only an actively involved public sphere opens the way for a truly democratic exchange" (57).

The second life given Powwow Highway as a popular video rental and subsequent word-of-mouth phenomenon demonstrates the public sphere writ small. On the one hand it received limited release and little attention at the movie theater. This is unsurprising for a film that does not conform to majority expectations. On the other hand there is something compelling about a comic adventure in which a pair of tribal misfits embarks on a subversive rescue mission that also doubles as a metaphorical quest for identity. Its contemporary theme resonates poignantly with Indigenous viewers and generates subsequent curiosity among a larger audience. It is the way this type of narrative appeals both to and for a vested audience that attests to its ongoing dialogue within the public sphere.

The critical tasks involved in analyzing mass media in general and films in particular are important to the understanding of how majority cultural claims are produced, dispersed, and reified. Serving the interests of capital, the culture industry is predicated on the notion that anything that benefits the majority is representative of the greater good. It conflates democracy with freedom, in which private industry enjoys a broader range of rights and privileges than granted most individuals. This includes the protections and special considerations given property, whether material or intellectual, print or multimedia, etc. Not unlike mineral resources that may be extracted for wealth, 
the culture industry exploits minority subject matter for the sake of profit. How this is condoned is addressed by such concepts as repressive tolerance. The illusion of choice explains how so many consumers are conditioned to the acceptance of what is offered, without so much as a tiny suspicion of how things might be different. Finally, the space given for the expression and exchange of ideas is more commercially administered than many citizens would be apt to acknowledge. Readymade opinions presented in "newspapers and magazines, radio and television are the media of the public sphere ... which organizes itself as the bearer of public opinion" (Habermas 136-37).

Taken in conjunction with one another, the concepts espoused by critical theory are useful in interrogating the truth claims of majority culture. They are also suggestive of other more affirmative approaches that promote the truer courses of liberation. One such avenue, as relates to mass media, is recognition of the need for expanded space in which to tell the minorant's stories. This occurs through engaging the culture industry to promote its "progressive features," in which the "proliferation of mass art, especially through film, [might] bring images of the contemporary world to the masses, to help raise political consciousness by encouraging scrutiny of the world, as well as to bring socially critical images to millions of spectators" (Kellner 124). Such is the task of a cinema designed to promote critical consciousness, a theater that mocks the status quo and substantiates the transcendent position of the minorant. The generative potential of a cinema aligned with Indigenous sensibilities is one such 
demonstration of critical accord. The salient features of its growth and development form the basis of the following chapter. 
Works Cited

Acker, Alison. Honduras: The Making of a Banana Republic. Boston: South End Press, 1988. Print.

Adorno, Theodor W. "The Culture Industry Reconsidered." Critical Theory and Society. Ed. Stephen Eric Bronner and Douglas MacKay Kellner. New York: Routledge, 1989: 128-35. Print.

Anderson, Eric Gary. “Driving the Red Road: Powwow Highway." Hollywood's Indian: The Portrayal of the Native American in Film. Ed. Peter C. Rollins and John E. O'Connor. Lexington, KY: The UP of Kentucky, 1998, 137-152. Print. Baudelaire, Charles Pierre. "The Generous Gambler.” Devil Stories: An Anthology. Ed. Maximilian J. Rudwin. New York: Alfred A. Knopf, 1923, 162-66. Print. Borradori, Giovanna. Philosophy in a Time of Terror: Dialogues with Jürgen Habermas and Jacques Derrida. Chicago: The U of Chicago P, 2003. Print. The Bourne Identity. Dir. Doug Liman. Perf. Matt Damon, Franka Potente, and Chris Cooper. Universal, 2002.

Brookfield, Stephen D. The Power of Critical Theory: Liberating Adult Learning and Teaching. San Francisco, CA: Jossey-Bass, 2005. Print.

Buscombe, Edward. 'Injuns!' Native Americans in the Movies. Bodmin, Cornwall: Reaktion Books, 2006. Print.

Dances with Wolves. Dir. Kevin Costner. Perf. Kevin Costner, Mary McDonnell, and Graham Greene. Tig Productions, 1990.

Ebert, Roger. "Windtalkers.” Chicago Sun-Times. 14 June 2002: 33. Print. 
Freire, Paulo. Pedagogy of Freedom: Ethics, Democracy, and Civic Courage. Lanham, MD: Rowman \& Littlefield Publishers, Inc., 1998. Print.

Fromm, E. The Sane Society. New York: Rinehart, 1956. Print.

Grande, Sandy. Red Pedagogy: Native American Social and Political Thought.

Lanham, MD: Rowman \& Littlefield Publishers, Inc., 2004. Print.

Habermas, Jürgen. “The Public Sphere: An Encyclopedia Article." Critical Theory

and Society. Ed. Stephen Eric Bronner and Douglas MacKay Kellner. New York:

Routledge, 1989: 136-142. Print.

Habermas, Jürgen. Between Facts and Norms: Contributions to a Discourse Theory of Democracy. Cambridge, MA: MIT Press, 1996. Print.

Horkheimer, Max and Theodor W. Adorno. Dialectic of Enlightenment:

Philosophical Fragments. Stanford, CA: Stanford UP, 2002. Print.

House Made of Dawn. Dir. Richardson Morse. Perf. Larry Littlebird, Judith Doty, and Jay Varela. Firebird Productions, 1973.

Imprint. Dir. Michael Linn. Perf. Tonantzin Carmelo, Corey Brusseau, and CarlaRae Holland. Linn Productions, 2007.

Kellner, Douglas. Critical Theory, Marxism, and Modernity. Baltimore, MD: The Johns Hopkins UP, 1989. Print.

Marcuse, Herbert. "Repressive Tolerance.” The Essential Marcuse: Selected Writings of Philosopher and Social Critic Herbert Marcuse. Ed. Andrew Feenberg and William Leiss. Boston, MA: Beacon P, 2007: 32-59. Print. Memmi, Albert. The Colonizer and the Colonized. Boston: Beacon P, 1965. Print. 
Mulvey, Laura. "Visual Pleasure and Narrative Cinema." The Narrative Reader. Ed. Martin McQuillan. New York: Routledge, 2000. 177-181. Print. Powwow Highway. Dir. Jonathon Wacks. Perf. A Martinez and Gary Farmer. HandMade Films, 1989.

Raheja, Michelle H. Reservation Reelism: Redfacing, Visual Sovereignty, and Representations of Native Americans in Film. Lincoln, NE: U of Nebraska P, 2011. Print.

Rollins, Peter C. and John E. O’Connor. “The Study of Hollywood's Indian: Still on a Scholarly Frontier?" Hollywood's Indian: The Portrayal of the Native American in Film. Ed. Peter C. Rollins and John E. O'Connor. Lexington, KY: The UP of Kentucky, 1998. 1-11. Print.

Serres, Michel. “The Algebra of Literature: The Wolf's Game.” Textual Strategies: Perspectives in Post-Structuralist Criticism. Ed. Josué V. Harari. Ithaca, NY: Cornell UP, 1979, 260-276. Print.

Sharkey, Alix. "A five-star hotel and casino. Well thanks, Kevin.” The Independent. 20 May 1995, London. Web.

Spider-Man. Dir. Sam Raimi. Perf. Tobey Maguire, Willem Dafoe, and Kirsten Dunst. Columbia Pictures, 2002.

Teacher's Discovery. (1999). Political Ideologies [Poster]. Auburn Hills, MI. Print. Whitcomb, Cynthia. Writing Your Screenplay: How to Write Great Screenplays for Movies and Television. Waukesha, WI: Kalmbach Publishing Co., 2002. Print. Willie, Roger. Personal interview. 23 March 2010. 
Windtalkers. Dir. John Woo. Perf. Nicolas Cage and Adam Beach. MGM, 2002.

Yúdice, George. The Expediency of Culture: Uses of Culture in the Global Era.

Durham, NC: Duke UP, 2003. Print. 


\section{CHAPTER V}

\section{Reconsidering the Trickster}

The Native American Trickster is a curiously misunderstood figure in much of contemporary literature and film. Scholars have often theorized this character as a mystical, rather than a mythical, being. This should come as no surprise considering that "the Indian of imagination and ideology continues to be derived ... from the polemical and creative needs of Whites" (Berkhofer 71). In other words, if the majority culture sees in its Other a romanticized reflection with whom it wishes to identify, that image is at risk of becoming co-opted or commodified. The so called "culture vultures" may therefore consider themselves as possessing or questing for mystical enlightenment through the ritual practice of another culture, but never do they refer to this as mythical (Crask 25).

Why is this? Perhaps it is because the mythical association is reserved solely for those self-proclaimed weightier narratives that guide most Western epistemologies. For example, the pilgrims' landing at Plymouth Rock is associated with a bigger, more universal idea. Freedom from religious persecution and the presumed right to cast a beacon unto the world is the ideology espoused by this popular myth. The fact that no such rock was ever referenced by the pilgrims themselves is beside the point. As scholar Ira Chernus explains, "A myth is a story [that] shapes people's view of truth," with 
little concern "whether it can be proven factually true ... It expresses something fundamental about the worldview and the values of the people who tell it" ("Essays about America's National Myths"). The landing at a fictional place called Plymouth Rock is central to the civilizing myth of the early settlers and continues to serve its purpose as justification for colonizing Indigenous spaces. That tribal narratives are not granted the same mythical authority underscores how they have become colonized themselves. Indeed, their subjugation to the realm of the mystical is really more of an invention of the white man, one that permits the majority to confiscate them in its own quest for existential meaning.

All of this details a complicit understanding of the privileged hierarchy at work, in which the mythical precedes the mystical. As the previous chapters indicate, it is those who assimilate the channels of production who keep the master narrative alive, front and center. Moreover, their position and influence determine how the majority of the world perceives the margins. As philosopher Aijaz Ahmad explains, "from Aeschylus onwards the West has never permitted the Orient to represent itself; it has represented the Orient," reinforcing notions that are "always somewhat one-sided, and therefore somewhat hazardous, for anyone whose own cultural apparatus is so overwhelmingly European" (172). The fundamental problem is that a culture unable to comprehend the experiences of another culture has nevertheless claimed the authority to do so. So while the information may not be legitimate, the channels through which it gets delivered are the ones that are most officially recognized. 
Perhaps the 'mythmakers' believe their inheritance is divinely providenced. Theirs are myths populated by gods, whereas animals occupy the domain of the Indigenous. Consider the difference between the Greek god Hermes, a divine messenger whose name recalls the art of hermeneutics (the scholarly study of interpretation), and the Navajo figure Coyote, a suspicious prankster whose actions are both humorous and cautionary. Wherever animals figure into Western schemas, they are regarded as little more than mystical folk characters belonging to a child's fairy tale or fable.

Reserved for so called lesser-civilized cultures in their less-than-human portrayals, these animal figures are decidedly crude and one dimensional when compared with the deities of Western narratives. After all, animals do not possess the sophistication of humans, possessing only those characteristics that are considered more base and instinctual. To affiliate such qualities with Indigenous epistemologies is to reduce them to something far less than the omniscient assignation given to Western deities. The commonly referred to raven, therefore, is not an equivalent messenger to the winged god Hermes. Nowhere it seems do animals figure into the majority prescriptive, except in certain peculiar instances, such as referenced earlier in the term 'culture vulture'.

Ironically, the vulture shares similar characteristics with the raven, and even less glamorously so, but the obscure term refers only to certain jet set tourist types. It is certainly not considered an archetype of western narratives, at least 
never by the majority's accounts of itself. Yet this parallel to the raven does carry profound meaning to an Indigenous audience, who sees in this symbol its consumption of artifacts, as though a scavenger picking through perceived cultural remains. This interpretation is mostly lost on the majority audience, who is accustomed to seeing itself in a more charitable role. Yet this is precisely the point of trickster narratives, which rely on the misreadings of one audience to the advantage of another.

Majority audiences are often oblivious to the Trickster's true aims. Ironically, it is their own set of narratives that contributes to their unawareness. The media is so saturated with popular stories reinforcing the majority opinion that very little critical analysis is required. One simply watches for entertainment. An audience willing to endorse the contrapositive interpretation, particularly through its association with a familiar character, is in a unique position to perceive and comprehend the duplicitous meaning of the Trickster. It is out of necessity that this figure remains indirect. Any direct challenge risks the danger of being discredited or subjected to peripheral concerns. Except, of course, when it appears to conform to majority stereotypes, which is typically what the Trickster's disguise does. It is in this form that the Trickster has broadest reach in delivering to minority audiences a type of "direction through indirection" (Gates 54). For these purposes, an animal works quite nicely.

In proper context, the Trickster is indeed a subversive figure. According to Henry Louis Gates' pivotal book The Signifying Monkey, the Trickster is 
understood first and foremost as a triangulator, an actor who mediates the space between two other entities, often at the expense of one or the other of them. That this is intended for and more properly understood by a minority audience is precisely the point. It recalls the idea that while "the master's tools will never dismantle the master's house, they may allow us to temporarily beat him at his own game" (Lorde 112).

In other words, this character is meant to do much more than entertain. Akin to the monkey in earlier African American scholarship, Native American forms of the Trickster emerge as agents of criticism and social change. Likewise, those involved with narrating them for both page and screen understand their activist potential. As scholar Joanna Hearne points out, celebrated Indigenous filmmakers such as Chris Eyre and Sherman Alexie "take advantage of the power of cinema to teach viewers in order to make things happen in the world beyond the screen" (xviii).

But to more properly understand the Trickster it is helpful to briefly summarize its heritage. Most cultures have some version of their own. Though distinctly separate, there are often certain similarities among them. Take, for example, the two most common North American varieties, those of African- and Native American lineage. Both are descended from an oral tradition that long predates any written account of their existence. As a consequence, their development was well refined by the time they reached the written page. Moreover, each encodes its messages into a third party signifier, a benign- 
appearing animal that operates as a clandestine messenger. Indeed, any lessthan-human form is likely to be mistaken by the majority, considered relatively harmless in the structure of ordered relations.

The failure to recognize the potential of the monkey or the coyote is to underestimate its true intentions. Both function similarly in that they are able to speak to the minority in a symbolic language that is easily misunderstood by the majority. Likewise, they are able to simultaneously confound and confuse the majority, who is generally none the wiser to its placement as the target of the minorant's exploitation. From the early days of African slaves communicating hidden messages in song to the later practice of tribal pranksters staging mystical experiences of enlightenment to new age spiritualists, the latent power of these animal referents is made apparent to those who comprehend their true duplicity. Indeed, they are evolved within these contexts, the spaces within which they are able to reclaim their sovereignty. The real trick, it seems, depends upon just how far they will be able to infiltrate successfully into mainstream media.

The most promising new directions in Native American cinema will most probably come at the hands of Native American writers, directors, and producers themselves. In particular, the theme of the trickster appears to be making its mark on these fascinating developments. The trickster, after all, is adept at the art of 'talking back'. In coming full circle, Jacquelyn Kilpatrick asserts, that in order "for a dialogue to truly exist, the represented subject must 
be able to talk back. An important question considered here is, do Native Americans have a space within mainstream Hollywood films to utter a response?" (xvi).

The Mystical Misinterpretation

The Trickster enjoys widespread inheritance among numerous Native American traditions. The signifying monkey, in fact, is most "probably derived from Cuban mythology," at a point along the historical continuum where such figures representing "the Yoruba systems of thought in Benin and Nigeria, Brazil and Cuba, Haiti and New Orleans, are divine: they are gods who function in sacred myths" (Gates 52). This being the case, why does the majority audience so often fail to place this character on equal footing with those of its own? Why does such an audience fail to position the Trickster within a mythological framework?

An unfortunate legacy of the Trickster when understood in a mystical rather than a mythical context is that many Western scholars are apt to perceive it as functionary to folklore, rather than pivotal to the more privileged paradigms that are usually examined with deeper scholarly concern. The trickster as a literary figure belonging to Western mythological frameworks has a long and privileged tradition among scholars. Such figures as Hermes and Loki, part of Greek and Norse traditions respectively, enjoy a place and status among the 'pantheon' of classic art and literature. Greek mythology, for example, would never be referred to as folklore. Why, then, do such designations of the Native American 
trickster continue to persist? Part of the answer may be uncovered in the ways in which most Western critics and scholars have approached this subversive and ambiguous figure.

While some of them may revere this figure, few understand the Trickster's true purpose. Simply put, confining the Trickster to the realm of the mystical is borne of an ethnocentric tendency to subjugate another's agency, all in an effort to strengthen its own position within the social hierarchy. This is typically accomplished in one of two ways. First, by positioning this character as anathema to logic and resolution. Second, by placing it in a time and space that is mostly foregone or forgotten.

The first instance includes abundant examples in the cinematic repertoire. Previous chapters have primarily discussed the scripted stories themselves. But to fully comprehend the positioning strategies at work in said hierarchies, it is necessary to further consider how the majority audience arranges and consumes these films. For example, a movie like Skins (2002), filmed by Indigenous director Chris Eyre, easily leads the majority viewer astray. It casts the Trickster in a dark and pranksteresque way. It is portrayed as an unclean spirit that takes hold of the main character, a tribal police officer whose frustrations with the poverty and injustice of life on the reservation leaves him feeling impotent to do much about it. Once he internalizes the Trickster, however, he begins taking the law into his own hands. Donning a mask and breaking the kneecaps of two youths who got away with killing a young boy and torching a liquor store 
frequented by his alcoholic brother, he goes on a rampage that appears both juvenile and futile. It is this very lack of rationality that the majority viewer is apt to notice and focus on. The fact that his actions can be interpreted as little more than gratuitous only serves to reinforce the majority's notion of the Trickster as an amateurish character. Rather than assigning this character the status of a mythically significant figure, it is relegated to the realm of the folkloric and superstitious.

Likewise, the majority audience has been influenced by generations of Hollywood films that have obsessively presented Indigenous Americans as a people of the past. Any customs or practices associated with them are synonymously framed as quaint and passé. In other words, a character such as the one portrayed in Skins is seen as "a version of the trickster spirit of Indian folklore ... a ghost from the past" (Johnson 73). It would appear to matter little that the story is set in modern times and attempts to address problems persisting on present day reservations. The focus instead revolves around the character's connection to his ancestral past, as though there is no place for him in the future. This, among other things, evacuates his agency. The Trickster of modern times is a product of the past. He is narratively constructed this way. Ironically, it is the work of some well-known scholars of the past that first began to associate the Trickster with a few of the conventional structures of mythology, albeit in a fairly misguided and reductionist sort of way. 
Scholars working within structuralist conventions have been most likely to examine the Trickster in mythical terms. Michael Carroll notes how "LéviStrauss's analysis of the trickster figure in North American mythology ... is important in the history of structuralist thought because it was presented in the very first article on myth that Lévi-Strauss (1955) ever wrote" (Carroll 302). To understand the Trickster, in other words, is to place this figure into proper context, namely the cultural structure within which it operates.

Unfortunately, it is no easy task for an outsider to recognize all the intricacies and subtleties of meaning that go hand-in-hand with the experiences of a cultural insider. To uphold the sovereignty of another system is to consider it no less valid than one's own. Those who advocate this are more likely to perceive the Trickster in equivalent terms, giving it the status of a mythical rather than a folkloric figure. Nevertheless, it does not mean that they are able to truly grasp the significance of this character in its entirety. Nor does it explain the ambiguities personified in certain symbols, such as the coyote and raven as understood by an Indigenous audience. Scholars may rightly understand that culture is important, but do they understand the culture?

\section{The Trickster as an Animal}

No less an authority than Claude Lévi-Strauss directs our attention to the mythical importance of the Trickster, beginning with the simple question: "Why is it that throughout North America the Trickster role is almost everywhere 
assigned to either coyote or raven?" (440). The question is certainly not random, as it permits him to draw the conclusion that Tricksters are neither providers of life (they are unlike edible plants) nor takers of life (they are not apex predators). This seems like an odd dichotomy at first appearance, but it allows us to consider a third category. "The category that mediates between herbivorous animals and carnivorous animals is 'carrion-eater,' since carrioneating animals (like herbivorous animals) do not kill, yet (like carnivorous animals) they eat animal flesh" (Carroll 302). The Trickster as carrion-eater, therefore, fulfills the role of an in-between or mediator.

The cultural significance of this role is evident, yet the affiliation of carrioneater is not a perfect signifier. Sociologists such as Michael Carroll have complied a wealth of information about the specific characteristics of the Trickster, but scholars sometimes get so caught up in the details that they forget the broader purposes of this figure. The mediator function probably comes closest to understanding the true character of the Trickster. But to this end, other more 'respectable' animals might merit worthy consideration. Basil Johnston reminds us that although never identified in this role, "for his service to mankind ... the turtle became the messenger of thought and feeling that flows and flashes between beings of different natures and orders. He became a symbol of thought given and received. The turtle, slowest of all creatures, represented celerity and communication between beings" (Johnston 15). It is one of the few creatures who live in two worlds, both on land and at sea. It is also an emissary 
between these two worlds. An extension of this analysis places the turtle as a messenger between the corporeal and ethereal realms, a being who communicates across both physical and spiritual boundaries. Yet despite these exalted characteristics, the turtle most decidedly does not fulfill the role of the Trickster.

The trouble with introducing Western analyses to the study of Native American myths is that it skews our understanding of the cultures that produced these myths. Thus, it becomes possible to misinterpret the Trickster figure in at least two common ways. First, there is the problem of becoming sidetracked. In observing "that so many myths ... revolve around the actions of trickster figures who are named after carrion-eating animals," Michael Carroll concludes that “Lévi-Strauss's explanation is flawed because it runs afoul of a very straightforward observation: coyotes are not primarily carrion eaters ... carrion accounts for only about one-quarter of the coyote's food supply [so] that, if anything, the eating habits of coyotes suggest that they are predators" (Carroll 303). While one can certainly appreciate the correction of such factual errors, this emphasis on the scientific explanatory schema does little to support Clifford Geertz's notion of thick description, in which "the aim is to draw large conclusions from small, but very densely textured facts that [accurately] support broad assertions about the role of culture" in interpreting "complex specifics" (Geertz 28). But the specifics can be so easily misunderstood that the forest 
often gets disguised behind all its trees. Getting caught or lost in the details can often obscure the broader meaning of a cultural act or interpretation.

Secondly, if not exactly false, the Western interpretive schema is oftentimes at least irrelevant. Consider Carroll's explanation that:

For Freud, myths derive ultimately from the shared childhood experiences of the members of a given culture. More specifically, myths are seen as projective systems in which those sexual impulses which are repressed during early childhood are expressed, sometimes directly and sometimes indirectly ... [so that] if Freud is right in arguing that all children are initially characterized by a tendency toward the immediate gratification of their sexual impulses, and that this tendency is generally repressed, then this alone (given his perspective on myth) would explain the popularity of a mythical figure, like Trickster, who is so overwhelmingly concerned with satisfying those desires for immediate sexual gratification that the rest of us have repressed. (306)

While it is true that much has been written about the sexual antics and animalistic instincts of the Trickster, Carroll's interpretation debases this figure. Presenting a character that is egoistic rather than altruistic does little to advance the Trickster beyond the category of a flat and one-dimensional archetype. D. C. Gill suggests, "While archetypes assist in binding members of a group together, their shallow story patterns necessarily prove limiting" (86). At least insofar as the majority typically understands them. But are they quick to assign such 
limiting characteristics only to other cultural figures, while reserving a more glamorous set of descriptors for figures of their own? For example, Carroll asserts how "the trickster is someone who is obsessed with satisfying his almost constant hunger or his seemingly uncontrollable desire for sexual intercourse" (305). This description paints a decidedly lascivious portrait. Yet the same characteristics can also be used to describe some other more celebrated filmic and literary characters, such as James Bond or Magnum, P.I. How is it that the Trickster suffers a negative valuation, while a pop culture hero like James Bond merits a positive one? Given the amount of colonizing scholarship and devalued forms of representation afforded the Native American Trickster, the question becomes: Are there any Western constructs or categories in which might be applied a more affirmative understanding of the Trickster?

\section{The Narrative Smokescreen}

One of the single most important observations made by scholars of Native American film is that the films themselves often tell us very little about Indigenous cultures or ways of life. They do, however, reveal a great deal about the mainstream culture's view of itself. To this end, the filmic archive provides a pretty good record of how the majority fancies itself, as well as the role it assigns to others in supporting this fantastical view. And insofar as film might aim to shape this record, it becomes a powerful medium for reinventing the past. In The Sublime Object of Ideology, Slavoj Žižek asserts, "we are all the time 
'rewriting history', retroactively giving the elements their symbolic weight by including them in new textures-it is this elaboration which decides retroactively what they (emphasis added) 'will have been'” (59).

Bloodthirsty Indian or noble savage, either way a symbol that distinguishes them from us. Categorically considered, wouldn't such an Other be precisely what history obsessively attempts to rewrite? This recalls another function of ideology — placing an entirely differentiated Other in a position that is advantageous only to the recognition of one's self. As Žižek explains, the self is known "only by being reflected in another-that is, in so far as this other offers an image of its unity—can the ego arrive at its self-identity; identity and alienation are thus strictly correlative" (20). Here again, the Native American is made to stand in as the opposing image that defines the western protagonist. In no place is this as obvious as in Hollywood.

Consider a telltale scene in Windtalkers. The protagonist, played by Nicolas Cage, is a shell-shocked killing machine, unable to find his own humanity until it confronts him in the form of the character portrayed by Adam Beach. As Cage traces the outline of a cathedral in a pile of spilled flour, Beach informs him that they share a common religious heritage. Cage is astonished by this acknowledgement, that a Navajo might also have been raised Catholic. The scene signals a turning point in the film. The reticent protagonist now must come to the rescue of his vulnerable partner, who is really symbolic of his own fragile self. This rupture in his psyche is both fertile and productive. In addition 
to finding himself, he must literally face a stereotype with which he has historically arranged a portion of his life.

As Žižek tells it, "Every historical rupture, every advent of a new mastersignifier, changes retroactively the meaning of all tradition, restructures the narration of the past, makes it readable in another, new way" (58). In other words, while the scene in Windtalkers does not reinvent the actual events of history - many Navajos were introduced to Catholicism while attending boarding schools - it does revise the majority culture's misunderstanding, causing it to reconsider the Native tradition in relation to its own. And even more to the point, challenging the validity of its own beliefs as popularly perceived throughout much of history. Disrupting the binaries of bloodthirsty Indian and noble savage, such encounters with a newly recognized Other inscribes a third category. It is within these ruptures that profound expressions of agency are often enacted. Such spaces can become fertile ground for the emergence of a third, more sovereign individual. The problem comes in trying to wrestle this space away from those who have already institutionalized it.

The hegemony of Western interpretations is, of course, the main culprit. "It is ultimately to the history of White values and ideas that we must turn for the basic conceptual categories, classificatory schema, explanatory frameworks, and moral criteria" that have continuously been used in the "centuries-old White effort to understand themselves through understanding Native Americans" (Berkhofer xvi). To further elaborate, Robert F. Berkhofer, Jr. explains, "Native 
Americans [are] classified only through the content of specific imagery and the context of a particular history and space. In the end, to understand the White image of the Indian is to understand White societies and intellectual premises over time more than the diversity of Native Americans" (xvi). In other words, the role ascribed to an 'Other' reveals much about the people assigning this role, including their own evolutionary place along the continuum of recognition and understanding. In the event that the Other is Native American, the comparison is cultural or racial. But this can also be compounded by gender.

\section{Gendered Generalizations}

As relates particularly to film, one of the most troubling objectifications concerns the portrayal of women. Western representations not only sexualize the female form, they also tend to represent the Trickster as "overwhelmingly concerned with satisfying [his] sexual impulses" (Caroll 306). But reality suggests that this speaks more to the audience for whom such forms are narrativized, which in general happens to be both white and male. Projecting these impulses onto a third party attempts to absolve the spectator from any deeper reflection upon his own illicit attractions to the 'object' of the female. Laura Mulvey contends that, "in their traditional exhibitionist role women are simultaneously looked at and displayed ... but as the narrative progresses [and the female object] falls in love with the main male protagonist and becomes his property, [she loses] her outward glamorous characteristics, her generalized 
sexuality" (Mulvey 179, 81). She is permitted so little narrative flexibility that the Trickster role is seldom assigned to her. Yet for all her significance as "the source of cultural identity, survival, and social continuity," her candidacy should be reconsidered (Babcock 402). Hollywood, however, sees this very differently.

Particularly with respect to films produced about Native Americans, the main Western hero always seems in opposition to an antagonist who is both dangerous and dehumanized, a character with whom the spectator is most certainly not meant to identify. Such is the case in The Searchers (1956), a movie in which John Wayne plays Ethan Edwards, a hero who must avenge the slaughter of his brother's family and search for his missing niece. Kidnapped by Indians and forced to live as the wife of his nemesis, Chief Scar, her virtue is tarnished. From a psychoanalytic perspective, her desirability is not only diminished, but becomes subject to the protagonist's irrational thoughts of "punishment or saving of the guilty object" (Mulvey 181). In other words, while the antagonist is a rapacious subhuman who must die, there is also little hope left for the helpless damsel who has now become the object of shame.

As Jacquelyn Kilpatrick points out:

In Hollywood's westerns, the ultimate solution for a sexual relationship between an Indian and a white was that the Indian would have to die. If the relationship, whether or not it included love, involved an Indian male and a white female, the Indian man must die, and the woman was ruined for life-to the point that she, too, was better off dead. Rather than give in 
to a sexual relationship, the woman was expected to kill herself; otherwise she was either crazy or a whore and definitely not welcome in the civilized world ... Miscegenation, whether by choice or force, was a scary proposition to audiences in the 1950s. (62-63)

The prohibition against miscegenation is also found in films that are purportedly sympathetic toward Native Americans. Consider Delmer Daves' Broken Arrow (1950). The protagonist Tom Jeffords, played by James Stewart, falls in love with an Apache princess named Sonseeahray, played by the white actress Debra Paget. As Kilpatrick explains, "the lovely 'Indian princess' is enormously attractive ... [and] could give herself to a white man ... [whose] seduction and/or love of an Indian woman is tragically romantic and provocative ... but [she] must die before any real damage is done to the purity of the gene pool" (xvii, 64). This, of course, is exactly what happens to Sonseeahray, who gives her life to save Tom Jeffords from the hostile faction of Indians within her own tribe.

Psychoanalytic film theorists are keen to recognize not only that "the object seen is present and hence presumably complicit... [in] a fiction that stipulates that the object 'agrees' and is therefore exhibitionist," but also that this presence "is not really the object... [but rather] its shade, its phantom, its double, its replica in a new kind of mirror" (Metz 807). This Lacanian notion is played out in various ways in filmic representations of Native Americans. Obviously, the spectator's recognition of the Other in terms of what is lacking is a powerful and 
colonizing fiction. As Robert Berkhofer, Jr. observes, a "persistent theme in White imagery is the tendency to describe Indian life in terms of its lack of White ways rather than being described positively from within the framework of the specific culture under consideration" (26). But even the supposedly more affirmative notions of the Other are notoriously problematic. Consider Enrique Lamadrid's admonishment that the "portrayal of the Indian as the 'Mystical Other' is so overt as to become immediately ludicrous" (9). Such is the case when Tom Jeffords is first introduced to Sonseeahray during the 'Sunrise Ceremony' for a young girl. The character Cochise, played by white actor Jeff Chandler, explains to Jeffords, "The girl inside the wickiup is in the holiest time of her life." Jeffords enters the ceremonial space where Sonseeahray asks to touch his wounded arm, flatly stating, "It will never hurt again. Your life will be long, the good things will be yours, the sun will shine for you."

Sonseeahray, like practically any other representation of a Native woman, is given no other dimension than to affirm the legitimacy of the dominant narrative. And while this falls far short of its potential in recognizing a feminine Trickster opportunity, the chance is not entirely missed in Korinna Sehringer's candid film Shouting Secrets (2011). As the matriarch of an Apache family, June (actress Tantoo Cardinal) carries all the secrets of each member's dysfunction, including her husband's excuses for drinking, her son's involvement with an under-aged girl, and her daughter's unexpected pregnancy. She sees how each of these dynamics has driven a wedge between them all. Yet she holds these 
secrets, even as terminal illness overtakes her. Comatose at the conclusion, there appears to be little hope for the family to resolve its differences, particularly in the face of her death.

Yet it is at her own funeral where her voice is heard most clearly. She has left a message for each of them on a digital recorder, giving invisible guidance and direction to her grieving family in a most compelling way. Her voice cheats both time and space, inscribing an entirely new dimension. It is within such dimensions that the Trickster is apt to emerge. Beyond the binary of bloodthirsty savage or noble Indian, innocent maiden or exotic lover, the Trickster operates within a third category.

\section{Organic Traces in Third Spaces}

The Trickster inscribes a third category. Although imperfectly understood, it is not completely unrecognized within Western tradition. As a type of activist, one might draw an appropriate parallel with Antonio Gramsci's notion of the organic intellectual, who occupies "the terrain on which [the oppressed] acquire consciousness of their position" (337). Moreover, such an agent "participates in a particular conception of the world, has a conscious line of moral conduct, and therefore contributes to sustain a conception of the world or to modify it, that is to bring into being new modes of thought" (9). Considered in this way, the Trickster becomes a blueprint for social change. 
There are many permutations of the organic intellectual, each offering something new by way of explanation. In conceiving of the Trickster as an intellectual, at least a couple of these merit consideration. First and foremost, the Trickster is an agent of the minority. It is a figure who can speak their language, interpret their symbols, and activate their sympathies. These are the 'organic' abilities which enable the Trickster to relate to its people. Secondly, the Trickster is a bewilderer of the majority, able to slip unnoticed into the master's house to steal his tools and use them against him. In the first instance, Joanne Rappaport investigates Gramsci's notion of the organic intellectual as someone who is "not so much focused on individuals as on the relationships [italics added] between intellectuals or groups of intellectuals and the social sectors in whose name they speak" (10). Without this relationship bridge, the Trickster cannot succeed.

In the second instance, this agent is seen as someone who is able to poach from dominant cultural forms those things that might also serve the interests of the oppressed. Putting them into new contexts, often at the obliviousness of the majority, increases the chances of activating the minority. In his book Keeping Faith: Philosophy and Race in America, Cornel West reframes this figure as an organic catalyst [italics added], "a person who stays attuned to the best of what the mainstream has to offer-its paradigms, viewpoints and methods-yet maintains a grounding in affirming and enabling sub-cultures of criticism" (24). Taking into account these variations' emphasis on the relational role of 
individuals acting as catalysts, it is plain to see how the Trickster inhabits an important place within this scheme.

In addition to comprising a third category, the Trickster also occupies a third space. In his article “Michel Serres' Philosophy of the 'Educated Third': Hermesian Confluences Among the Humanities, Science, and Technology," Ciro Sandoval identifies how Serres' philosophy of the "'educated third' must be imagined within a 'third place' where a confluence, mélange, or 'mestizaje' of genetic, cultural, humanistic, and scientific historical inheritance allows him to come into being ... [as an] 'expert of cognizance' ... 'who prefers action to capitulation'” (117). To locate a space of both intercultural and interdisciplinary activism, scholars are compelled to confront their own institutional biases and to reconsider the privileged domain of proprietary intellectual knowledge. To this end, Rappaport calls on us to acknowledge the critical role of shamans:

Whose discourses are rooted in an exchange with the spirit world and not with the dominant society and whose knowledge provides a potent language for the construction of politicized cultural forms ... [such shamans might be called] sabedores or 'knowers,' in acknowledgement of the recognition ... given them as the source of ... cultural imaginings and their role as brakes against ... ideological colonization by external forces. (15) 
Given such understandings, the Trickster is neither confined to a binary role nor a binary space. Rather, the Trickster fulfills an intermediary function in each of these relational contexts, existing in both interactional and interstitial space.

In conceiving of intermediary third spaces, another type of Trickster is particularly instructive. Henry Louis Gates writes that, "the Signifying Monkey exists, or is figured, in a densely structured discursive universe, one absolutely dependent on the play of differences" (53). This African American Trickster is both dependent and thrives upon the deliberate practice of 'crossing wires' in indeterminate intercultural spaces. Gates employs Robert D. Abrahams' definition of "Signifyin(g) [as] a 'technique of indirect argument or persuasion,' ‘a language of implication,' 'to imply, goad, beg, boast, by indirect verbal or gestural means' ... [that which displays] the language of trickery [as a] set of words or gestures [capable of] achieving Hamlet's 'direction through indirection'” (54).

Gates' proposition therefore offers a counter-hegemonic theory of agency. The catalyst who enacts this agency is personified in the form of the Signifying Monkey, a trickster who becomes "a central character in the crucial scene of instruction ... [a] doctor of interpretation" $(15,20)$. In this guise, the Trickster is able to move unseen, at least until the opportune moment at which point the trap has already been sprung, the table already turned. Following Jacquelyn Kilpatrick's explanation, "A trickster always turns things upside down" (186). Or as Patricia Bizzell and Bruce Herzberg tactically define it, "the Monkey is the champion signifier, fomenting strife between others by clever innuendo and 
escaping blame by sophistry" (1550). By way of example, Gates employs the following analogy, which:

turns upon the action of three stock characters-the Monkey, the Lion, and the Elephant—who are bound together in a trinary relationship. The Monkey-a trickster figure ... who is a rhetorical genius-is intent on demystifying the Lion's selfimposed status as King of the Jungle. The Monkey, clearly, is no match for the Lion's physical prowess: the Elephant is, however. The Monkey's task, then, is to trick the Lion into tangling with the Elephant, who is the true King of the Jungle for everyone else in the animal kingdom. (56)

Whether a monkey, raven, or coyote, the Trickster serves a mediating function. This function, much like that of the organic intellectual's, is to liberate its host culture from the 'self-imposed status' of the dominant or dominating culture. The Trickster, therefore, is a restorative figure, a hero "in a densely structured discursive universe," such as might be found in the medium of literature or film (53). And rightly so, the inclusion of the Trickster signals a turning point in the production of films about Native Americans.

\section{Affirmative Portrayals}

Films that employ the trope of the Trickster tend to resonate affirmatively with an Indigenous audience. Unfortunately with the present century's production of 
big name titles such as Windtalkers (2002), one must look back at earlier films in order to find this figure in the cinematic frame. He or she is usually recognizable through the act of signifying, as relates to the fooling of majority figures into taking various actions against their own self-interests, according to their own unexamined biases. This is especially effective in situations where the majority tries to identify with the minority, often in stereotypical and transgressive ways that are easy to undermine.

A fitting example is found in William Patrick Kinsella's Dance Me Outside (1996). An Irish-Canadian screenwriter, he celebrates the Trickster as the voice of the oppressed, stating that "oppressed people survive by making fun of the people who oppress them," insisting that "this is essentially what my Indian stories are all about" ("W. P. Kinsella"). And this is precisely what happens in one of the most memorable scenes of the film, in which the main character Silas Crow invites his white brother-in-law Pete to a make-believe naming ceremony. As Pete becomes more and more intoxicated, unwittingly and foolishly playing into his own repressed stereotypes of Indian culture, the ceremony's true intent (a cleverly devised smokescreen) is poignantly revealed to the audience as Silas's sister seeks her former boyfriend in order to become pregnant. Pete, it turns out, is a sterile white man, while the former boyfriend is a sexually potent Native American. Pete's enthusiasm for 'playing Indian' and being bestowed with mystical enlightenment has been expeditiously used against him. As he 
falls victim to his own cultural avarice, the ruse of the Trickster is made apparent (to the film's viewers anyway).

Other examples come from earlier still. House Made of Dawn (1973), Harold of Orange (1983), and Powwow Highway (1989) offer a prescient sensibility of the direction a future cinema rooted in Native American sovereignty might take. The first two titles were written by noted Native American authors: N. Scott Momaday and Gerald Vizenor, respectively. The third one features versatile Cayuga actor Gary Farmer in the starring role. All three films give primacy to the subversive role of the Trickster and tend to privilege the Native American audience. Given that the majority culture continues to be fascinated with Native folklore, conceiving of it as mystical rather than mythical, this often opens a set of doors from which the Trickster can conveniently emerge.

The point is made clear in Harold of Orange. The film's plot is centered on a meeting between the 'Warriors of Orange', an enterprising group of Native American Tricksters led by Harold Sinseer, and the board of directors of a charitable foundation who is considering the warriors' proposal for funds to open a reservation coffee house. Among the all-White foundation members is Fannie Mason, an ex-girlfriend of Harold's. When viewers are first introduced to Fannie, the following dialogue takes place:

Foundation Director: "Fannie studied American Indian folklore." Fannie: "Well actually, literature, which is a much larger subject than folklore." 
Foundation Member: "Do Indians have a written language?"

Fannie: "No, they have oral tradition"

Effective in its use of double meaning, this exchange addresses two duplicitous interpretations at once. The first is encoded in Fannie's correction of the foundation member, exposing the subtlety of his prejudice. The second is unwittingly coded in sexual innuendo, which is later expressed when Harold inquires if she remembers "the oral tradition."

In the rest of the film, the Tricksters' scheme to "reclaim their estate from the white man ... [by] challenging his very foundations" (including, of course, his financial grant foundations) is perhaps best summed up by Harold's pronouncement that the Warriors of Orange are "tricksters in the new school of social acupuncture, where a little pressure fills the pocketbook" (Vizenor 1983). The Warriors of Orange prove themselves to be quite adept at the art of signifying. One particularly effective example of this strategy includes turning the white man's own ill-conceived stereotypes against him. Throughout the film, several of the foundation members express such sentiments as, "We celebrate your desire to better yourselves" (Vizenor 1983). In response to the TricksterWarriors' proposal to open coffee houses that specialize in "pinch bean" coffee, one of the foundation members initiates the following dialogue, after acknowledging that he has a rather difficult question to ask:

Foundation Member: "My question is how did all of you overcome the need and temptation to use alcohol? You're all so sober, a credit to your race!" 
Harold: "Pinch beans. Pinch beans are the cure. Pinch beans are a booze blocker. The beans will block the temptation to take alcohol. Our proposal to establish coffee houses on the reservations will lead to a sober revolution!"

Foundation Member: “Fantastic! This is fantastic! You've got my vote for sure!"

Using complicatedly simple rhetorical strategies, the Trickster manages to open a new space for social action. As the title song for Harold of Orange contends, in order to "reroute some of that money green, move the banks and you change the stream" (Sainte-Marie 1982). It is through the use of such clever analogies that messages are encoded to carry simultaneous modes of meaning. The semantics of a Trickster's words operate not just within a linguistic sense, but ultimately also within a cultural field of understanding.

The other titles, N. Scott Momaday's House Made of Dawn (1973) and Jonathon Wacks' Powwow Highway (1989), play on similar understandings. In the first film, the Trickster, Tosamah, is a master deconstructionist. The protagonist first encounters him in prison while attending a rehabilitation session. Tosamah initiates the session by referring to the Bible and the power of the Word, which quickly transforms into a subversive lesson about "the turning of words against themselves" (Kilpatrick 182). He removes his mask, so to speak, and reveals his true shamanic identity. To the warden and corrections officers, he is merely a new age Christian minister; to the Others, a powerful imitator who derives his 
very power through ruse. While Tosamah quite obviously fulfills the role of Trickster, he does so in a dark and frightening way, not unlike the protagonist in the aforementioned movie Skins. To viewers familiar with the construct, his portrayal skirts dangerously close to the realm of witchcraft. Powwow Highway's Philbert Bono, on the other hand, is a character more closely approximating the comic power of the Trickster.

A curious thing about film is how the audience connects with the characters onscreen. Ordinarily, the viewer is more cognizant of narrative events than any given character. But this is not always true. A case in point, Philbert is easily mistaken as a naïve and gullible sidekick who is scripted to provide comic relief. But as the film progresses, this sleight of hand is revealed. The humor is in fact a disguise that enables him to get away with more than anyone may have seen coming. In the end he is able to spring his buddy's sister from jail, escape from the crooked cops, and make off with a small fortune, all because he appears harmless.

Barthes writes of the audience's relationship to the screen as one which "abandons itself to the primary virtue of the spectacle... [that] what matters is not what it thinks but what it sees" (15). To the extent that this may be so, the Trickster occupies a prime position for catching an audience off guard. In comic fashion, such a subversive agent might be capable of achieving what would otherwise seem impossible. The power of laughter is that it possesses a disarming quality. As Mikhail Bakhtin observes, "Laughter demolishes fear and 
piety before an object, before a world, making of it an object of familiar contact and thus clearing the ground for an absolutely free investigation of it" (23). As the actor portraying Philbert, Gary Farmer delivers a comically astute performance. The power of the Trickster often arrives from other characters' notions of this figure as a naïve individual, notions that by extension are generally adopted as the viewer's own. So when Philbert detours through the Black Hills on the way to Santa Fe, thereby infuriating his traveling companion who has scheduled the trip to bail his falsely accused sister out of jail, the audience comprehends the 'characteristic' humor of the situation. What is not anticipated, however, is that the sister's escape will come at the hands of the very person who refused to follow a direct course to her rescue. As Kilpatrick explains, "Phil is a trickster figure, and as such he always turns the expected into the unexpected" (117).

A theorist and fiction writer who similarly appropriates the trope of the Trickster is Gerald Vizenor. In his novel The Heirs of Columbus, he tells of a character whose "reports to the tribe were couched in binaries and metaphors that resolved rumors and suspicions" (161). Such communication strategies are precisely the point. One culture's misunderstandings become another's understandings, or as Vizenor puts it, "your questions are my very answers" (171). A valid case in point is his screenplay Harold of Orange. Adapted from one of his own short stories, Vizenor explains that: 
When the film was newly finished he received an early morning call from the director who was anxious about audience reaction ... [Vizenor] suggested that the director's anxiety could be easily relieved by a couple of special showings ... the first was to an audience of Native Americans [who] laughed uproariously ... the second was to an audience of board members from various notfor-profit institutions [who] did not laugh. At all. (192) Just how this film accomplished that feat reveals the rhetorical duality of the Trickster, who represents one thing to one person and something completely different to another. Vizenor underscores this dichotomy most directly when Harold and the Warriors of Orange challenge a group of foundation directors to a softball game. The directors, of course, are little more than stand-ins for what might conceivably be considered any among a broad number of the white man's indulgent or so-called charitable foundations.

The privy Native American team is given white-colored t-shirts with the mascot 'Anglos' written across the chest. The foundation members wear red shirts with the word 'Indians' across the front. The juxtaposition is intentional, as Harold visits each team's dugout for a pre-game speech. He appears first to his Native American teammates, the 'Anglos', addressing them as if they were actually white. He reminds them of the precedent of Manifest Destiny and tells them they must win the game in the name of God. He then makes his way toward the foundation directors' team, pulling off his shirt to reveal a second 
shirt beneath. This one says 'Indians', matching those of the directors. Utilizing Gates' strategy of 'signifying', he mockingly addresses them through indirection, saying that it is best for all 'Indians' to remember what the missionaries told their elders - that it is the white man who must win. He goes on to explain that when the white man wins, everyone wins. The white man, he explains, will then want to discover his inner self on the reservation and to become just like the Indians, at which time the Indians will leave him to live on the land he had originally carved off for them. As the game unfolds, it is clear that the Native Americans, wearing 'Anglo' shirts, intend to lose. By intentionally throwing the game, the 'Indians' team is sure to win. But the foundation directors do not understand this ruse and actually play to win. In short, they never suspect that their victory was literally handed to them. And by winning the game, the 'Indians' have actually won.

Admittedly, the film requires a more cerebral reading than much of what Hollywood produces. Its interrogation of hegemonic myths and narratives does not privilege the metropolitan audience. Consequently, it has never become a major motion picture. This is unsurprising, given that blockbuster films about Indians have never really been about Indians. As historian Robert Berkhofer explains, "even today's sympathetic artists chiefly understand Native Americans according to their own artistic needs and moral values rather than in terms of the outlook and desires of the people they profess to know and depict" (103). Historian and Film Studies journal editor, John O'Connor agrees. As he puts it, 
"Movies and television, the popular art forms of today, continue to speak more about the current interests of the dominant culture than they do about Indians .. . [but] to the extent that commercial concerns influence all art, the huge monetary investments necessary to produce a feature film make art and commerce inseparable" $(28,30)$. To this end, one might also add that commerce is inseparable from ideology. In other words, if a picture does not fit within a particular ideological framework, if it does not match the interests of the socalled 'dominant' culture, it is unlikely to receive much investment or attention.

Films like House Made of Dawn, Powwow Highway, and Harold of Orange may have signaled a promising new direction in the progression of Native American film, but their reach will never be as global as that of Dances with Wolves. As critic Ted Jojola says of the first two films, "House Made of Dawn was produced outside of Hollywood circles ... and saw very limited play and distribution ... [while] Powwow Highway was given an unexpected second life [only] as a rental video" (qtd. in Rollins and O'Connor, 15, 23). As for Harold of Orange, Jacquelyn Kilpatrick writes, "Because it was made for an Other audience, [it] is available only through obscure sources and an occasional university video library" (193). Unlike the big name Hollywood director, "the revolutionary filmmaker ... will experience the loneliness of those who aspire to the praise of the System's promotion media only to find that those media are closed to him" (Solanas and Gettino 278). Yet the subtle Trickster, whether in character or filmmaker form (for one does not exist without the other in theater), "can be found in the 
revolutionary opening towards a cinema outside and against the System, in a cinema of liberation: the third cinema" (273). That the Trickster as an agent of postcolonial and critical origins is recognizable only to some suggests that his or her true transformational power comes at the place where understanding meets misunderstanding, where the underprivileged perceive what the over-privileged cannot.

The Indigenous Trickster is likely to continue to be misunderstood by Western culture, so long as this figure remains hidden in the animal categories of coyote or raven, or even the broader considerations of carrion-eater versus predator. On the other hand, maybe this lack of Western apprehension is a fortunate arrangement. After all, the Trickster's power is derived most deliberately from within such discursive spaces of misunderstanding. Perhaps the Trickster most decidedly is a type of predator after all. 
Works Cited

Ahmad, Aijaz. In Theory: Classes, Nations, Literatures. New York: Verso, 1992. Print.

Babcock, Barbara A. “'A New Mexican Rebecca': Imaging Pueblo Woman.” Journal of the Southwest 32.4 (1990): 400-37. Print.

Bakhtin, Mikhail. The Dialogic Imagination. Austin, TX: U of Texas P, 1996. Print. Barthes, Roland. Mythologies. New York: Hill and Wang, 1972. Print.

Berkhofer, Robert F., Jr. The White Man's Indian: Images of the American Indian from Columbus to the Present. New York: Vintage Books, 1978. Print.

Bizzell, Patricia and Bruce Herzberg. The Rhetorical Tradition: Readings from Classical Times to the Present. Boston: Bedford/St. Martin's, 2001. Print. Chernus, Ira. "Essays about America's national myths in the past, present, and future," < http://mythicamerica.wordpress.com/about-mythic-america/> Web.

Crask, Paul. Grenada, Carriacou, Petite Martinique. Guilford, CT: The Globe Pequot Press Inc., 2012. Print.

Broken Arrow. Dir. Delmer Daves. Perf. James Stewart, Jeff Chandler, and Debra Paget. Twentieth Century Fox, 1950.

Carroll, Michael P. "Lévi-Strauss, Freud, and the Trickster: A New Perspective Upon an Old Problem." American Ethnologist 8.2 (1981): 301-313. Print. Dance Me Outside. Dir. Bruce McDonald. Perf. Ryan Rajendra Black, Adam Beach, And Jennifer Podemski. Cineplex-Odeon Films, 1996. 
Dances with Wolves. Dir. Kevin Costner. Perf. Kevin Costner, Mary McDonnell, and Graham Greene. Tig Productions, 1990.

Gates, Henry Louis. The Signifying Monkey: A theory of African-American Literary Criticism. New York: Oxford UP, 1989. Print.

Geertz, Clifford. The Interpretation of Cultures: Selected Essays. New York: Basic Books, 1973. Print.

Gill, D. C. How We are Changed by War: A Study of Letters and Diaries from Colonial Conflicts to Operation Iraqi Freedom. New York: Routledge, 2010. Print.

Gramsci, Antonio. Selections from the Prison Notebooks. Ed. Quintin Hoare and Geoffrey Nowell-Smith. London: Lawrence and Wishart, 1971. Print.

Harold of Orange. Dir. Richard Weise. Perf. Charlie Hill, Barbara Davidson, and Cathleen Fuller. Film in the Cities, 1983.

Hearne, Joanna. Smoke Signals: Native Cinema Rising. Lincoln, NE: U of Nebraska P, 2012. Print.

House Made of Dawn. Dir. Richardson Morse. Perf. Larry Littlebird, Judith Doty, and Jay Varela. Firebird Productions, 1973.

Johnson, Brian. "Epic Struggles: Revealing the Rage When Natives Meet Whites." Maclean's 104.40 (1991): 73. Print.

Johnston, Basil. Ojibway Heritage. Lincoln, NE: U of Nebraska P, 1976. Print. Jojola, Ted. "Absurd Reality II: Hollywood Goes to the Indian." Hollywood's Indian: The Portrayal of the Native American in Film. Ed. Peter C. Rollins and 
John E. O’Connor. Lexington, KY: The UP of Kentucky, 1998. 12-26. Print.

Kilpatrick, Jacquelyn. Celluloid Indians: Native Americans and Film. Lincoln, NE:

U of Nebraska P, 1999. Print.

Kinsella, W. P. “The Canadian Encyclopedia,”

< http://www.thecanadianencyclopedia.ca/en/article/wp-kinsella/ > Web.

Lamadrid, Enrique. Ig/Noble Savages of New Mexico's Silent Cinema, 1912-1914.

Boston: Houghton Mifflin, 1992. Print.

Lévi-Strauss, Claude. “The Structural Study of Myth.” The Journal of American

Folklore. 68.270 (1955): 428-444. Print.

Lorde, Audre. Sister Outsider: Essays and Speeches. Berkeley, CA: Crossing Press, 2007. Print.

Lynn, T. J. “Tricksters Don’t Walk the Dogma: Nkem Nwankwo’s 'Danda'”. College Literature 32 (2005): 1-20. Print.

Manchel, Frank. “Cultural Confusion: Broken Arrow.” Hollywood's Indian: The Portrayal of the Native American in Film. Ed. Peter C. Rollins and John E.

O'Connor. Lexington, KY: The UP of Kentucky, 1998. 91-106. Print.

Metz, Christian. "The imaginary signifier: Identification, mirror." Film Theory and

Criticism: Introductory Readings. Ed. Leo Braudy and Marshall Cohen. Oxford:

Oxford UP, 1999. 800-817. Print.

Mulvey, Laura. "Visual Pleasure and Narrative Cinema." The Narrative Reader.

Ed. Martin McQuillan. New York: Routledge, 2000. 177-181. Print.

O’Connor, John. “The White Man's Indian: An Institutional Approach.” 
Hollywood's Indian: The Portrayal of the Native American in Film. Ed. Peter C.

Rollins and John E. O'Connor. Lexington, KY: The UP of Kentucky, 1998. 27-38.

Print.

Powwow Highway. Dir. Jonathon Wacks. Perf. A Martinez and Gary Farmer.

HandMade Films, 1989.

Rappaport, Joanne. Intercultural Utopias: Public Intellectuals, Cultural

Experimentation, and Ethnic Pluralism in Colombia. Durham, NC: Duke UP, 2005. Print.

Sainte-Marie, Buffy. Trickster. 1982.

Sandoval, Ciro. “Michel Serres' Philosophy of the 'Educated Third': Hermesian

Confluences among the Humanities, Science, and Technology." Philosophy

Today, 39 (1995): 107-118. Print.

The Searchers. Dir. John Ford. Perf. John Wayne and Jeffrey Hunter. Warner Bros, 1956.

Serres, Michel. “The Algebra of Literature: The Wolf's Game.” Textual Strategies:

Perspectives in Post-Structuralist Criticism. Ed. Josué V. Harari. Ithaca, NY:

Cornell UP, 1979. 260-276. Print.

Shively, JoEllen. “Cowboys and Indians: Perceptions of Western Films among American Indians and Anglos." American Sociological Review 57.6 (1992):

725-34. Print.

Shouting Secrets. Dir. Korinna Sehringer. Perf. Chaske Spencer, Q’orianka Kilcher, and Tantoo Cardinal. Joker Film Productions, 2011. 
Singer, Beverly. Wiping the War Paint off the Lens. Minneapolis, MN: U of Minnesota, 2001. Print.

Skins. Dir. Chris Eyre. Perf. Eric Schweig, Graham Greene and Gary Farmer. First Look Pictures, 2002.

Solanas, Fernando and Octavio Gettino. "Towards a Third Cinema." Film Theory: An Anthology. Ed. Robert Stam and Toby Miller. Malden: Blackwell Publishers, 2000. 265-286. Print.

Vizenor, Gerald. The Heirs of Columbus. Middletown, CT: Wesleyan UP, 1991. Print.

West, Cornel. Keeping Faith: Philosophy and Race in America. New York: Routledge, 1993. Print.

Windtalkers. Dir. John Woo. Perf. Nicolas Cage and Adam Beach. MGM, 2002. Žižek, Slavoj. The Sublime Object of Ideology (2nd ed.). New York: Verso, 2009. Print. 